\title{
Cross-compartment signal propagation in the Mitotic Exit Network.
}

Xiaoxue Zhou ${ }^{1, *}$, Wenxue $\mathrm{Li}^{2}$, Yansheng $\mathrm{Liu}^{2}$, Angelika Amon ${ }^{1, *}$

${ }^{1}$ David H. Koch Institute for Integrative Cancer Research, Howard Hughes Medical Institute, Massachusetts Institute of Technology, Cambridge, MA 02139, USA

${ }^{2}$ Yale Cancer Biology Institute, Department of Pharmacology, Yale University, West Haven, CT 06516, USA

"Correspondence to: xiaoxue@mit.edu and angelika@mit.edu 


\section{ABSTRACT (150 words)}

2 In budding yeast, the Mitotic Exit Network (MEN), a GTPase signaling cascade integrates

3 spatial and temporal cues to promote exit from mitosis. This signal integration requires

4 transmission of a signal generated on the cytoplasmic face of spindle pole bodies (SPBs; yeast

5 equivalent of centrosomes) to the nucleolus, where the MEN effector protein Cdc14 resides.

6 Here, we show that the MEN activating signal at SPBs is relayed to Cdc14 in the nucleolus

7 through the dynamic localization of its terminal kinase complex Dbf2-Mob1. Cdc15, the protein

8 kinase that activates Dbf2-Mob1 at SPBs, also regulates its nuclear access. Once in the nucleus,

9 priming phosphorylation of Cfi1/Net1, the nucleolar anchor of Cdc14, by the Polo-like kinase

10 Cdc5 targets Dbf2-Mob1 to the nucleolus. Nucleolar Dbf2-Mob1 then phosphorylates Cfi1/Net1

11 and Cdc14, activating Cdc14. The kinase-primed transmission of the MEN signal from the

12 cytoplasm to the nucleolus exemplifies how signaling cascades can bridge distant inputs and

13 responses. 


\section{INTRODUCTION}

16 In cellular signaling, the sensing of signals (e.g. binding of signaling molecules at cell surface)

17 and the response (e.g. transcription in the nucleus) often occur in different cellular

18 compartments. Determining how signals are transmitted across compartments is thus essential

19 for understanding signal transmission. The Mitotic Exit Network (MEN), a Ras-like GTPase

20 kinase signaling cascade and budding yeast homolog of the Hippo pathway (Hergovich and

21 Hemmings, 2012), represents such an example for signaling across cellular compartments. The

22 MEN-activating signal is sensed and processed at the cytoplasmic face of spindle pole bodies

23 (SPBs; yeast functional equivalent of the centrosomes), whereas the MEN effector protein Cdc14

24 resides in the nucleolus (Figure 1A). Because budding yeast undergo a closed mitosis without

25 disassembling the nuclear envelope and nucleolus, the MEN must transmit a signal generated at

26 the cytoplasmic face of SPBs, across the nuclear envelope and into the nucleolus to activate its

27 effector Cdc14. The molecular mechanisms governing this cross-compartment signaling process

28 remain largely unknown.

The central function of the MEN is to couple the final cell cycle transition, exit from

30 mitosis (when the mitotic spindle is disassembled, chromosomes decondense and cytokinesis

31 ensues), to nuclear/spindle position. In many organisms including budding yeast, fission yeast

32 and some plant species, the site of cytokinesis/division plane (i.e. the bud neck) is determined

33 prior to mitosis (Guertin et al., 2002). Thus, the mitotic spindle must be positioned appropriately

34 to ensure accurate genome partitioning between the daughter cells. In addition, these organisms

35 have evolved surveillance mechanisms to monitor spindle position and regulate cell cycle

36 progression in response. This surveillance mechanism is best understood in budding yeast where

37 spindle position controls the activity of the MEN. 
The MEN senses spindle position through a Ras-like GTPase Tem1. Tem1 is activated when a SPB enters the bud (Bardin et al., 2000; Pereira et al., 2000). Together with the Polo-like kinase Cdc5, Tem1 activates its effector, the Hippo-like protein kinase Cdc15, presumably by recruiting Cdc15 to the SPBs (Rock and Amon, 2011) (Figure 1A). Cdc15 then activates the phosphorylates the MEN scaffold Nud1, a core component of the SPB outer plaque. This phosphorylation creates a docking site for Dbf2-Mob1 on Nud1, facilitating phosphorylation and activation of Dbf2-Mob1 by Cdc15 (Mah et al., 2001; Rock et al., 2013). progression through the downstream kinases Cdc15 and Dbf2-Mob1 (Campbell et al., 2019). activation of Cdc15 depends on Cdc5 activity (Rock and Amon, 2011) which occurs only in mitosis (Cheng et al., 1998); (2) Initiation of anaphase: cyclin-dependent kinases (CDKs)

51 phosphorylate Cdc15 and Mob1 thereby inhibiting their activity (Jaspersen and Morgan, 2000; König et al., 2010). At the onset of anaphase, CDK activity declines due to cyclin degradation, which lifts this inhibition. This loss of inhibition by CDKs creates a state whereby the MEN is poised for activation.

Once activated, the MEN promotes exit from mitosis by activating the phosphatase

57 promotes mitotic CDK inactivation thereby returning the cell to a G1 state (reviewed in

58 Stegmeier and Amon, 2004). Given the central role of Cdc14 in promoting mitotic exit, it is not

59 surprising that the phosphatase is tightly regulated. Cdc14 is sequestered in the nucleolus by its

60 inhibitor Cfi1/Net1 from G1 until the onset of anaphase (Shou et al., 1999; Visintin et al., 1999). 
61 During anaphase, Cdc14 is released from its inhibitor and spreads throughout the nucleus and cytoplasm to dephosphorylate its targets.

Two pathways, the Cdc fourteen early anaphase release (FEAR) network and the MEN

64 promote the dissociation of $\mathrm{Cdc} 14$ from its inhibitor during anaphase. Upon anaphase entry,

65 Cdc14 is transiently released from the nucleolus by the FEAR network (reviewed in Rock and

66 Amon, 2009). The FEAR network promotes dissociation of Cdc14 from Cfi1/Net1 by facilitating

67 phosphorylation of Cfi1/Net1 by mitotic CDKs (Azzam, 2004; Queralt et al., 2006). This

68 transient release, although not essential for exit from mitosis, is crucial for the timely execution

69 of several anaphase events such as segregation of the nucleolus (D’Amours et al., 2004; Sullivan

70 et al., 2004; Torres-Rosell et al., 2004) and MEN activation by counteracting CDK inhibition of

71 MEN kinases (Campbell et al., 2019; Jaspersen and Morgan, 2000; König et al., 2010). In late

72 anaphase, the activated MEN drives a more sustained and complete release of Cdc14 from the

73 nucleolus which ultimately results in exit from mitosis. In the absence of MEN activity, Cdc14,

74 after a transient FEAR network-mediated release from the nucleolus during early anaphase, is re-

75 sequestered in the nucleolus and cells arrest in late anaphase.

Despite our extensive knowledge of the MEN and Cdc14, how the MEN promotes the

77 sustained release of $\mathrm{Cdc} 14$ from its inhibitor in the nucleolus is not well understood. One

78 contributing mechanism involves the phosphorylation of the nuclear localization signal (NLS)

79 sequence in the C-terminus of Cdc14 by the MEN kinase Dbf2-Mob1 (Mohl et al., 2009).

80 Inactivation of the NLS by the MEN promotes redistribution of Cdc14 via its nuclear export

81 signal (NES) from the nucleus to the cytoplasm. However, retention of Cdc14 in the cytoplasm is

82 not required for mitotic exit (Bembenek et al., 2005; Kuilman et al., 2015; Mohl et al., 2009).

83 Furthermore, a Cdc14 mutant lacking the Dbf2 phosphorylation sites within its NLS is still 
84 released from the nucleolus in late anaphase (Mohl et al., 2009). These results suggest that MENmediated cytoplasmic retention of $\mathrm{Cdc} 14$ is not the main mechanism whereby the MEN activates

Cdc14. Rather, the MEN must also disrupt the interaction between Cdc14 and its inhibitor

87 Cfi1/Net1 in the nucleolus.

How does the MEN, activated at the outer plaque of SPBs in the cytosol, liberate Cdc14

89 from its inhibitor in the nucleolus? Proteome array screens for Dbf2-Mob1, the terminal kinase

90 in the MEN, have identified Cfi1/Net1 as a potential Dbf2 substrate in vitro (Mah et al., 2001;

91 Ptacek et al., 2005) suggesting that the MEN might liberate Cdc14 from Cfi1/Net1 through

92 phosphorylating Cfi1/Net1. However, given that Dbf2-Mob1 and Cfi1/Net1 normally reside in

93 different cellular compartments, whether this phosphorylation occurs in vivo and contributes to

94 Cdc14 activation is unclear. In addition, the Polo-like kinase Cdc5, an important regulator of

95 mitotic exit and essential for Cdc14 activation, has also been shown to phosphorylate Cfi1/Net1

96 (Loughrey Chen et al., 2002; Shou et al., 2002; Yoshida and Toh-e, 2002). Whether and how this

97 phosphorylation contributes to MEN-mediated Cdc14 release is not understood.

98 Here, we demonstrate that Dbf2-Mob1 serves as a molecular messenger traveling

99 between the SPBs and the nucleolus to release Cdc14 from its inhibitor. We show that Dbf2-

100 Mob1, normally kept out of the nucleus by Crm1, gains access to the nucleus following

101 activation by Cdc15. We further demonstrate that Dbf2-Mob1 utilizes a nucleolar docking site

102 created by Cdc5 to phosphorylate Cfi1/Net1, resulting in Cdc14 liberation. These findings define

103 the molecular mechanisms of cross-compartment signal transmission in the MEN and provide a

104 novel paradigm for how signaling can occur across organelle boundaries. 


\section{Dbf2-Mob1 dynamically associates with SPBs.}

108 When the MEN is activated in anaphase, Dbf2-Mob1 is recruited to the outer plaque of SPBs by

109 binding to Cdc15-phosphorylated Nud1 (Rock et al., 2013). However, immobilizing Dbf2-Mob1

110 at SPBs by fusing Mob1 to Nud1 disrupts MEN activity (Rock et al., 2013), suggesting that

111 Dbf2-Mob1 is likely needed away from the SPBs for the MEN to function. Additionally, a small

112 fraction of Dbf2-Mob1 was found to enter mitotic nuclei (Stoepel et al., 2005). Thus, we

113 hypothesized that the MEN liberates Cdc14 from its nucleolar inhibitor through the dynamic

114 shuttling of Dbf2-Mob1 between the outer plaque of the SPB and the nucleolus. We reasoned

115 that as a messenger between the SPB and nucleolus, Dbf2-Mob1 needs to be mobile at the SPB.

116 To test this hypothesis, we performed fluorescence recovery after photobleaching (FRAP)

117 analysis on eGFP tagged Mob1 in anaphase cells (Figure 1B). We observed a rapid recovery of

118 fluorescence with a half-recovery time of $4.6 \pm 0.7 \mathrm{~s}$ (mean $\pm \mathrm{std}, n=6$ cells) after

119 photobleaching of Mob1-eGFP fluorescence either at the daughter (dSPB) or the mother (mSPB)

120 SPB. This fast turnover rate $(\sim 1 / 500$ of the total duration for Dbf2-Mob1's SPB localization in

121 anaphase) indicates that localization of Dbf2-Mob1 to SPBs is highly dynamic.

Dbf2-Mob1 transiently localizes to the nucleolus during anaphase.

124 We next investigated whether Dbf2-Mob1 localizes to the nucleolus by live-cell fluorescence

125 microscopy. Although subtle, we observed transient localization of Mob1-eGFP to the nucleolus

126 in some cells as judged by co-localization with the nucleolar protein Cfi1/Net1. Importantly, this

127 nucleolar localization was only observed in late anaphase cells after nucleolar segregation, when

128 the MEN is normally active (Figure 1C). 
It was reported previously that two N-terminally truncated Mob1 mutant proteins,

130 Mob1 $\Delta 78$ and Mob1 $\Delta 132$ (Mob1 missing the first 78 and 132 amino acids, respectively),

131 localize more prominently to the nucleus (Stoepel et al., 2005). We found that they also

132 displayed increased nucleolar localization (Figure 1D-F). We hypothesize that the N-terminus of

133 Mob1 harbors auto-inhibitory sequences that prevent access of the protein to the nucleolus.

134 Hence, deleting these sequences ought to cause hyperactivation of Dbf2-Mob1. Indeed, we found

135 that N-terminal truncation mutants of Mob1 partially suppressed temperature sensitive alleles of

136 upstream MEN components (cdc15-2 and tem1-3; Figure 1-figure supplement 1A). This

137 suppression was not a result of elevated Mob1 protein levels because overexpression of Mob1

138 from the GPD promoter did not suppress the growth defect of $c d c 15-2$ or tem 1-3 mutants (Figure

139 1-figure supplement 1A-B), nor did it increase Mob1's nucleolar localization (Figure 1-figure

140 supplement $1 \mathrm{C}-\mathrm{D})$. We conclude that $\mathrm{N}$-terminal truncations result in enhanced nucleolar

141 localization and hyperactivation of Mob1.

To further characterize the cellular localization of Dbf2-Mob1, we quantified the relative

143 enrichment of full-length and truncated GFP-Mob1 at SPBs and in the nucleolus during the cell

144 cycle (Figure 1E). Full-length Mob1 localized to SPBs and the nucleolus during anaphase.

145 Localization of Mob1 $\Delta 78$ and Mob1 $\Delta 132$ to SPBs was similar to that of full-length Mob1. The

146 nucleolar localization of Mob1 and truncated Mob1 (Figure 1E) correlated with MEN activation,

147 as judged by Mob1 association with SPBs, translocation of the MEN activity reporter NLS Cdc14 $_{4}$

148 (Campbell et al., 2019) into the cytoplasm, and MEN-mediated Cdc14 release from the nucleolus

149 (Figure 1-figure supplement 2). Consistent with earlier observations, the Mob1 truncations

150 displayed significantly greater nucleolar enrichment relative to full-length Mob1 in anaphase

$151(\sim 30 \%$ and $120 \%$ increase on average for Mob1 $\Delta 78$ and Mob1 $\Delta 132$ respectively, Figure $1 \mathrm{~F})$. 
152 Mob1 $\Delta 78$ localization to the nucleolus was, like full-length Mob1, restricted to anaphase but

153 accumulated in the nucleolus to higher levels. In contrast, Mob1 $\Delta 132$ displayed both greater and

154 earlier nucleolar enrichment, evident already in metaphase. We conclude that Dbf2-Mob1

155 localizes to the nucleolus during anaphase when the MEN is active. N-terminal truncation

156 mutants of Mob1 exhibit enhanced nucleolar localization and are hypermorphic. Given that the

157 nucleolar localization of full-length Mob1 is quite subtle, we used the Mob1 truncation mutants

158 as tools to study Dbf2-Mob1's nucleolar localization.

160 Dbf2-Mob1 localizes to the nucleolus through interacting with Cfi1/Net1.

161 To validate the nucleolar localization of Mob1 we observed by microscopy and to identify the

162 potential nucleolar receptor for Dbf2-Mob1, we performed TurboID proximity-based labeling

163 (Branon et al., 2018). We fused the promiscuous biotin ligase TurboID to the MEN components

164 Mob1, Dbf2, Tem1 and Cdc15, and identified their protein interactors by streptavidin pull-down

165 followed by mass spectrometry (MS) (Figure 2-figure supplement 1A). In this experiment, we

166 identified the nucleolar protein Cfi1/Net1 as the top hit for Mob1- and Dbf2-TurboID labeling

167 (Figure 2A, Figure 2-figure supplement 1B, Table S3). Biotinylation of Cfi1/Net1 by Mob1-

168 TurboID was further confirmed by the detection of a biotinylated peptide of Cfi1/Net1 (Figure 2-

169 figure supplement 1C). Importantly, Cfi1/Net1 was only detected in the labeling experiments

170 where Mob1 or Dbf2 were tagged with TurboID but not when Tem 1 or Cdc15 were used as baits

171 (Figure 2A). In contrast, Nud1, the MEN scaffold protein at SPBs, was detected in the TurboID

172 labeling experiments for all MEN proteins (Figure 2A).

173 We validated these MS findings using streptavidin gel-shift assays (Fairhead and

174 Howarth, 2015; Housley et al., 2014). To monitor whether a target protein was biotinylated by 
175 the TurboID-tagged bait protein in vivo, we treated the denatured cell lysates with excess

176 streptavidin prior to immunoblotting. Biotinylated form(s) of the target protein will migrate more

177 slowly in SDS-PAGE due to binding of streptavidin, with each added biotin molecule causing a

178 theoretical size increase of up to $53 \mathrm{kD}$, the size of a streptavidin tetramer (Figure 2-figure

179 supplement 1D). Using this assay, we observed a slower migrating form of Nud1 in cell lysates

180 from cells expressing all TurboID-tagged MEN proteins (Figure 2B). Slower migrating forms of

181 Cfi1/Net1 were only observed in lysates obtained from cells expressing Mob1-TurboID (Figure

182 2B).

To determine whether Cfi1/Net1 was the sole receptor for Mob1 in the nucleolus, we

184 characterized the localization of Mob1 $\Delta 78$ and Mob1 $\Delta 132$ in cells lacking CFI1/NET1. While

185 still localized to SPBs, Mob1 $\Delta 78$ and Mob1 $\Delta 132$ no longer accumulated in the nucleolus during

186 anaphase in cfil/net1 $\Delta$ cells (Figure 2C-D). Furthermore, when we overexpressed CFI1/NET1

187 from the strong galactose-inducible GAL1-10 promoter, nucleolar localization of both full-length

188 and N-terminal truncation mutants of Mob1 was increased by at least $50 \%$ (full-length) and up to

$189300 \%$ (truncations) (Figure 2E-F). It is worth noting that the observed decrease in Mob1's dSPB

190 localization with CFI1/NET1 overexpression (Figure 2F) is likely the result of Cdc14 inhibition

191 by Cfi1/Net1 (Visintin et al., 1999) leading to reduced MEN activation. We conclude that Dbf2-

192 Mob1 localization in the nucleolus during anaphase is mediated by interactions with Cfi1/Net1.

194 Nucleolar localization of Dbf2-Mob1 depends on MEN activation.

195 The localization pattern of Dbf2-Mob1 leads to the model in which Dbf2-Mob1 is activated by

196 Cdc15 at SPBs. Active Dbf2-Mob1 then binds to and phosphorylates Cfi1/Net1, promoting the

197 dissociation of Cdc14 from its inhibitor to carry out mitotic exit. This model predicts that the 
198

199

200

201

202

203

204

205

206

207

208

209

210

211

212

213

214

215

216

217

218

219

nucleolar localization of Dbf2-Mob1 depends on MEN activity. To test this prediction, we employed an analog-sensitive allele of CDC15, cdc15-as1 (Bishop et al., 2000; D’Aquino et al., 2005). As expected, inhibition of $c d c 15$-as1 (through addition of the analog 1-NA-PP1)

prevented localization of Mob1 to SPBs and translocation of the MEN activity reporter NLS Cdc14 $_{4}$ into the cytoplasm (Figure 3A). Nucleolar localization of full-length Mob1 was also significantly reduced (Figure 3A). Nucleolar localization of the N-terminally truncated Mob1 $\Delta 78$ and

Mob1 $\Delta 132$ mutants, on the other hand, was only moderately reduced (Figure $3 \mathrm{~A}$ ), which is consistent with the finding that these alleles partially suppress the temperature sensitive growth defect of $c d c 15-2$ cells (Figure 1-figure supplement 1B). We conclude that Mob1 localization to the nucleolus depends on MEN activity. The N-terminal hyperactive truncation mutations in Mob1 are less reliant on upstream MEN kinases for their nucleolar localization.

\section{Cdc15 regulates nuclear access of Dbf2-Mob1.}

How does Cdc15 cause Dbf2-Mob1 to localize to the nucleolus? To reach the nucleolus, Dbf2-

Mob1 must first enter the nucleus. Considering that the size of the complex $(102 \mathrm{kD})$ is above the passive diffusion limit of the nuclear envelope ( 40-60 kD) (Knockenhauer and Schwartz, 2016), we hypothesized that nuclear access of Dbf2-Mob1 is regulated. We explored this possibility using the PhyB-PIF based light-inducible organelle targeting system (Yang et al., 2013) (Figure 3-figure supplement 1A). We fused Mob1-eGFP to the PIF protein, which binds PhyB upon exposure to red light $(650 \mathrm{~nm})$. Using this system, we successfully recruited Mob1eGFP-PIF to various subcellular locations such as SPBs or the outer mitochondrial membrane (Figure 3-figure supplement 1B). 
To gauge Dbf2-Mob1's nuclear access in different cell cycle stages, we created a trap for nuclear Dbf2-Mob1 using nucleolar-anchored PhyB (PhyB-Sik1, Figure 3B). If Dbf2-Mob1 was

222 shuttling between the nucleus and cytoplasm, PhyB-Sik1 would capture nuclear Mob1-eGFP-PIF

223 when activated by light. Interestingly, in pre-anaphase cells, we were not able to capture a

224 notable amount of nuclear Dbf2-Mob1 after 2 minutes of red-light activation. In contrast, in

225 anaphase cells in which the MEN is active, Dbf2-Mob1 was readily recruited to the nucleolus

226 within 2 minutes (Figure 3C). We obtained similar results with a Dbf2-PIF fusion (Figure 3-

227 figure supplement 1C). Furthermore, when we activated PhyB every 15 minutes for 2 minutes to 228 recruit Mob1 to the nucleolus in cells progressing through the cell cycle, Mob1 was only

229 recruited to the nucleolus by light during anaphase when the protein was also present at SPBs

230 (Figure 3-figure supplement 1D). By comparison, we were not able to recruit the upstream

231 kinase Cdc15 to the nucleolus in any cell cycle stage (Figure 3-figure supplement 1C). Given

232 that (1) Dbf2-Mob1 protein levels do not fluctuate considerably during the cell cycle (Visintin

233 and Amon, 2001), that (2) the interaction between other PIF fusions and PhyB-Sik1 are not cell

234 cycle regulated (Yang et al., 2013), and that (3) Mob1 can be recruited to cytoplasmic targets

235 throughout the cell cycle (Figure 3-figure supplement 1B), we conclude that nuclear access of

236 Dbf2-Mob1 is cell cycle regulated.

237 Because nuclear access of Dbf2-Mob1 correlates with MEN activation, we next tested

238 whether it was regulated by the MEN by quantifying the relative enrichment of Mob1 in the

239 nucleolus as a function of PhyB activation time (exposure to $650 \mathrm{~nm}$ light) in $C D C 15$ or $c d c 15-2$

240 cells. In cells with wild-type $C D C 15$, light-induced nucleolar recruitment of Mob1 was higher in

241 anaphase than pre-anaphase cells. In contrast, in $c d c 15-2$ cells this difference was abolished

242 (Figure 3D). We conclude that in addition to activating Dbf2's kinase activity (Mah et al., 2001), 
243 Cdc15 regulates Dbf2-Mob1's nuclear access. Consistent with this notion, we find that

244 Mob1 $\Delta 78$, which partially suppresses the temperature sensitivity of the $c d c 15-2$ allele, displayed

245 increased nuclear access in all cell cycle stages (Figure 3-figure supplement 1E).

\section{Dbf2-Mob1 is exported from the nucleus by Crm1.}

Dbf2-Mob1 is a substrate of the nuclear exportin Crm1 in vitro (K1rlı et al., 2015). To quantified the nucleolar localization of full-length and truncated Mob1 in cells carrying an allele of CRM1 (crm1T539C) that is sensitive to the nuclear export inhibitor leptomycin B (LMB)

252 (Neville, 1999). Treatment of crm1T539C cells with LMB led to an increase in nucleolar

2A), suggesting that Crm1 controls nuclear export of Dbf2-Mob1. galactose-inducible GAL1-10 promotor. Overexpressed Mob1 was enriched in the nucleus no longer nuclear enriched, suggesting that Dbf2 not Mob1 harbors a NES. Consistently, when

261 overexpressed on its own, Dbf2 exhibited diffuse localization but inhibition of crm1T539C with

262 LMB led to accumulation of Dbf2 in the nucleus (Figure 3-figure supplement 2C). 


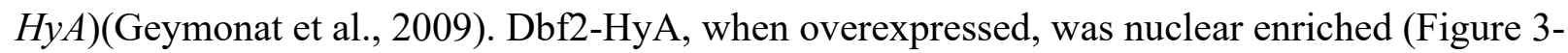

267 figure supplement 2E). Inspired by this observation, we overexpressed $D B F 2$ mutants where L12

268 had been mutated to either methionine $(d b f 2-L 12 M)$ or alanine $(d b f 2-L 12 A)$. Both mutants

269 accumulated in the nucleus (Figure 3-figure supplement 2E). Furthermore, we found that the first

27023 amino acids of Dbf2 were sufficient to drive nuclear export of eGFP (Figure 3-figure

271 supplement 2E, G). To test whether the NES in Dbf2 influences Dbf2-Mob1's nucleolar

272 localization in anaphase under normal expression level, we characterized Mob1's cellular

273 localization in $d b f 2-L 12 A$ and observed an increase in nucleolar localization by at least $40 \%$ for

274 both full-length and N-terminally truncated Mob1(Figure 3E).

A previous phosphoproteomic study reported that S17 and S20 within the NES of Dbf2

276 are phosphorylated in anaphase-arrested cells (Holt et al., 2009). We found that mutating S17

277 and S20 to phospho-mimetic residues (S17,20D or S17,20E) disrupted the NES whereas

278 mutating these residues to alanine (S17,20A) retained the NES activity of Dbf2 (Figure 3-figure

279 supplement $2 \mathrm{~F}, \mathrm{G})$. We propose that phosphorylation of S17 and S20 is regulated, possibly by

280 Cdc15, to control nuclear access of Dbf2-Mob1. Nucleolar localization of Mob1, particularly of

281 Mob1 $\Delta 78$, was reduced in cells harboring the $d b f 2-S 17,20 A$ allele compared to cells with wild-

282 type DBF2 (Figure 3-figure supplement 3A). However, cells carrying the $d b f 2-S 17,20 A$ allele,

283 while exhibiting reduced nuclear access of Mob1 during all cell cycle stages, still showed

284 differential nuclear access between pre-anaphase and anaphase, as is observed in DBF2 cells

285 (Figure 3-figure supplement 3B). This observation suggests that additional regulatory

286 mechanism(s) control Dbf2-Mob1's nuclear access. In contrast, cells harboring the $d b f 2-S 17,20 D$

287 allele exhibited increased nuclear access of Mob1 during all cell cycle stages (Figure 3-figure

288 supplement 3B), confirming that Dbf2-Mob1 is normally kept out of the nucleus through Dbf2's 
NES. The NES sequence in Dbf2 is well conserved among Saccharomycetes (Figure 3-figure supplement 2D) suggesting that regulated nuclear access of Dbf2-Mob1 is conserved at least

291 across this class of fungi.

Nucleolar localization of Dbf2-Mob1 is regulated by Cdc5.

294 The analysis of nuclear access and nucleolar localization of the N-terminal truncations of Mob1

295 indicated that the MEN is not the only pathway controlling Dbf2-Mob1's nucleolar localization.

296 The truncation mutants localize to the nucleolus in a manner largely independent of the MEN,

297 yet their nucleolar localization is still restricted to metaphase and anaphase (Figure 3A). This

298 restriction of nucleolar localization is not due to limited nuclear access. Truncated Mob1 mutants

299 have increased nuclear access prior to anaphase (Figure 3-figure supplement 1E). These data

300 indicate that nucleolar localization or the interaction between Dbf2-Mob1 with Cfi1/Net1 is

301 regulated by additional factors.

An obvious candidate for this additional regulator is the Polo-like kinase Cdc5, which is active throughout mitosis and plays multiple essential roles in mitotic exit (Lee et al., 2005). As part of both the FEAR network (Rock and Amon, 2009; Stegmeier et al., 2002) and the MEN,

305 Cdc5 is indispensable for Cdc14's nucleolar release. However, the exact role(s) of Cdc5 during

306 this process is not fully understood. To determine whether Cdc5 regulates binding of Dbf2-Mob1

307 to Cfi1/Net1, we examined the consequences of inhibiting Cdc5's kinase activity on nucleolar

308 localization of Dbf2-Mob1 using an analog-sensitive allele of CDC5 (cdc5-as 1). Consistent with

309 the known functions of Cdc5 in MEN activation, we observed loss of Mob1's SPB localization

310 and Dbf2-Mob1's kinase activity as monitored by translocation of the NLS $\mathrm{Cdc14}_{\text {reporter into the }}$

311 cytoplasm when Cdc5 was inhibited (Figure 4A). Nucleolar localization of Mob1, Mob1 $\Delta 78$ and 
312 Mob1 132 was also lost in cells lacking Cde5 activity (Figure 4A). This is in direct contrast to

313 Cdc15 inhibition, where the nucleolar localization of N-terminal Mob1 truncation mutants

314 particularly Mob1 $\Delta 132$ was only partially reduced (Figure 3A). These results suggested that

315 Cdc5 regulates Dbf2-Mob1's nucleolar localization independently of its role in activating Cdc15.

316 To directly determine whether CDC5 regulated Dbf2-Mob1's nucleolar localization

317 independently of the MEN, we took advantage of a hyperactive CDC15 allele, GAL-CDC15(1-

318 750) (Bardin et al., 2003), which is active even in the absence of CDC5 (Rock and Amon, 2011).

319 When GAL-CDC15(1-750) was expressed, Mob1's SPB localization and Dbf2-Mob1's kinase

320 activity was no longer restricted to anaphase but rather was high throughout the cell cycle as a

321 result of MEN hyper-activation (Figure 4B). Interestingly, GAL-CDC15(1-750) did not abolish

322 cell-cycle regulation of Mob1's nucleolar localization but rather advanced it to early anaphase

323 and metaphase (Figure 4B). In cells expressing GAL-CDC15(1-750), inactivation of CDC5 still

324 abolished nucleolar localization of both full-length and the hyperactive N-terminally truncated

325 Mob1 while Mob1 binding to SPBs was unaffected (Figure 4B). These results demonstrate that

326 nucleolar localization of Dbf2-Mob1 directly depends on Cdc5 independently of its role in MEN

327 activation.

328 Could CDC5 regulate the nucleolar localization of Dbf2-Mob1 through its role in the

329 FEAR network? To test this, we quantified Mob1's nucleolar localization in cells lacking the

330 FEAR network component SLK19 (slk194). MEN activation (as determined by Mob1

331 localization to the $\mathrm{dSPB}$ and nuclear release of the NLS $\mathrm{Sdc14}_{\mathrm{C}}$ reporter) and as a result mitotic exit

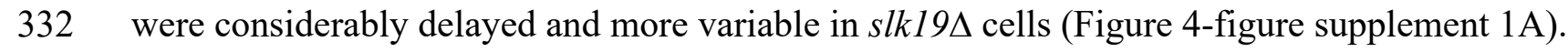

333 Consistent with a delay in MEN activation, nucleolar localization of Mob1 and Mob1 $\Delta 78$ but not

334 Mob1 132 was also delayed. Importantly, maximum enrichment of Mob1 in the nucleolus was 
not reduced in slk19A cells for all three forms of Mob1 (Figure 4-figure supplement 1B). We conclude that Cdc5 regulates Dbf2-Mob1's nucleolar localization through mechanisms in

337 addition to its role in the MEN and the FEAR network.

\section{Cdc5 and Dbf2-Mob1 phosphorylate Cfi1/Net1 at distinct sites.}

340 Our results suggest a model where Cdc5 promotes the interaction between Dbf2-Mob1 and its 341 nucleolar receptor Cfi1/Net1, likely through phosphorylating Cfi1/Net1. This interaction then

342 facilitates phosphorylation of Cfi1/Net1 by Dbf2-Mob1 to bring about the release of Cdc14 from

343 Cfi1/Net1. Cfi1/Net1 is a highly phosphorylated protein with 64 known phosphorylation sites in

344 vivo (Holt et al., 2009; Swaney et al., 2013). About one fifth of these sites were identified as

345 CDK targets (Holt et al., 2009) including six key CDK sites whose phosphorylation is controlled

346 by the FEAR network (Azzam, 2004). To map sites in Cfi1/Net1 that are phosphorylated in a

347 CDC5 or MEN-dependent manner, we performed phosphoproteomic analyses on wild-type

348 anaphase cells and cells in which Cdc5 or Cdc15 were inhibited using the $c d c 5$-as 1 and $c d c 15$ -

349 as 1 alleles, respectively (Figure 5-figure supplement 1A). This analysis identified 44 of the 64

350 previously known sites in Cfi1/Net1 and 18 new sites (Table S4). To achieve complete or close

351 to complete coverage of Cfi1/Net1's phosphorylation sites in anaphase, we also performed

352 immunoprecipitation-mass spectrometry (IP-MS) for Cfi1/Net1 in anaphase enriched cultures

353 and identified 9 additional sites (Table S4) resulting in an astonishing total of 91 phosphorylation

354 sites in Cfi1/Net1. These phosphorylation sites appear to cluster in regions of disorder as

355 predicted by the PONDR score (Romero et al., 1997) (Figure 5A).

356 By comparing the peptide signals between wild-type, $c d c 15$-as 1, and cdc5-as 1 cells in

357 our quantitative phosphoproteomics dataset, we identified phosphorylation sites that depended 
on Cdc15 or Cdc5 activity or both (Figure 5-figure supplement 1B-E). Among them, we found sites fit Dbf2-Mob1's preferred sequence motif RXXS* (* represents the phosphorylation site)

361 (Mah et al., 2005), supporting our model that Dbf2-Mob1 phosphorylates Cfi1/Net1. Given that

362 Cdc5 activates Cdc15, sites that depended on CDC15 ought to also depend on CDC5. This was

363 indeed the case for 10 of the 11 CDC15-dependent phosphorylation sites in Cfi1/Net1. dependent sites from $C D C 5$-dependent sites yielding 12 sites (denoted as CDC5-only, Figure 5A). Based on the distribution of all 91 phosphorylation sites and degree of disorder, we divided Cfi1/Net1 into four zones: residues 31-69 (z1, 7 sites), 160-615 (z2, 53 sites), 676-840 (z3, 12 sites) and 1017-1166 (z4, 19 sites) (Figure 5A). CDC15-dependent phosphorylation sites were concentrated in zone 2, whereas $C D C 5$-dependent sites were also found in zones 1 and 3 . In contrast to Cfi1/Net1, all the CDC5-dependent phosphorylation sites in Dbf2 and Mob1 were also CDC15-dependent (Figure 5-figure supplement 1F). These data indicate that Cdc5 and Dbf2-Mob1 directly phosphorylate Cfi1/Net1. Dbf2-Mob1 on the other hand is a direct substrate of Cdc15 but not Cdc5.

\section{Cdc5 promotes Dbf2-Mob1's nucleolar localization by phosphorylating Cfi1/Net1.}

376 Having identified phosphorylation sites within Cfi1/Net1, we next asked whether they were

377 important for the interaction between Cfi1/Net1 and Dbf2-Mob1. We generated a CFI1 allele in which all 91 phosphorylation sites were mutated to alanine (cfil-91A). Cells harboring this allele as the sole source of $C F I 1 / N E T 1$ were viable and progressed through anaphase with only a slight 
381 Interestingly, Mob1 $\Delta 132$, which showed the most pronounced nucleolar localization among all

382 Mob1 alleles analyzed, still localized to the SPBs during anaphase in cfil-91A cells, but failed to

383 accumulate in the nucleolus (Figure 5B-C, Figure5-figure supplement 2A). We conclude that

384 Cfi1/Net1 phosphorylation is required for interacting with Dbf2-Mob1.

385 Next, we tested whether CDC5-dependent phosphorylation of Cfi1/Net1 regulated Dbf2-

386 Mob1's nucleolar localization. We focused our analysis on zone 2 of Cfi1/Net1 because previous

387 studies had shown that the first 621 amino acids of the protein are sufficient to confer Cdc14

388 regulation (Azzam, 2004). We further note that mutating phosphorylation sites in zone 1 and 3 of

389 Cfi1/Net1 did not affect the nucleolar localization of Mob1 132 (Figure 5B-C, Figure 5-figure

390 supplement 2A). We generated a CFI1/NET1 allele with mutated phosphorylation sites in zone 2

391 that were phosphorylated in a CDC5-dependent but CDC15-independent manner (henceforth

392 cfil-Cdc5only(z2)). For comparison we generated a CFI1/NET1 allele in which we only mutated

393 sites that were phosphorylated in a CDC15-dependent manner (henceforth $c f i 1-C d c 15(z 2))$.

394 Analysis of Mob1 $\Delta 132$ localization in these mutants revealed that, similar to inhibition of Cdc5,

395 cfil-Cdc5only(z2) abolished the nucleolar localization of Mob1 1132 , while cfil-Cdc15(z2)

396 slightly increased nucleolar localization of the protein (Figure 5D-E, Figure 5-figure supplement

397 2B). To validate these findings, we performed TurboID labeling experiments followed by

398 Streptavidin gel-shift assays to probe the interaction between TurboID tagged full-length Mob1

399 and 13Myc tagged Cfi1/Net1. The slower migrating form corresponding to biotinylated

400 Cfi1/Net1 was absent in cells expressing cfil-Cdc5only(z2) but present in cells expressing CFI or $401 \quad c f i 1-C d c 15(z 2)$ (Figure 5F). We conclude that phosphorylation of Cfi1/Net1 by Cdc5 is required

402 for Dbf2-Mob1 binding to the protein. 
Three lines of evidence indicate that Cdc5 directly phosphorylates Cfi1/Net1. First, consistent with the finding that Cdc5 is already active in metaphase, 10 out of 12 CDC5-only

405 sites identified in anaphase cells are already phosphorylated in cells arrested in metaphase using 406 the microtubule depolymerizing drug nocodazole (Figure 5-figure supplement 3) with 6 of them 407 also determined to be CDC5-dependent in metaphase (Figure 5-figure supplement 3E). Second, 408 we found considerable overlap between $C D C 5$-dependent phosphorylation sites in vivo and sites 409 identified in vitro (Loughrey Chen et al., 2002; Shou et al., 2002). Four out of five in vivo

410 Cdc5only sites in region 1-341 were previously found to be phosphorylated by Cdc5 in vitro

411 (Table S4). Third, Cdc5 and Cfi1/Net1 interact with each other in vivo as determined by TurboID

412 labeling (Figure 5-figure supplement 4A). The biotinylation of Cfi1/Net1 by Cdc5-TurboID was

413 further confirmed by the detection of biotinylated peptides in Cfi1/Net1 as well as the

414 streptavidin gel-shift assay (Figure 5-figure supplement 4B-C). We conclude that Cdc5

415 phosphorylates Cfi1/Net1 at the onset of metaphase which serves as a priming event for Dbf2-

416 Mob1 binding to Cfi1/Net1 in anaphase. We note that these findings also explain why

417 Mob1 $\Delta 132$ 's nucleolar localization is already evident in metaphase (Figure 4B).

$418 \quad$ How does phosphorylation of Cfi1/Net1 by Cdc5 promote its binding to Dbf2-Mob1?

419 Dbf2-Mob1 binds to Cdc15-phosphorylated Nud1 through Mob1's phosphoserine-threonine

420 binding domain (Rock et al., 2013). We propose that a similar mechanism might also mediate the

421 interaction between Dbf2-Mob1 and Cdc5-phosphorylated Cfi1/Net1. To test this possibility, we

422 introduced the mutation R253A,R254A,R257A (3RA), shown to abolish Mob1's ability to bind

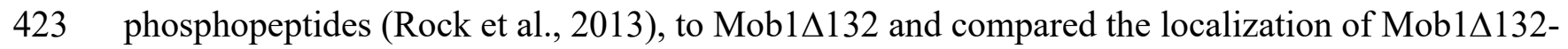

424 eGFP and Mob1 1 132-3RA-eGFP expressed ectopically (Figure 5-figure supplement 5A). The 
425 3RA mutation, while retained nuclear access, abolished both the SPB and nucleolar localization

426 of Mob1 $\Delta 132$ (Figure 5G and Figure 5-figure supplement 5).

Dbf2-Mob1 promotes the release of Cdc14 from the nucleolus through Cdc5-mediated priming

\section{9 of Cfi1/Net1.}

430 To determine whether the CDC5 and MEN-dependent phosphorylation sites in Cfi1/Net1

431 regulate the interaction between Cfil/Net1 and Cdc14 as our model predicted, we examined the

432 consequences of disrupting these phosphorylation sites on the release of Cdc14 from the

433 nucleolus. We first determined which region of Cfi1/Net1 was mediating phospho-regulation of

434 this interaction. We mutated all phosphorylation sites in the individual zones as well as in

435 combination and analyzed the effects on Cdc14 release from the nucleolus. This analysis

436 revealed that only phosphorylation in zone 2 controlled Cdc14 release from Cfi1/Net1 (Figure 6-

437 figure supplement 1A-B). It is important to note that mutating the phosphorylation sites in zone 2

438 also affected the ability of Cfi1/Net1 to bind Cdc14, as judged by the lower degree of Cdc14

439 nucleolar sequestration prior to anaphase and localization of Cdc14 to the dSPB prior to

440 anaphase (Figure 6-figure supplement 1C). This finding indicates that the same residues involved

441 in regulating the interaction between Cfi1/Net1 and Cdc14 are also important for forming the

442 complex in the first place and mutating them to alanine weakens this interaction. Alternatively,

443 mutating so many residues at once (53 sites in zone 2) could change the structure of Cfi1/Net1

444 and thus disrupt binding to Cdc14. Nevertheless, the increased level of free Cdc14 in the cell

445 with $c f i 1-91 A$ and the zone 2-phosphomutant explains why such severe defect in Cdc14 release

446 from the nucleolus did not cause a significant anaphase delay as assayed by the kinetics of Cdc14

447 re-sequestration. 
Next, we examined kinase-specific phospho-mutants in Cfi1/Net1. There are three known kinases that phosphorylate Cfi1/Net1 to regulate binding to Cdc14: mitotic CDKs (mainly Clb2Cdk1), Cdc5 and Dbf2-Mob1. CDK phosphorylation of Cfi1/Net1 during early anaphase underlies FEAR network-dependent release of Cdc14 from its inhibitor (Azzam, 2004). In FEAR

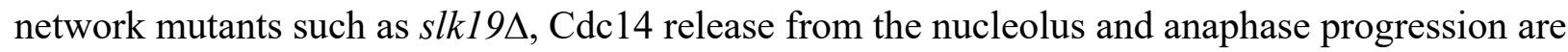
delayed and are accompanied by increased cell-to-cell variability (Figure 6A). As reported

454 previously (Azzam, 2004), cells harboring a CFI1/NET1 allele with 6 CDK sites mutated to 455 alanine, $c f i 1 /$ net1-6Cdk, caused Cdc14 release defects similar to those of FEAR network mutants 456 (Figure 6B). pattern of Cdc14 localization, where Cdc14 is initially released from the nucleolus by the FEAR network during early anaphase but is then re-sequestered in the nucleolus during later stages of anaphase (Stegmeier et al., 2002) (Figure 6A). Mutating the CDC15-dependent phosphorylation

461 sites in zone $2(c f i 1-C d c 15(z 2))$ resulted in a significant reduction of Cdc14 release from the 462 nucleolus but only recapitulated $\sim 50 \%$ of the effect of inactivating CDC15 (compare Figure $6 \mathrm{~A}$ and B). As previously reported (Visintin et al., 2008), inhibition of the analog sensitive cdc5-as 1

464 allele caused defects in both FEAR network and MEN-mediated release of Cdc14 from the nucleolus (Figure 6A). Mutating the CDC5-only phosphorylation sites in zone 2 (cfilCdc5only(z2)) resulted in a similar reduction of Cdc14 release from the nucleolus (Figure 6B) as inhibiting Cdc5. Finally, combining cfil-Cdc5only(z2) with cfi1-Cdc15(z2) (cfilmutant alone (Figure 6B, Figure 6-figure supplement 2). These results confirmed our model 
471 Dbf2-Mob1 to Cfi1/Net1. Phosphorylation of Cfi1/Net1 by Dbf2-Mob1 then promotes the

472 dissociation of Cdc14 from Cfi1/Net1.

\section{Phosphorylation of Cfi1/Net1 by Cdc5 and Dbf2-Mob1 promotes mitotic exit.}

Preventing the dissociation of Cdc14 from its inhibitor during anaphase ought to interfere with mitotic exit. Indeed, we observed a delay in all mutants analyzed (Figure 6C, Figure 6-

477 figure supplement 3). Both $c f i 1-C d c 15(z 2)$ and $c f i 1-C d c 5 o n l y(z 2)$ mutant cells exited mitosis

478 with an average delay of $\sim 6$ minutes ( $25 \%$ increase, Figure $6 \mathrm{C})$. In addition, consistent with

479 Cdc5's role in the FEAR network, we observed a significant delay in nucleolar segregation in $480 \quad c f i 1-C d c 5$ only(z2) mutant cells (Figure 6C). Surprisingly, cfil-Cdc15\&Cdc5(z2) double mutant 481 cells which had the most severe defect in Cdc14 release from the nucleolus exhibited a similar 482 delay in mitotic exit as the $c f i 1-C d c 15(z 2)$ and $c f i 1-C d c 5 o n l y(z 2)$ single mutants and a less severe 483 defect in nucleolar segregation compared to cfil-Cdc5only(z2) (Figure 6C). This relatively short 484 delay in mitotic exit is likely due to the fact that Cdc14 was not tightly sequestered in this mutant 485 prior to anaphase. We observed elevated levels of Cdc14 at dSPB, indicating the presence of free 486 Cdc14 not sequestered in the nucleolus, in both $c f i 1-C d c 15(z 2)$ and $c f i 1-C d c 15 \& C d c 5(z 2)$ cells 487 prior to anaphase (Figure 6D, Figure 6-figure supplement 2). It appears that mutating CDC15488 dependent sites in Cfi1/Net1 interferes with its ability to bind Cdc14. Nonetheless, the majority $489(>60 \%)$ of Cdc14 was not released during anaphase in cells harboring $c f i 1-C d c 15 \& C d c 5$.

$490 \quad$ One possible explanation for the apparent discrepancy between the severity of the Cdc14 491 release defect and the more subtle delay in mitotic exit is that, in addition to targeting Cfi1/Net1, 492 MEN also promotes cytoplasmic retention of Cdc14 by phosphorylating its NLS (Mohl et al., 493 2009). To determine the contribution of this MEN function to promoting mitotic exit in 
Cfil/Net1 mutants, we constructed a CDC14 mutant $(c d c 14-3 A)$ in which all three potential

Dbf2-Mob1 phosphorylation sites capable of driving translocation of the NLS $\mathrm{Sdc}_{\mathrm{C} 14}$ reporter into the cytoplasm were mutated to alanine (Figure 6-figure supplement 4A). Interestingly, cells expressing $c d c 14-3 A$ instead of $C D C 14$ exited from mitosis without significant delays (Figure 6figure supplement 4B) indicating that cytoplasmic retention of Cdc14 does not play a major role in promoting mitotic exit.

501 eluded our MS analysis. However, given that Cdc14 is a potent phosphatase, we favor the idea that, incomplete sequestration of Cdc14 prior to anaphase coupled with FEAR network-mediated nucleolar release of Cdc14 during early anaphase is sufficient to promote exit from mitosis with only a modest delay in the $c f i 1-C d c 15 \& C d c 5$ mutant. Consistent with this idea, we found that the cfil-Cdc5only(z2) mutant, which does not display defects in sequestering Cdc14 prior to

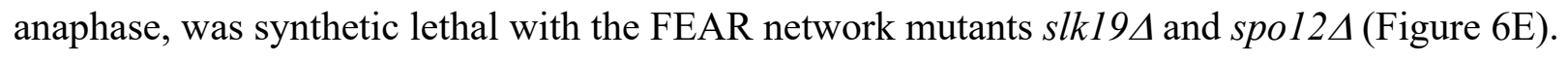
Furthermore, combining $c f i 1-C d c 5 o n l y(z 2)$ with the FEAR mutant $c f i 1-6 C d k$ resulted in severe

508 defects in both FEAR network and MEN mediated Cdc14 release (Figure 6-figure supplement

$5095 \mathrm{~A}$ ) and $\sim 20$-minute delays in both mitotic exit and nucleolar segregation (Figure 6-figure

510 supplement 5B), the strongest defect in all mutants we have characterized. We conclude that

511 CDC5 and MEN-dependent phosphorylation of Cfi1/Net1 controls the protein's binding to

512 Cdc14 and exit from mitosis.

\section{DISCUSSION}

515 As a model system for mitotic exit control and cellular signaling in eukaryotes, the MEN has 516 been studied extensively for decades. Yet, how the MEN activates its effector Cdc14 to promote 
517 exit from mitosis has remained an enigma. Furthermore, the spatial aspect of signal transmission

518 in the MEN, namely how a signal generated at the outer plaque of the SPBs in the cytosol

519 reaches its target in the nucleolus, was largely unexplored. Our study provides mechanistic

520 insights into these questions and together with prior observations lead to a model for Cdc14

521 regulation and mitotic exit in budding yeast (Figure 7).

\section{The role of the Polo-like kinase Cdc5 in regulating Cdc14 activation.}

524 The Polo-like kinase Cdc5 is essential for Cdc14 activation and is part of both the FEAR 525 network and the MEN. However, the exact role(s) of Cdc5 in regulating Cdc14's nucleolar

526 release has remained elusive due to its multiple functions in the MEN and the FEAR network.

527 Using an allele that bypasses $C D C 5$ 's role in MEN activation, we revealed a novel function of

528 Cdc5 as a priming kinase that targets Dbf2-Mob1 to its substrate Cfi1/Net1.

529 It was hypothesized that phosphorylation of Cfi1/Net1 by Cdc5 weakens the interaction

530 between Cfi1/Net1 and Cdc14. Additional phosphorylation by mitotic CDKs or Dbf2-Mob1

531 were thought to further reduce the interaction resulting in the dissociation of Cdc14 from its

532 inhibitor. Our results suggest an alternative model. Instead of, or at least in addition to,

533 weakening the Cfi1/Net1-Cdc14 interaction, Cdc5 phosphorylation targets Dbf2-Mob1 to

534 Cfi1/Net1. Mutating the Cdc5-only phosphorylation sites in Cfi1/Net1 abolished nucleolar

535 enrichment of Dbf2-Mob1 and resulted in a reduction in MEN-mediated dissociation of Cdc14

536 from Cfi1/Net1. Interestingly, this mutation also caused severe defects in the FEAR network

537 mediated release of $\mathrm{Cdc} 14$ from Cfi1/Net1. We thus propose that Cdc5 priming phosphorylation

538 is required not only for Dbf2-Mob1 to phosphorylate Cfi1/Net1 but also for mitotic CDKs

539 (Figure 7). Consistent with this hypothesis, we found that most Cdc5 phosphorylation sites in 
540 Cfi1/Net1 are already phosphorylated by Cdc5 in metaphase (Figure 5-figure supplement 3E).

541 This observation indicates that the docking site(s) on Cfi1/Net1 for Dbf2-Mob1 (and mitotic

$542 \mathrm{CDKs}$ ) is already present in metaphase prior to the activation of the FEAR network and the MEN

543 (Figure 7). This model is further supported by the observation that inhibition of Cdc5 eliminates

544 CDK mediated phosphorylation of T212 in Cfi1/Net1 (Azzam, 2004). Cdc5 activity is regulated

545 by the DNA damage checkpoint (Cheng et al., 1998; Sanchez, 1999). We speculate that making

546 FEAR network and MEN-mediated release of Cdc14 from the nucleolus dependent on Cdc5's

547 priming activity ensures that DNA damage has been repaired and the checkpoint silenced prior to 548 exit from mitosis.

The FEAR network and the MEN regulate Cdc14 binding to Cfi1/Net1 by different

\section{mechanisms.}

552 Although both mitotic CDKs and Dbf2-Mob1 appear to require $C D C 5$-dependent priming

553 phosphorylation of Cfi1/Net1, the mechanism whereby mitotic CDKs and Dbf2-Mob1 disrupt

554 the interaction between Cfi1/Net1 and Cdc14 is quite different. Mitotic CDKs phosphorylate

555 Cfi1/Net1 mainly on S166, T212, S252, T297 and T304; Dbf2-Mob1 targets sites S259, S295,

556 S362, S439 and S497 (Figure 5A, Table S4). Given that mitotic CDKs and Dbf2-Mob1 target

557 different sites, we propose that increasing the acidity of aa160-500 within Cfi1/Net1 rather than

558 site-specific phosphorylation disrupts the interaction between Cdc14 and its inhibitor. Cfi1/Net1

559 is an integral part of the nucleolus, which has recently been described as a phase-separated

560 structure (Feric et al., 2016; Shin and Brangwynne, 2017). Overall phosphorylation rather than

561 phosphorylation of specific sites has been shown to disrupt interactions within such structures 
562 (Carpenter et al., 2018; Owen and Shewmaker, 2019). Perhaps extraction of Cdc14 from the

563 nucleolar phase requires a similar mechanism.

\section{The MEN as a model for cross-compartment signaling.}

566 The MEN, most closely related to the Hippo pathway, employs most, if not all, of the principles

567 governing classic receptor tyrosine signaling logic to convey a signal generated at SPBs to the

568 MEN effector Cdc14 in the nucleolus: (1) scaffold assisted signaling (at the SPB), (2) signal

569 transmission across organelle boundaries - from the cytoplasm to the nucleus, and (3) activation

570 of the effector in a sub-compartment (the nucleolus). As such, we believe that the molecular

571 mechanisms governing MEN activity are broadly applicable to intracellular signal transmission

572 in general.

(1) Dynamic scaffold assisted signaling.

575 Scaffold assisted assembly of signaling complexes is a widespread phenomenon in eukaryotic

576 signal transduction cascades (Good et al., 2011). We find that in the MEN, assembly of Cdc15-

577 (Dbf2-Mob1) signaling complex on the scaffold Nud1 is highly dynamic and this dynamicity is

578 crucial for effector activation. We propose that this dynamicity also serves to amplify the signal.

579 Cdc15 is the limiting enzyme of the pathway: it is the least abundant component of the MEN and

580 hyperactivating Cdc15 increases Dbf2-Mob1's kinase activity by $>40$-fold (Rock and Amon,

581 2011). We further hypothesize that the relatively low affinity of Mob1 for phosphorylated-Nud1

$582\left(K_{d}=2.4 \mu \mathrm{M}\right.$; note that for an optimal Mob1 binding phosphopeptide the $K_{d}$ is $\left.174 \mathrm{nM}\right)($ Rock et

583 al., 2013) is selected for to facilitate the fast turnover rate of Dbf2-Mob1 at SPBs and thus to

584 promote release of the kinase and signal amplification. In this model, the binding 
585 affinity/kinetics of kinases to their signaling scaffolds is an important parameter that cells finetune to generate desirable signaling properties of scaffold-assisted signaling pathways.

\section{(2) Regulated compartment access.}

589 Many signals, be they generated outside or within the cell, ultimately, result in a nuclear

590 response. As such, signals have to be propagated from the cytoplasm into the nucleus. Our

591 studies have led to the discovery that in the MEN, this nuclear access is cell cycle regulated.

592 Prior to anaphase, Dbf2-Mob1 is actively exported out of the nucleus by Crm1 through the conserved NES within the N-terminus of Dbf2. Upon MEN activation, nuclear partitioning of Dbf2-Mob1 increases, likely a result of both increased nuclear import through modification of Mob1's inhibitory N-terminus and decreased nuclear export through modification of Dbf2. One potential mechanism for the latter is via phosphorylation of Dbf2's NES at S17 and S20, possibly by Cdc15. Our observation that mutating these two sites exacerbated the temperature sensitivity of $c d c 15-2$ (Figure 3-figure supplement 3C) is consistent with this possibility.

602 Cdc15 to enter the nucleus at any given time during anaphase. Active Dbf2-Mob1 is also needed 603 in the cytosol to phosphorylate substrates other than Cfi1/Net1 such as those involved in

604 cytokinesis. We speculate that fine-turning the balance of nuclear versus cytosolic Dbf2-Mob1, possibly through maintaining a dynamic shuttling of active Dbf-Mob1 between the nucleus and cytoplasm, is important for the timing of late cell cycle events. The dynamic shuttling of Dbf2- 
608 the absence of visible nuclear translocation of Dbf2-Mob1 upon activation. Interestingly,

609 mammalian Dbf2, known as LATS and is thought to mainly function in the cytosol (Yu and

610 Guan, 2013), has been found to localize to the nucleus (Britschgi et al., 2017; Li et al., 2014),

611 indicating nuclear shuttling of kinases might play a role in Hippo signaling as well.

613 (3) Substrate targeting by priming phosphorylation.

614 Upon entry into the nucleus, Dbf2-Mob1 specifically functions in the nucleolus to promote the

615 dissociation of Cdc14 from its inhibitor Cfi1/Net1. Priming phosphorylation by Cdc5 on

616 Cfi1/Net1 ensures that Dbf2-Mob1 executes this function effectively. Dbf2-Mob1 binds to

617 Cdc15-phosphorylated Nud1 through Mob1's phosphoserine-threonine binding domain (Rock et

618 al., 2013). We demonstrated that a similar mechanism mediates the interaction between Dbf2-

619 Mob1 and Cdc5-phosphorylated Cfi1/Net1 (Figure 5G). Interestingly, during cytokinesis,

620 phosphorylation of Dbf2-Mob1's substrate Hof1 by Cdc5 has also been shown to facilitate the

621 binding of Hof1 to Mob1 (Meitinger et al., 2011; Rock et al., 2013). Based on our observation

622 that a quarter of potential Dbf2-Mob1 substrates are also targets of Cdc5 (Figure 5-figure

623 supplement 1E) we further speculate that priming phosphorylation by Cdc5 is a general

624 mechanism for targeting Dbf2-Mob1 to its substrates.

625 It is worth noting that $\mathrm{Cdc5}$ 's consensus motif with an acidic residue at the -2 position of

626 the pS/T (Kettenbach et al., 2011; Nakajima et al., 2003) does not fit well with the optimal Mob1

627 binding motif which prefers $\mathrm{Y} / \mathrm{F}$ at the -2 position of the $\mathrm{pS} / \mathrm{T}$ (Rock et al., 2013). This is likely

628 beneficial as a low affinity between Dbf2-Mob1 and its substrates would increase substrate

629 turnover and prevent sequestration of active Dbf2-Mob1. This low affinity would also explain

630 the weak and transient localization of Dbf2-Mob1 in the nucleolus that evaded detection 
631 previously. Mob1's phosphoserine-threonine binding domain is well conserved from yeast to

632 humans (Rock et al., 2013) suggesting that substrate targeting through priming phosphorylation

633 might occur for LATS-MOB1 in the Hippo pathway as well.

634 Priming phosphorylation is a widely used mechanism to ensure effective kinase action at

635 a particular site in the cell. Perhaps the best studied example for priming is the Polo-like kinases

636 whose polo-box domain directs the kinase to specific subcellular structures and substrates that

637 have been previously phosphorylated by a priming kinase such as CDKs (Elia et al., 2003;

638 Lowery et al., 2005). Although MAP kinases are mainly directed to their substrates through

639 specialized docking motifs (Bardwell, 2006; Cargnello and Roux, 2011) without priming, it has

640 been demonstrated that successive phosphorylation through priming could contribute to the

641 sensing of MAPK signal duration and strength (Murphy et al., 2002). These examples together

642 with our findings for Dbf2-Mob1 underscore the importance of priming phosphorylation as a

643 conserved paradigm for achieving specificity and efficiency in cellular signal transduction.

\section{ACKNOWLEDGEMENTS}

646 We thank F. Luca (Philadelphia, USA), R. Deshaies (Caltech, USA), E. Schiebel (ZMBH,

647 Germany), E. Unal (Berkeley, USA) and J. Haber (Waltham, USA) for strains and reagents; R.

648 Schiavoni and the Biopolymers \& Proteomics Facility at Koch Institute Swanson Biotechnology

649 Center for processing samples for the TurboID-MS experiments; S. Bell, A. Seshan and

650 members of our laboratory for their critical reading of the manuscript. This work was supported

651 by National Institute of General Medical Science (GM 118066 to A.A.) and the Eunice Kennedy

652 Shriver National Institute of Child Health and Human Development (HD085866 to A.A.). X.Z.

653 was supported by a Helen Hay Whitney postdoctoral fellowship. A.A. is also investigator of the 
654 Howard Hughes Medical Institute and the Paul F. Glenn Center for Biology of Aging Research

655 at MIT.

656

657 AUTHOR CONTRIBUTIONS

658 X.Z. and A.A. conceived the study. X.Z. performed all experiments. W.L. and Y.L. provided the

659 phosphoproteomic analysis. X.Z. and A.A. wrote the manuscript with input from all coauthors.

660

661 COMPETING INTERESTS

662 The authors declare no competing interests. 


\section{MATERIALS AND METHODS}

\begin{tabular}{|c|c|c|c|c|}
\hline \multicolumn{5}{|c|}{ Key Resources Table } \\
\hline $\begin{array}{l}\text { Reagent type } \\
\text { (species) or } \\
\text { resource }\end{array}$ & Designation & $\begin{array}{l}\text { Source or } \\
\text { reference }\end{array}$ & Identifiers & $\begin{array}{l}\text { Additional } \\
\text { information }\end{array}$ \\
\hline $\begin{array}{l}\text { gene }(S . \\
\text { cerevisiae) }\end{array}$ & See Table S1 & & & \\
\hline $\begin{array}{l}\text { strain, strain } \\
\text { background } \\
(S . \text { cerevisiae })\end{array}$ & W303 & & & \\
\hline $\begin{array}{l}\text { genetic } \\
\text { reagent }(S . \\
\text { cerevisiae) }\end{array}$ & See Table S1 & & & \\
\hline $\begin{array}{l}\text { recombinant } \\
\text { DNA reagent }\end{array}$ & See Table S2 & & & \\
\hline $\begin{array}{l}\text { strain, strain } \\
\text { background } \\
\text { (E. coli) }\end{array}$ & $\mathrm{DH} 5 \alpha$ & $\begin{array}{l}\text { New England } \\
\text { Biolabs }\end{array}$ & Cat\# C2987U & $\begin{array}{l}\text { Chemical } \\
\text { competent } \\
\text { cells }\end{array}$ \\
\hline antibody & $\begin{array}{l}\text { anti-GFP [JL-8] } \\
\text { (Mouse } \\
\text { monoclonal) }\end{array}$ & Takara Bio & $\begin{array}{l}\text { Cat\# 632381; } \\
\text { RRID:AB_2313808 }\end{array}$ & WB $(1: 1000)$ \\
\hline antibody & $\begin{array}{l}\text { anti-Myc [9E10] } \\
\text { (Mouse } \\
\text { monoclonal) }\end{array}$ & Abcam & $\begin{array}{l}\text { Cat\# ab32; } \\
\text { RRID:AB_303599 }\end{array}$ & WB (1:500) \\
\hline antibody & $\begin{array}{l}\text { anti-V5 (Mouse } \\
\text { monoclonal) }\end{array}$ & Invitrogen & $\begin{array}{l}\text { Cat\# R960-25; } \\
\text { RRID:AB_255656 }\end{array}$ & WB $(1: 2000)$ \\
\hline antibody & $\begin{array}{l}\text { Rabbit } \\
\text { polyclonal anti- } \\
\text { Kar2 }\end{array}$ & $\begin{array}{l}\text { Gift from } \\
\text { Mark Rose }\end{array}$ & $N / A$ & $\begin{array}{l}\text { WB } \\
(1: 200,000)\end{array}$ \\
\hline antibody & $\begin{array}{l}\text { HRP-conjugated } \\
\text { anti-mouse lgG }\end{array}$ & GE & $\begin{array}{l}\text { Cat\# NA9310; } \\
\text { RRID:AB_772193 }\end{array}$ & $(1: 10,000)$ \\
\hline
\end{tabular}




\begin{tabular}{|c|c|c|c|c|}
\hline antibody & $\begin{array}{l}\text { HRP-conjugated } \\
\text { anti-rabbit IgG }\end{array}$ & GE & $\begin{array}{l}\text { Cat\# NA934; } \\
\text { RRID:AB_772206 }\end{array}$ & $(1: 10,000)$ \\
\hline antibody & $\begin{array}{l}\text { anti-tubulin } \\
\text { [YOL1/34] (Rat } \\
\text { monoclonal) }\end{array}$ & Abcam & $\begin{array}{l}\text { Cat\# Ab6161; } \\
\text { RRID:AB_305329 }\end{array}$ & IF (1:100) \\
\hline antibody & $\begin{array}{l}\text { FITC-Donkey } \\
\text { anti-Rat IgG }\end{array}$ & $\begin{array}{l}\text { Jackson } \\
\text { ImmunoRese } \\
\text { arch }\end{array}$ & $\begin{array}{l}\text { Cat\# 712-095-153; } \\
\text { RRID:AB_2340652 }\end{array}$ & $(1: 50)$ \\
\hline $\begin{array}{l}\text { peptide, } \\
\text { recombinant } \\
\text { protein }\end{array}$ & Streptavidin & Sigma-Aldrich & Cat\# 189730 & \\
\hline $\begin{array}{l}\text { peptide, } \\
\text { recombinant } \\
\text { protein }\end{array}$ & $\alpha$-factor & $\begin{array}{l}\text { The Koch } \\
\text { Institute } \\
\text { Swanson } \\
\text { Biotechnology } \\
\text { Center - } \\
\text { Biopolymers } \\
\text { Core Facility }\end{array}$ & $\mathrm{N} / \mathrm{A}$ & \\
\hline $\begin{array}{l}\text { commercial } \\
\text { assay or kit }\end{array}$ & $\begin{array}{l}\text { Gibson } \\
\text { Assembly } \\
\text { Master Mix }\end{array}$ & $\begin{array}{l}\text { New England } \\
\text { Biolabs }\end{array}$ & Cat\# E2611S & \\
\hline $\begin{array}{l}\text { commercial } \\
\text { assay or kit }\end{array}$ & $\begin{array}{l}\text { Q5 Site-Directed } \\
\text { Mutagenesis Kit }\end{array}$ & $\begin{array}{l}\text { New England } \\
\text { Biolabs }\end{array}$ & Cat\# E05545 & \\
\hline $\begin{array}{l}\text { commercial } \\
\text { assay or kit }\end{array}$ & $\begin{array}{l}\text { Bradford protein } \\
\text { assay }\end{array}$ & BioRad & Cat\# 5000006 & \\
\hline $\begin{array}{l}\text { commercial } \\
\text { assay or kit }\end{array}$ & $\begin{array}{l}\text { BCA protein } \\
\text { assay }\end{array}$ & Pierce & Cat\# 23227 & \\
\hline $\begin{array}{l}\text { commercial } \\
\text { assay or kit }\end{array}$ & $\begin{array}{l}\text { MyOne } \\
\text { Streptavidin C1 } \\
\text { dynabeads }\end{array}$ & $\begin{array}{l}\text { Thermo Fisher } \\
\text { Scientific }\end{array}$ & Cat\# 65001 & \\
\hline $\begin{array}{l}\text { chemical } \\
\text { compound, } \\
\text { drug }\end{array}$ & Nocodazole & Sigma-Aldrich & Cat\# M1404 & \\
\hline
\end{tabular}




\begin{tabular}{|c|c|c|c|}
\hline $\begin{array}{l}\text { chemical } \\
\text { compound, } \\
\text { drug }\end{array}$ & Biotin & Sigma-Aldrich & Cat\# B4639 \\
\hline $\begin{array}{l}\text { chemical } \\
\text { compound, } \\
\text { drug }\end{array}$ & 1-NA-PP1 & $\begin{array}{l}\text { Cayman } \\
\text { Chemical }\end{array}$ & Cat\# 10954 \\
\hline $\begin{array}{l}\text { chemical } \\
\text { compound, } \\
\text { drug }\end{array}$ & CMK & $\begin{array}{l}\text { MedChem } \\
\text { Express }\end{array}$ & Cat\# HY-52101 \\
\hline $\begin{array}{l}\text { chemical } \\
\text { compound, } \\
\text { drug }\end{array}$ & $\begin{array}{l}\text { Phycocyanobilin } \\
\text { (PCB) }\end{array}$ & $\begin{array}{l}\text { Santa Cruz } \\
\text { Biotechnology }\end{array}$ & Cat\# sc-396921 \\
\hline $\begin{array}{l}\text { software, } \\
\text { algorithm }\end{array}$ & FIJI (ImageJ) & $\begin{array}{l}\text { (Schindelin et } \\
\text { al., 2012) }\end{array}$ & RRID:SCR_002285 \\
\hline $\begin{array}{l}\text { software, } \\
\text { algorithm }\end{array}$ & $\begin{array}{l}\text { MATLAB_R2018 } \\
b\end{array}$ & $\begin{array}{l}\text { Mathworks, } \\
\text { Inc. (2018) }\end{array}$ & RRID:SCR_001622 \\
\hline $\begin{array}{l}\text { software, } \\
\text { algorithm }\end{array}$ & SnapGene v4.3 & $\begin{array}{l}\text { https://www.s } \\
\text { napgene.com }\end{array}$ & RRID:SCR_015052 \\
\hline $\begin{array}{l}\text { software, } \\
\text { algorithm }\end{array}$ & $\begin{array}{l}\text { Custom } \\
\text { MATLAB codes }\end{array}$ & This paper & $\begin{array}{l}\text { https://github.com/s } \\
\text { now-zhou/Dbf2- } \\
\text { Mob1 }\end{array}$ \\
\hline other & $\begin{array}{l}\text { Mini Bead } \\
\text { Beater }\end{array}$ & $\begin{array}{l}\text { Biospec } \\
\text { Products }\end{array}$ & $N / A$ \\
\hline
\end{tabular}

\section{Construction of Yeast strains and plasmids}

666 All Saccharomyces cerevisiae yeast strains used in this study are derivatives of W303 (A2587)

667 and are listed in Table S1. All plasmids used in this study are listed in Table S2. Yeast were

668 cultured in standard YEP media (1\% yeast extract, $2 \%$ peptone) with $2 \%$ D-glucose, or in

669 standard Synthetic Complete media (SC) with either 2\% D-glucose or 2\% raffinose prior to 
670 induction of $G A L 1 / 10$ promoters with $1 \%$ raffinose $+1 \%$ galactose as indicated in the figure

671 legends. Cells were cultured at $25^{\circ} \mathrm{C}$ unless noted otherwise.

672 C-terminal fusions were constructed using standard PCR-based methods. N-terminal

673 truncation of $M O B 1$ mutants were made by first constructing the truncations with $\mathrm{N}$-terminal

674 eGFP fusion in plasmids (pA2828-2830) based on pRS305H-MOB1 (König et al., 2010). PCR

675 products of the fusion with $500 \mathrm{bp}$ upstream promoter region and $300 \mathrm{bp}$ downstream of the

$676 M O B 1$ ORF as well as the hphMX6 marker were transformed and integrated at the $M O B 1$ locus.

677 Correct integration and mutations were confirmed by PCR and sequencing. The NLS $\mathrm{Cdc}_{14}$

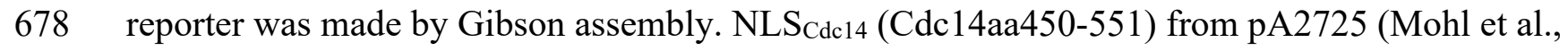

679 2009) and synthesized yeast codon optimized miRFP670 (Shcherbakova and Verkhusha, 2013)

680 (denoted as ymiRFP670) were assembled into the p404TEF1 vector (pA2726) which yielded

681 pA2786 for integration at the trp1 locus. The PhyB constructs were integrated at the leu2 locus

682 as single integrants (Yang et al., 2013). The eGFP-PIF C-terminal tagging plasmid (pA2821) was

683 made by replacing the mCitrine in pA2721 with eGFP and correcting the frame shift mutation

684 (missing a $\mathrm{G}$ at codon\#2) in the natMx6 coding sequence in the original plasmid acquired from

685 Addgene. The TurboID tagging plasmid (pA2859) was constructed by inserting the TurboID-V5

686 sequence from pA2847 (Branon et al., 2018) into the vector backbone of pA2821 between the

687 linker and natMx6.

688 Point mutations and truncations in the GAL-DBF2 plasmids were made using Q5 site-

689 directed mutagenesis (NEB). Single point mutation in DBF2 (dbf2-L12A) was introduced at the

690 endogenous locus using Cas9-mediated gene editing based on previously published protocols

691 (Anand et al., 2017) with modifications. Briefly, BplI cut plasmid pA2911 containing Cas9 and

692 gRNA missing the 20 bp target specific complementary sequence was transformed into A2587 
693 together with (1) a 250 bp synthesized double stranded DNA (IDT) containing the $20 \mathrm{bp}$

694 complementary sequence for DBF2 (TGCTCATATTGCCTGCCAAG) sandwiched with

695 homologous sequences to the gRNA sequence in plasmid pA2911 for gap repair, and (2) an

696 80mer single strand DNA harboring $d b f 2-L 12 A$ mutation as the repair template. Successfully

697 edited clones were checked by sequencing and cured of the Cas9 plasmid. Phospho-mutants of

$698 D B F 2(d b f 2-S 17,20 A$ and $d b f 2-S 17,20 D)$ were first constructed in plasmids (pA2948, pA2953

699 and pA2954) by Q5 site-directed mutagenesis. The DBF2 ORF as well as the URA3 marker were

700 then PCR amplified and transformed into A32629 to integrate at the DBF2 locus as the sole copy

701 of $D B F 2$. Correct integration and mutations were confirmed by PCR and sequencing.

To generate CFI1/NET1 phospho-mutants, a fusion of wild-type CFI1/NET1 and

703 mScarlet-I with $\sim 300$ bp upstream and downstream regions of CFI1/NET1 were first Gibson

704 assembled into a single-integration vector backbone to generate plasmid pA2898. CFI1/NET1

705 phospho-mutants were synthesized (Twist Bioscience) in two segments (aa25-624 and aa617-

706 1173) and Gibson assembled into the vector backbone of pA2898 to replace wild-type

707 CFI1/NET1. These CFI1/NET1 constructs were integrated into strain A41362 harboring a

708 heterozygous deletion of CFI1/NETIand haploid strains with cfil $\Delta$ and different phospho-mutant

709 forms of CFI1/NET1 integrated as a single copy at the leu2 locus as the sole source of

710 CFI1/NET1 were obtained through tetrad dissection. We attempted to generate phospho-mimetic

711 mutants of CFI1/NET1 where either the Cdc15-dependent or Cdc5only sites in zone 2 were

712 replaced with the Asp or Glu to mimic phosphorylation (A41695-A41706). However, as

713 observed with many other proteins such as Cdc15 phosphorylation of Nud1 (Rock et al., 2013),

714 these mutations did not effectively mimic phosphorylation and in the case of Cdc5only sites led

715 to a loss of function with respect to Mob1 localization to the nucleolus. 

mutations into the integration plasmid (pA2735) with Q5 site-directed mutagenesis and then transformed and integrated at the ura3 locus. The triple mutants of CDC14 (S531,537,546A) was introduced at the endogenous locus in A2588 using Cas9-mediated gene editing as described above. The 20 bp complementary sequence for the gRNA used to target CDC14 was GGAGAGTAACGTCAGGGAGA. Ectopically expressed mob1 $1132-e G F P$ and mob1 $132-$ $3 R A-e G F P$ were made by removing the first 132aa of Mob1 from pA2124 and pA2126 (Rock et al., 2013) with Q5 site-directed mutagenesis, generating pA2972 and pA2973. These plasmids were integrated at the $\operatorname{trp} 1$ locus and were expressed under the endogenous $M O B 1$ promoter in the presence of a wild-type copy of $M O B 1$.

\section{FRAP analysis}

728 FRAP analysis was performed on a DeltaVision-OMX Super-Resolution Microscope (Applied

729 Precision, GE Healthcare Bio-Sciences) using a 60x oil objective and a 488 nm laser adjusted to

730 bleach an area of approximately $0.5 \mu \mathrm{m}$ in radius. Two prebleach images were acquired followed

731 by a laser pulse (100\% intensity) of $0.02 \mathrm{~s}$ duration and postbleach images were acquired at 1

$732 \mathrm{~s} /$ frame for $30 \mathrm{~s}$. Images at each time points were maximum projections of $7 z$ stacks with $0.5 \mu \mathrm{m}$

733 spacing. Images were analyzed with a custom MATLAB script. After subtracting the

734 background, fluorescence intensities in the cytosol, $I_{c y t o s o l}(t)$, and at the $\operatorname{SPB}, I_{S P B}(t)$ were

735 measured after segmenting the cell and SPBs. Photobleaching was corrected by normalizing $I_{S P B}$

$736(t)$ with $I_{\text {cytosol }}(t), I_{S P B_{-} \text {norm }}(t)=I_{S P B}(t) / I_{\text {cytosol }}(t)$. Double normalization for FRAP was calculated

737 to scale the photobleaching effect between 0 and $1: I_{S P B \_F R A P}(t)=\left[I_{S P B \_n o r m}(t)-I_{S P B \_n o r m}(0)\right] /$

$738\left[I_{S P B \_n o r m}(p r e)-I_{S P B_{-} n o r m}(0)\right]$, where $t=0$ is the time point (frame) right after photobleaching and 
$t=$ pre is the time point (frame) right before photobleaching. The double normalized FRAP

740 curves were then fitted to a single exponential curve: $y=y_{\max }\left(1-e^{\left(-\ln 2 / t_{1 / 2}\right) t}\right)$, where $y_{\max }$

741 is the fraction recovered while $t_{1 / 2}$ is the half-recovery time.

\section{Microscopy and image analysis}

744 For live-cell microscopy, cells were imaged on agarose pads ( $2 \%$ agarose in SC medium $+2 \%$

745 glucose, unless otherwise noted) affixed to a glass slide and covered with a coverslip. Imaging

746 was performed on a DeltaVision Elite platform (GE Healthcare Bio-Sciences) with an InsightSSI

747 solid state light source, an UltimateFocus hardware autofocus system and a model IX-71,

748 Olympus microscope controlled by SoftWoRx software. A 60x Plan APO 1.42NA objective and

749 CoolSNAP HQ2 camera were used for image acquisition. For each time point, $7 z$ sections with

$7501 \mu \mathrm{m}$ spacing were collect for each channel and were deconvolved. Maximum projections of the

751 deconvolved $z$ stack were used for fluorescence quantification.

Image analysis was performed with custom scripts in MATLAB. First, yeast cells were

753 segmented and tracked through time using the bright-field image stacks and a previously

754 reported algorism (Ricicova et al., 2013). A few modifications were made for the tracking

755 process. Images were first aligned to correct for drift in the $x y$ plane and cell segmentations in the

756 last frame of the time-lapse series were used as the reference for tracking. Next, fluorescence

757 images of cell cycle markers (such as Spc42 and or Cfi1/Net1) were segmented and tracked

758 based on cell segmentation. Appearance of a cell cycle marker in a cell during the acquisition

759 period was used to identify buds (daughter cells) and cell division events. Tracking of the cell

760 cycle markers that migrated into the buds were used to identify the corresponding mother cells. 
761 Finally, for each division event identified, localization of Mob1 (or Cdc14) at regions defined by

762 the cell cycle markers was quantified.

For Mob1 localization at the SPBs $\left(I_{S P B}\right)$, maximum intensity of Mob1 at SPBs (dilated

764 from the SPB area based on segmentation of Spc42) was used given that the size of SPBs $(\sim 100$

$765 \mathrm{~nm}$ ) is within the diffraction limit of light microscopy. For Mob1 localization in the nucleolus

766 ( $\left.I_{\text {nucleolus }}\right)$, the median intensity of Mob1 in the nucleolus as segmented by Cfi1/Net1 was used.

767 To calculate the relative enrichment of Mob1 at the SPB or in the nucleolus, Mob1 intensities at

768 these sites as defined above were normalized to the median intensity of Mob1 in the cytosol

769 which was defined as the cell area with cell cycle marker area subtracted $\left(I_{\text {cytosol }}\right)$ :

$770 I_{S P B}$ or nucleolus $/ I_{\text {cytosol }}-1$. For the Dbf2-Mob1 kinase activity reporter, NLS $\mathrm{Sdc}_{\mathrm{C} 14}$, its

771 translocation from the nucleus into the cytoplasm was quantified with the coefficient of variation

$772(\mathrm{CV})$ of the pixel intensities within the dividing cell. $\mathrm{CV}$ is defined as the standard deviation

773 divided by the mean.

774 To quantify Cdc14 release from the nucleolus, the ratio of Cdc14 intensity to Cfi1/Net1

775 intensity $\left(I_{C d c 14} / I_{C f i 1}\right)$ was calculated for each pixel within the nucleolus as segmented using

776 Cfi1/Net1 and averaged.

777 Single cell traces were aligned based on the timing of anaphase onset or the movement of

778 a SPB into the bud as indicated in figures, and averaged. 95\% confidence intervals were

779 calculated as $\mu \pm 1.96 * \sigma / \sqrt{n}$, where $\mu$ and $\sigma$ denote the mean and standard deviation

780 respectively and $n$ is the number of cells measured.

\section{Immunoblot analysis}


Log-phase cultures of cells grown in YEP $+2 \%$ glucose were harvested and treated with

$7845 \% \mathrm{TCA}$ at $4{ }^{\circ} \mathrm{C}$ overnight. TCA treated cell pellets were washed with acetone, air dried, and

785 resuspended in lysis buffer $(10 \mathrm{mM}$ Tris, $1 \mathrm{mM}$ EDTA, $2.75 \mathrm{mM}$ DTT, $\mathrm{pH}=8)$. Cells were

786 lysed by bead-beating using a Multivortexer (max speed, 20 minutes) and glass beads at $4^{\circ} \mathrm{C}$ and

787 followed by boiling in SDS PAGE protein loading buffer for 5 minutes. Lysates were clarified

788 by centrifugation and were resolved on a 15-well NuPAGE 4-12\% Bis-Tris protein gel (Thermo

789 Fisher Scientific) prior to transfer onto nitrocellulose membranes. GFP-Mob1 and variants were

790 detected using an anti-GFP antibody (Clontech, JL-8) at a 1:1000 dilution. Nud1-13myc and

791 Cfi1/Net1-3myc were detected using an anti-Myc antibody (abcam, 9E10) at a 1:500 dilution.

792 Mob1-V5-TurboID was detected using an anti-V5 antibody (Invitrogen) at a 1:2000 dilution.

793 Kar2 was detected using a rabbit anti-Kar2 antiserum at a 1:200,000 dilution. Secondary

794 antibodies were used at a $1: 10,000$ dilution. Blots were imaged using the ECL Plus system (GE

795 Healthcare).

TurboID-MS and streptavidin gel-shift assay

798 To identify biotinylated proteins as a result of interaction or physical proximity with TurboID

799 tagged bait protein by mass spectrometry (MS), log-phase cells with TurboID tagged bait and

800 untagged control cells were grown in YEP $+2 \%$ glucose $+50 \mu \mathrm{M}$ biotin at room temperature for

$8013.5 \mathrm{~h}$ ( $\sim$ two doublings). $\sim 40$ OD of cells were harvested for each sample and were treated with

$8025 \%$ trichloroacetic acid (TCA) at $4{ }^{\circ} \mathrm{C}$ for a minimum of 10 minutes. TCA treated cells were

803 pelleted, washed with $50 \mathrm{mM}$ Tris $(\mathrm{pH}=7.5)$ and acetone, and dried. Dried cell pellets were

804 resuspended in lysis buffer (50 mM Tris, pH 7.5, 1 mM EDTA, 5 mM DTT, 1 mM PMSF, and

805 complete mini protease inhibitor cocktail by Roche) and were lysed by bead-beating with chilled 
806 MiniBeadbeater (Biospec) and glass beads for 5 minutes followed by boiling in 1\% SDS for 5

807 minutes. Lysates were diluted with RIPA buffer (50 mM Tris, pH 7.5, $150 \mathrm{mM} \mathrm{NaCl,} \mathrm{0.1 \%} \mathrm{SDS,}$

$808 \quad 0.5 \%$ sodium deoxycholate, $1 \%$ NP40) and clarified by centrifugation. Protein concentration of

809 the lysates was measured by Bradford assay. $350 \mu 1$ MyOne streptavidin C1 dynabeads (Thermo

810 Fisher Scientific) were washed twice with RIPA buffer, incubated with clarified lysates

811 containing $\sim 3 \mathrm{mg}$ of total protein for each sample with rotation for 1 hour at room temperature,

812 then moved to $4^{\circ} \mathrm{C}$ and incubated overnight with rotation. On the second day, the supernatants

813 (flow through) were removed and the beads were washed twice with $1 \mathrm{ml}$ of $0.1 \mathrm{M} \mathrm{Na}_{2} \mathrm{CO}_{3}$,

814 once with $1 \mathrm{ml}$ of $2 \mathrm{M}$ urea in $10 \mathrm{mM}$ Tris $(\mathrm{pH}=7.5)$, and twice with $1 \mathrm{ml}$ RIPA buffer. Bound

815 proteins were eluted by boiling the beads in $30 \mu 13 x$ protein loading buffer supplemented with 2

$816 \mathrm{mM}$ biotin. Small aliquots of samples were saved along the process to monitor for the

817 enrichment for biotinylated proteins by immunoblotting for V5 (included in the TurboID tagged

818 bait) and biotin.

Eluted proteins were resolved on a 10-well NuPAGE 4-12\% Bis-Tris protein gel (Thermo

820 Fisher Scientific), stained with Coomassie (Imperial Protein Stain, Thermo Fisher Scientific) and

821 entire gel lanes were excised and cut into 1-mm pieces. Proteins were reduced with $20 \mathrm{mM}$

822 dithiothreitol (Sigma) for 1 hour at $56^{\circ} \mathrm{C}$ and then alkylated with $60 \mathrm{mM}$ iodoacetamide (Sigma)

823 for 1 hour at $25^{\circ} \mathrm{C}$ in the dark. Proteins were then digested with $12.5 \mathrm{ng} / \mathrm{uL}$ modified trypsin

824 (Promega) in $50 \mu \mathrm{L} 100 \mathrm{mM}$ ammonium bicarbonate, $\mathrm{pH} 8.9$ at $25^{\circ} \mathrm{C}$ overnight. Peptides were

825 extracted by incubating the gel pieces with 5\% formic acid in 50\% acetonitrile then $100 \mathrm{mM}$

826 ammonium bicarbonate, repeated twice followed by incubating the gel pieces with 100\%

827 acetonitrile then $100 \mathrm{mM}$ ammonium bicarbonate, repeated twice. Each fraction was collected, 
828 combined, and reduced to near dryness in a vacuum centrifuge. Peptides were desalted using

829 C18 SpinTips (Protea, Morgantown, WV).

$830 \quad$ Peptides were separated by reverse phase HPLC (Thermo Easy nLC1000) using a

831 precolumn (made in house, $6 \mathrm{~cm}$ of $10 \mu \mathrm{m} \mathrm{C18)}$ and a self-pack $5 \mu \mathrm{m}$ tip analytical column (12

$832 \mathrm{~cm}$ of $5 \mu \mathrm{m} \mathrm{C18,} \mathrm{New} \mathrm{Objective)} \mathrm{over} \mathrm{a} \mathrm{140-minute} \mathrm{gradient} \mathrm{before} \mathrm{nanoelectrospray} \mathrm{using} \mathrm{a}$

833 QExactive HF-X mass spectrometer (Thermo). Raw mass spectral data files (.raw) were searched

834 using Proteome Discoverer (Thermo) and Mascot version 2.4.1 (Matrix Science). Mascot search

835 parameters were: $10 \mathrm{ppm}$ mass tolerance for precursor ions; $15 \mathrm{mmu}$ for fragment ion mass

836 tolerance; 2 missed cleavages of trypsin; fixed modification was carbamidomethylation of

837 cysteine; variable modifications were methionine oxidation and lysine biotinylation. Only

838 peptides with a Mascot score greater than or equal to 25 and an isolation interference less than or

839 equal to 30 were included in the data analysis.

840 There are several endogenous biotinylated proteins in yeast. To identify specific proteins

841 enriched in the TurboID labeling experiments (hits), total peptides identified for each protein in

842 cells with TurboID tagged bait were compared with the unlabeled control cells to calculate the

843 ratio of enrichment. A threshold of 10 standard deviations above the average ratio of enrichment

844 for all proteins in each sample was used to identify hits (see Figure 2-figure supplement 1B).

845 For the streptavidin gel-shift assays, cell lysates were prepared as for typical

846 immunoblotting experiments. Prior to loading samples onto protein gels, 20 ul of lysates for each

847 sample was incubated with $2 \mu \mathrm{l}$ of $10 \mathrm{mg} / \mathrm{ml}$ streptavidin for $10 \mathrm{~min}$ at room temperature with

848 rotation. Treated samples were then resolved by SDS-PAGE gel at $4^{\circ} \mathrm{C}$ and processed for

849 immunoblotting as described above. 


\section{$851 \quad$ PhyB-PIF based optogenetics}

852 The PhyB-PIF based optogenetics experiments were performed based on previous reports (Jost

853 and Weiner, 2015; Yang et al., 2013). Cells grown to log phase in 1x SC medium $+2 \%$ glucose

854 were incubated with $31.25 \mu \mathrm{M}(0.5 \mu \mathrm{l}$ of $12.5 \mathrm{mM}$ stock in 200 ul culture $)$ Phycocyanobilin

855 (PCB, Santa Cruz Biotechnology) for 2 hours at room temperature in the dark. Cells were then

856 pelleted and resuspended in fresh medium without PCB and were mounted onto an agarose pad

857 with $2 x$ SC medium $+2 \%$ glucose for imaging. To apply the light, we attached one $650 \mathrm{~nm}$ and

858 one $750 \mathrm{~nm}$ light-emitting diode (LED, Light-speed Technologies) onto the microscope

859 condenser. Light was controlled manually during the experiments. For the continuous exposure

860 of $650 \mathrm{~nm}$ light during time-course experiments, the light was briefly turned off for each image

861 acquisition. To quantify the relative enrichment of target protein in the PhyB-anchored region,

862 pixel intensities of the target protein (Mob1-eGFP-PIF, $I_{\mathrm{PIF}}$ ) and PhyB (PhyB-mCherry, $I_{\mathrm{PhyB}}$ )

863 inside the cell were fitted to a line $\left(I_{\mathrm{PIF}}=\alpha+\beta I_{\mathrm{PhyB}}\right)$. The slope of the fitted line $(\beta)$ was used

864 to assess the extent of co-localization or enrichment of the target protein in the PhyB-anchored

865 region. This method is robust against both photobleaching of the target protein during the time-

866 course and difference in the shape and size of the anchored region (the nucleolus) at different cell

867 cycle stages.

869 Phosphoproteomics

870 To map phosphorylation events that depend on CDC5 or CDC15 (MEN) activity, we used the

871 analog-sensitive alleles of $C D C 5(c d c 5$-as 1) or CDC15 (cdc15-as1) and compared

872 phosphopeptides with and without inhibiting the kinase in anaphase (and metaphase for Cdc5)

873 enriched cultures. To enrich for anaphase cells, we first synchronized cells in G1 with $\alpha$-factor (5 
$874 \mu \mathrm{g} / \mathrm{ml}$ for 2.5 hours). $\alpha$-factor arrested cultures were then washed and released into YEP $+2 \%$

875 glucose + inhibitor $(5 \mu \mathrm{M} \mathrm{CMK}$ for $C D C 5 / c d c 5$-as 1 or $10 \mu \mathrm{M} 1-\mathrm{NAPP} 1$ for $C D C 5 / c d c 5$-as 1$)$ at

876 room temperature to progress to anaphase ( 100 minutes). Synchronization and cell cycle stage

877 were assessed by monitoring budding and spindle length at various time points. Spindles were

878 visualized by immunofluorescence using an anti-tubulin antibody (Abcam ab6161). Cultures

879 collected for the anaphase experiment harbored 74\% (WT + 1-NA-PP1), 95\% (cdc15-as 1, 1-NA-

880 PP1), 69\% (WT + CMK), and 94\% (cdc5-as $1+\mathrm{CMK})$ cells with anaphase spindles.

Phosphopeptide preparation was based on previous methods (Holt et al., 2009; Villén and

882 Gygi, 2008). 25 ODs of cells were harvested for each replicate (6 replicates per samples for the anaphase experiment and 3 replicates per sample for the metaphase experiment) by centrifugation (5 min at $3000 \mathrm{rpm})$. Cell pellets were washed with cold $50 \mathrm{mM}$ Tris $(\mathrm{pH}=7.5)$ and resuspended in cold lysis buffer containing $8 \mathrm{M}$ urea in $50 \mathrm{mM}$ Tris $(\mathrm{pH}=7.5), 75 \mathrm{mM}$ $\mathrm{NaCl}, 50 \mathrm{mM} \mathrm{NaF}, 50 \mathrm{mM} \beta$-glycerophosphate, $1 \mathrm{mM}$ sodium orthovanadate, $10 \mathrm{mM}$ sodium pyrophosphate and protease inhibitor cocktail (complete mini, EDTA-free, Roche). Cells were lysed under denaturing conditions by bead-beating with a chilled MiniBeadbeater (Biospec, two rounds of 3 cycles of $90 \mathrm{~s}$ each) and glass beads. The protein extract was then separated from the beads and insoluble material by centrifugation. Protein concentration of the lysate was

891 determined by BCA protein assay (Pierce).

893 a VialTweeter device (Hielscher-Ultrasound Technology). The proteins extracted were then

894 processed with a precipitation-based digestion protocol using trypsin (Promega) at a ratio of 1:20

895 as described previously(Collins et al., 2017). About $500 \mu \mathrm{g}$ of resultant peptides from each 
897 (Thermo Scientific, A32992) according to the kit instruction, as described previously(Gao et al.,

898 2019). About $1.5 \mu \mathrm{g}$ of phosphopeptides enriched from each sample were used for DIA-MS

899 measurement on an Orbitrap Fusion Lumos Tribrid mass spectrometer (Thermo Scientific)

900 platform coupled to a nanoelectrospray ion source, as described previously (Mehnert et al.,

901 2019). DIA-MS data analyses were performed using Spectronaut v13 (Bruderer et al., 2017)

902 using default setting, by searching against a database of 6632 yeast open reading frames(Hebert

903 et al., 2014) and the Swiss-prot yeast proteome database. In particular, the PTM localization

904 option in Spectronaut v13 was enabled to locate phosphorylation sites (Bekker-Jensen et al.,

905 2020; Collins et al., 2017), with the probability score cutoff $>0.75(7)$, resulting Class-I peptides

906 to be identified and quantified. Both peptide and protein FDR cutoff ( $Q$ value) were controlled at

$9071 \%$, and the label-free protein quantification of proteome and phospho-proteome was performed

908 using the default settings in Spectronaut.

909 To identify peptides whose phosphorylation depended on CDC5 or CDC15, we

910 calculated the ratio as well as the $p$-value of peptide intensities in $W T$ versus as 1 samples. The $p$ -

911 values were calculated using a two-sided Student's $t$-test and were adjusted for false discovery

912 rate (FDR) of multiple hypothesis testing using the linear step-up procedure (Benjamini-

913 Hochberg procedure). A threshold of ratio $R>2$ and $p_{a d j}<0.05$ was used to identify hits.

914 Additional hits were also included for peptides that were not defected in the as 1 samples but

915 were detected in at least 5 out of 7 replicates (or 4 out of 6 replicates in the metaphase

916 experiment) of the $W T$ samples. Peptides that were only detected in one replicate of the as 1

917 samples but were detected in at least 5 out of 7 replicates (or 4 out of 6 replicates in the

918 metaphase experiment) of the $W T$ samples with a ratio $>2$ were also included. After we have

919 identified hits for peptides, we mapped the peptides and phosphorylation sites in those peptides 
920 to proteins in the yeast proteome. For phosphorylation sites that were detected in multiple

921 peptides, peptides with a single phosphorylation were given priority. We marked a site as a

922 strong hit only when all single phosphorylation peptides for the specific site fit our selection

923 criteria. If a site was only detected in multi-phosphorylation peptides that fit our selection

924 criteria, we designated that site as a weak hit.

925

$926 \quad$ Plasmid shuffling

927 To assess the genetic interactions between different CFI1/NET1 phospho-mutants and FEAR

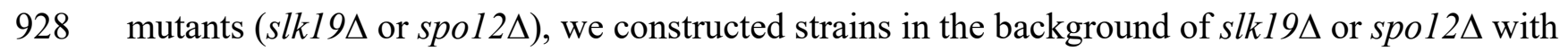

929 cfil/net1 $\Delta$ carrying a URA3-based CEN plasmid expressing wild-type $C F I 1 / N E T 1$ (pA2858) and

930 different CFI1/NET1 phospho-mutants integrated at the leu2 locus (A41645-A41654). Growing

931 these strains on plates with 5'-fluoroorotic acid (5-FOA) selects cells that are viable after losing

932 the $U R A 3$ plasmid.

933

934 Data and Code Availability

935 The mass spectrometry phosphoproteomics data have been deposited to the ProteomeXchange

936 Consortium via the PRIDE (Perez-Riverol et al., 2019) partner repository with the dataset

937 identifier PXD020369. Custom MATLAB scripts are available at https://github.com/snow-

938 zhou/Dbf2-Mob1. 


\section{REFERENCES}

Anand, R., Memisoglu, G., and Haber, J. (2017). Cas9-mediated gene editing in Saccharomyces cerevisiae. Protoc. Exch.

Azzam, R. (2004). Phosphorylation by Cyclin B-Cdk Underlies Release of Mitotic Exit Activator Cdc14 from the Nucleolus. Science 305, 516-519.

Bardin, A.J., Visintin, R., and Amon, A. (2000). A Mechanism for Coupling Exit from Mitosis to Partitioning of the Nucleus. Cell 102, 21-31.

Bardin, A.J., Boselli, M.G., and Amon, A. (2003). Mitotic Exit Regulation through Distinct Domains within the Protein Kinase Cdc15. Mol. Cell. Biol. 23, 5018-5030.

Bardwell, L. (2006). Mechanisms of MAPK signalling specificity. Biochem. Soc. Trans. 34, 837-841.

Bekker-Jensen, D.B., Bernhardt, O.M., Hogrebe, A., Martinez-Val, A., Verbeke, L., Gandhi, T., Kelstrup, C.D., Reiter, L., and Olsen, J.V. (2020). Rapid and site-specific deep phosphoproteome profiling by data-independent acquisition without the need for spectral libraries. Nat. Commun. 11,787 .

Bembenek, J., Kang, J., Kurischko, C., Li, B., Raab, J.R., Belanger, K.D., Luca, F.C., and Yu, H. (2005). Crm1-Mediated Nuclear Export of Cdc14 is Required for the Completion of Cytokinesis in Budding Yeast. Cell Cycle 4, 961-971.

Bishop, A.C., Ubersax, J.A., Petsch, D.T., Matheos, D.P., Gray, N.S., Blethrow, J., Shimizu, E., Tsien, J.Z., Schultz, P.G., Rose, M.D., et al. (2000). A chemical switch for inhibitor-sensitive alleles of any protein kinase. Nature 407, 395-401.

Branon, T.C., Bosch, J.A., Sanchez, A.D., Udeshi, N.D., Svinkina, T., Carr, S.A., Feldman, J.L., Perrimon, N., and Ting, A.Y. (2018). Efficient proximity labeling in living cells and organisms with TurboID. Nat. Biotechnol. 36, 880-887.

Britschgi, A., Duss, S., Kim, S., Couto, J.P., Brinkhaus, H., Koren, S., De Silva, D., Mertz, K.D., Kaup, D., Varga, Z., et al. (2017). The Hippo kinases LATS1 and 2 control human breast cell fate via crosstalk with ER $\alpha$. Nature 541, 541-545.

Bruderer, R., Bernhardt, O.M., Gandhi, T., Xuan, Y., Sondermann, J., Schmidt, M., GomezVarela, D., and Reiter, L. (2017). Optimization of Experimental Parameters in Data-Independent Mass Spectrometry Significantly Increases Depth and Reproducibility of Results. Mol. Cell. Proteomics MCP 16, 2296-2309.

Campbell, I.W., Zhou, X., and Amon, A. (2019). The Mitotic Exit Network integrates temporal and spatial signals by distributing regulation across multiple components. ELife 8 .

Cargnello, M., and Roux, P.P. (2011). Activation and Function of the MAPKs and Their Substrates, the MAPK-Activated Protein Kinases. Microbiol. Mol. Biol. Rev. 75, 50-83. 
Carpenter, K., Bell, R.B., Yunus, J., Amon, A., and Berchowitz, L.E. (2018). PhosphorylationMediated Clearance of Amyloid-like Assemblies in Meiosis. Dev. Cell 45, 392-405.e6.

Cheng, L., Hunke, L., and Hardy, C.F.J. (1998). Cell Cycle Regulation of the Saccharomyces cerevisiae Polo-Like Kinase Cdc5p. Mol. Cell. Biol. 18, 7360-7370.

Collins, B.C., Hunter, C.L., Liu, Y., Schilling, B., Rosenberger, G., Bader, S.L., Chan, D.W., Gibson, B.W., Gingras, A.-C., Held, J.M., et al. (2017). Multi-laboratory assessment of reproducibility, qualitative and quantitative performance of SWATH-mass spectrometry. Nat. Commun. 8, 291.

D’Amours, D., Stegmeier, F., and Amon, A. (2004). Cdc14 and Condensin Control the Dissolution of Cohesin-Independent Chromosome Linkages at Repeated DNA. Cell 117, 455469.

D’Aquino, K.E., Monje-Casas, F., Paulson, J., Reiser, V., Charles, G.M., Lai, L., Shokat, K.M., and Amon, A. (2005). The Protein Kinase Kin4 Inhibits Exit from Mitosis in Response to Spindle Position Defects. Mol. Cell 19, 223-234.

Elia, A.E.H., Rellos, P., Haire, L.F., Chao, J.W., Ivins, F.J., Hoepker, K., Mohammad, D., Cantley, L.C., Smerdon, S.J., and Yaffe, M.B. (2003). The Molecular Basis for Phosphodependent Substrate Targeting and Regulation of Plks by the Polo-Box Domain. Cell $115,83-95$.

Fairhead, M., and Howarth, M. (2015). Site-specific biotinylation of purified proteins using BirA. Methods Mol. Biol. Clifton NJ 1266, 171-184.

Feric, M., Vaidya, N., Harmon, T.S., Mitrea, D.M., Zhu, L., Richardson, T.M., Kriwacki, R.W., Pappu, R.V., and Brangwynne, C.P. (2016). Coexisting Liquid Phases Underlie Nucleolar Subcompartments. Cell 165, 1686-1697.

Gao, Q., Zhu, H., Dong, L., Shi, W., Chen, R., Song, Z., Huang, C., Li, J., Dong, X., Zhou, Y., et al. (2019). Integrated Proteogenomic Characterization of HBV-Related Hepatocellular Carcinoma. Cell 179, 1240.

Geymonat, M., Spanos, A., de Bettignies, G., and Sedgwick, S.G. (2009). Lte1 contributes to Bfa1 localization rather than stimulating nucleotide exchange by Tem1. J. Cell Biol. 187, 497511.

Good, M.C., Zalatan, J.G., and Lim, W.A. (2011). Scaffold proteins: hubs for controlling the flow of cellular information. Science 332, 680-686.

Guertin, D.A., Trautmann, S., and McCollum, D. (2002). Cytokinesis in Eukaryotes. Microbiol. Mol. Biol. Rev. 66, 155-178.

Hebert, A.S., Richards, A.L., Bailey, D.J., Ulbrich, A., Coughlin, E.E., Westphall, M.S., and Coon, J.J. (2014). The one hour yeast proteome. Mol. Cell. Proteomics MCP 13, 339-347. 
Hergovich, A., and Hemmings, B.A. (2012). Hippo signalling in the G2/M cell cycle phase: Lessons learned from the yeast MEN and SIN pathways. Semin. Cell Dev. Biol. 23, 794-802.

Holt, L.J., Tuch, B.B., Villen, J., Johnson, A.D., Gygi, S.P., and Morgan, D.O. (2009). Global Analysis of Cdk1 Substrate Phosphorylation Sites Provides Insights into Evolution. Science 325, $1682-1686$.

Housley, M.P., Reischauer, S., Dieu, M., Raes, M., Stainier, D.Y.R., and Vanhollebeke, B. (2014). Translational profiling through biotinylation of tagged ribosomes in zebrafish. Development 141, 3988-3993.

Jaspersen, S.L., and Morgan, D.O. (2000). Cdc14 activates Cdc15 to promote mitotic exit in budding yeast. Curr. Biol. 10, 615-618.

Jost, A.P.-T., and Weiner, O.D. (2015). Probing Yeast Polarity with Acute, Reversible, Optogenetic Inhibition of Protein Function. ACS Synth. Biol. 4, 1077-1085.

Kettenbach, A.N., Schweppe, D.K., Faherty, B.K., Pechenick, D., Pletnev, A.A., and Gerber, S.A. (2011). Quantitative Phosphoproteomics Identifies Substrates and Functional Modules of Aurora and Polo-Like Kinase Activities in Mitotic Cells. Sci. Signal. 4, rs5-rs5.

Kırlı, K., Karaca, S., Dehne, H.J., Samwer, M., Pan, K.T., Lenz, C., Urlaub, H., and Görlich, D. (2015). A deep proteomics perspective on CRM1-mediated nuclear export and nucleocytoplasmic partitioning. ELife 4, e11466.

Knockenhauer, K.E., and Schwartz, T.U. (2016). The Nuclear Pore Complex as a Flexible and Dynamic Gate. Cell 164, 1162-1171.

König, C., Maekawa, H., and Schiebel, E. (2010). Mutual regulation of cyclin-dependent kinase and the mitotic exit network. J. Cell Biol. 188, 351-368.

Kuilman, T., Maiolica, A., Godfrey, M., Scheidel, N., Aebersold, R., and Uhlmann, F. (2015). Identification of Cdk targets that control cytokinesis. EMBO J. 34, 81-96.

Lee, K.S., Park, J.-E., Asano, S., and Park, C.J. (2005). Yeast polo-like kinases: functionally conserved multitask mitotic regulators. Oncogene 24, 217-229.

Li, W., Cooper, J., Zhou, L., Yang, C., Erdjument-Bromage, H., Zagzag, D., Snuderl, M., Ladanyi, M., Hanemann, C.O., Zhou, P., et al. (2014). Merlin/NF2 loss-driven tumorigenesis linked to CRL4(DCAF1)-mediated inhibition of the hippo pathway kinases Lats1 and 2 in the nucleus. Cancer Cell 26, 48-60.

Loughrey Chen, S., Huddleston, M.J., Shou, W., Deshaies, R.J., Annan, R.S., and Carr, S.A. (2002). Mass Spectrometry-based Methods for Phosphorylation Site Mapping of

Hyperphosphorylated Proteins Applied to Net1, a Regulator of Exit from Mitosis in Yeast. Mol. Cell. Proteomics 1, 186-196. 
Lowery, D.M., Lim, D., and Yaffe, M.B. (2005). Structure and function of Polo-like kinases. Oncogene 24, 248-259.

Mah, A.S., Jang, J., and Deshaies, R.J. (2001). Protein kinase Cdc15 activates the Dbf2-Mob1 kinase complex. Proc. Natl. Acad. Sci. 98, 7325-7330.

Mah, A.S., Elia, A.E.H., Devgan, G., Ptacek, J., Schutkowski, M., Snyder, M., Yaffe, M.B., and Deshaies, R.J. (2005). Substrate specificity analysis of protein kinase complex Dbf2-Mob1 by peptide library and proteome array screening. BMC Biochem. 6, 22.

Mehnert, M., Li, W., Wu, C., Salovska, B., and Liu, Y. (2019). Combining Rapid Data Independent Acquisition and CRISPR Gene Deletion for Studying Potential Protein Functions: A Case of HMGN1. Proteomics 19, e1800438.

Meitinger, F., Boehm, M.E., Hofmann, A., Hub, B., Zentgraf, H., Lehmann, W.D., and Pereira, G. (2011). Phosphorylation-dependent regulation of the F-BAR protein Hofl during cytokinesis. Genes Dev. 25, 875-888.

Mohl, D.A., Huddleston, M.J., Collingwood, T.S., Annan, R.S., and Deshaies, R.J. (2009). Dbf2-Mob1 drives relocalization of protein phosphatase Cdc14 to the cytoplasm during exit from mitosis. J. Cell Biol. 184, 527-539.

Murphy, L.O., Smith, S., Chen, R.-H., Fingar, D.C., and Blenis, J. (2002). Molecular interpretation of ERK signal duration by immediate early gene products. Nat. Cell Biol. 4, 556564.

Nakajima, H., Toyoshima-Morimoto, F., Taniguchi, E., and Nishida, E. (2003). Identification of a Consensus Motif for Plk (Polo-like Kinase) Phosphorylation Reveals Myt1 as a Plk1 Substrate*. J. Biol. Chem. 278, 25277-25280.

Neville, M. (1999). The NES-Crm1p export pathway is not a major mRNA export route in Saccharomyces cerevisiae. EMBO J. 18, 3746-3756.

Owen, I., and Shewmaker, F. (2019). The Role of Post-Translational Modifications in the Phase Transitions of Intrinsically Disordered Proteins. Int. J. Mol. Sci. 20, 5501.

Pereira, G., Höfken, T., Grindlay, J., Manson, C., and Schiebel, E. (2000). The Bub2p Spindle Checkpoint Links Nuclear Migration with Mitotic Exit. Mol. Cell 6, 1-10.

Perez-Riverol, Y., Csordas, A., Bai, J., Bernal-Llinares, M., Hewapathirana, S., Kundu, D.J., Inuganti, A., Griss, J., Mayer, G., Eisenacher, M., et al. (2019). The PRIDE database and related tools and resources in 2019: improving support for quantification data. Nucleic Acids Res. 47, D442-D450.

Ptacek, J., Devgan, G., Michaud, G., Zhu, H., Zhu, X., Fasolo, J., Guo, H., Jona, G., Breitkreutz, A., Sopko, R., et al. (2005). Global analysis of protein phosphorylation in yeast. Nature 438, 679-684. 
Queralt, E., Lehane, C., Novak, B., and Uhlmann, F. (2006). Downregulation of PP2ACdc55 Phosphatase by Separase Initiates Mitotic Exit in Budding Yeast. Cell 125, 719-732.

Ricicova, M., Hamidi, M., Quiring, A., Niemisto, A., Emberly, E., and Hansen, C.L. (2013). Dissecting genealogy and cell cycle as sources of cell-to-cell variability in MAPK signaling using high-throughput lineage tracking. Proc. Natl. Acad. Sci. 110, 11403-11408.

Rock, J.M., and Amon, A. (2009). The FEAR network. Curr. Biol. CB 19, R1063-1068.

Rock, J.M., and Amon, A. (2011). Cdc15 integrates Tem1 GTPase-mediated spatial signals with Polo kinase-mediated temporal cues to activate mitotic exit. Genes Dev. 25, 1943-1954.

Rock, J.M., Lim, D., Stach, L., Ogrodowicz, R.W., Keck, J.M., Jones, M.H., Wong, C.C.L., Yates, J.R., Winey, M., Smerdon, S.J., et al. (2013). Activation of the Yeast Hippo Pathway by Phosphorylation-Dependent Assembly of Signaling Complexes. Science 340, 871-875.

Romero, P., Obradovic, Z., Kissinger, C., Villafranca, J.E., and Dunker, A.K. (1997). Identifying disordered regions in proteins from amino acid sequence. In Proceedings of International Conference on Neural Networks (ICNN'97), (Houston, TX, USA: IEEE), pp. 90-95.

Sanchez, Y. (1999). Control of the DNA Damage Checkpoint by Chk1 and Rad53 Protein Kinases Through Distinct Mechanisms. Science 286, 1166-1171.

Schindelin, J., Arganda-Carreras, I., Frise, E., Kaynig, V., Longair, M., Pietzsch, T., Preibisch, S., Rueden, C., Saalfeld, S., Schmid, B., et al. (2012). Fiji: an open-source platform for biological-image analysis. Nat. Methods 9, 676-682.

Shcherbakova, D.M., and Verkhusha, V.V. (2013). Near-infrared fluorescent proteins for multicolor in vivo imaging. Nat. Methods 10, 751-754.

Shin, Y., and Brangwynne, C.P. (2017). Liquid phase condensation in cell physiology and disease. Science 357 , eaaf4382.

Shou, W., Seol, J.H., Shevchenko, A., Baskerville, C., Moazed, D., Chen, Z.W.S., Jang, J., Shevchenko, A., Charbonneau, H., and Deshaies, R.J. (1999). Exit from Mitosis Is Triggered by Tem1-Dependent Release of the Protein Phosphatase Cdc14 from Nucleolar RENT Complex. Cell 97, 233-244.

Shou, W., Azzam, R., Chen, S.L., Huddleston, M.J., Baskerville, C., Charbonneau, H., Annan, R.S., Carr, S.A., and Deshaies, R.J. (2002). Cdc5 influences phosphorylation of Net1 and disassembly of the RENT complex. BMC Mol. Biol. 14.

Stegmeier, F., and Amon, A. (2004). Closing Mitosis: The Functions of the Cdc14 Phosphatase and Its Regulation. Annu. Rev. Genet. 38, 203-232.

Stegmeier, F., Visintin, R., and Amon, A. (2002). Separase, Polo Kinase, the Kinetochore Protein Slk19, and Spo12 Function in a Network that Controls Cdc14 Localization during Early Anaphase. Cell 108, 207-220. 
Stoepel, J., Ottey, M.A., Kurischko, C., Hieter, P., and Luca, F.C. (2005). The Mitotic Exit Network Mob1p-Dbf2p Kinase Complex Localizes to the Nucleus and Regulates Passenger Protein Localization $\square \mathrm{D} \square \mathrm{V}$. Mol. Biol. Cell 16, 15.

Sullivan, M., Higuchi, T., Katis, V.L., and Uhlmann, F. (2004). Cdc14 Phosphatase Induces rDNA Condensation and Resolves Cohesin-Independent Cohesion during Budding Yeast Anaphase. Cell 117, 471-482.

Swaney, D.L., Beltrao, P., Starita, L., Guo, A., Rush, J., Fields, S., Krogan, N.J., and Villén, J. (2013). Global analysis of phosphorylation and ubiquitylation cross-talk in protein degradation. Nat. Methods 10, 676-682.

Torres-Rosell, J., Machín, F., Jarmuz, A., and Aragón, L. (2004). Nucleolar Segregation Lags Behind the Rest of the Genome and Requires Cdc14p Activation by the FEAR Network. Cell Cycle 3, 494-500.

Villén, J., and Gygi, S.P. (2008). The SCX/IMAC enrichment approach for global phosphorylation analysis by mass spectrometry. Nat. Protoc. 3, 1630-1638.

Visintin, R., and Amon, A. (2001). Regulation of the mitotic exit protein kinases Cdc 15 and Dbf2. Mol. Biol. Cell 12, 2961-2974.

Visintin, C., Tomson, B.N., Rahal, R., Paulson, J., Cohen, M., Taunton, J., Amon, A., and Visintin, R. (2008). APC/C-Cdh1-mediated degradation of the Polo kinase Cdc5 promotes the return of Cdc14 into the nucleolus. Genes Dev. 22, 79-90.

Visintin, R., Hwang, E.S., and Amon, A. (1999). Cfi1 prevents premature exit from mitosis by anchoring Cdc14 phosphatase in the nucleolus. 398, 6.

Yang, X., Jost, A.P.-T., Weiner, O.D., and Tang, C. (2013). A light-inducible organelle-targeting system for dynamically activating and inactivating signaling in budding yeast. Mol. Biol. Cell 24, 2419-2430.

Yoshida, S., and Toh-e, A. (2002). Budding yeast Cdc5 phosphorylates Net1 and assists Cdc14 release from the nucleolus. Biochem. Biophys. Res. Commun. 294, 687-691.

Yu, F.-X., and Guan, K.-L. (2013). The Hippo pathway: regulators and regulations. Genes Dev. $27,355-371$. 
Figure 1. Dbf2-Mob1 transiently localizes to the nucleolus in late anaphase.

A

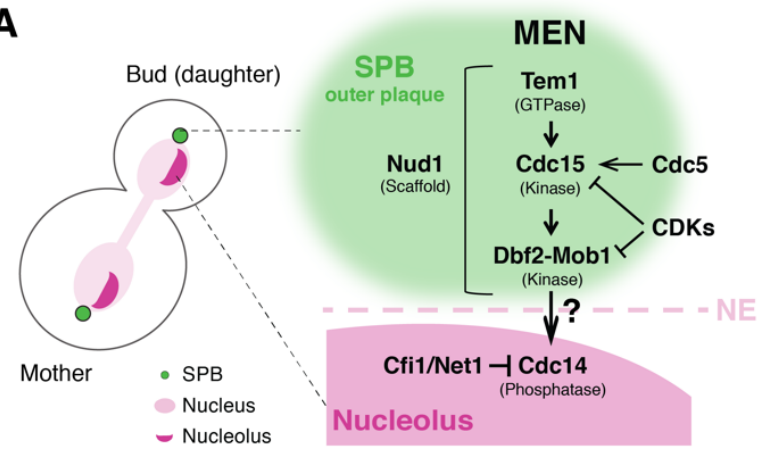

B

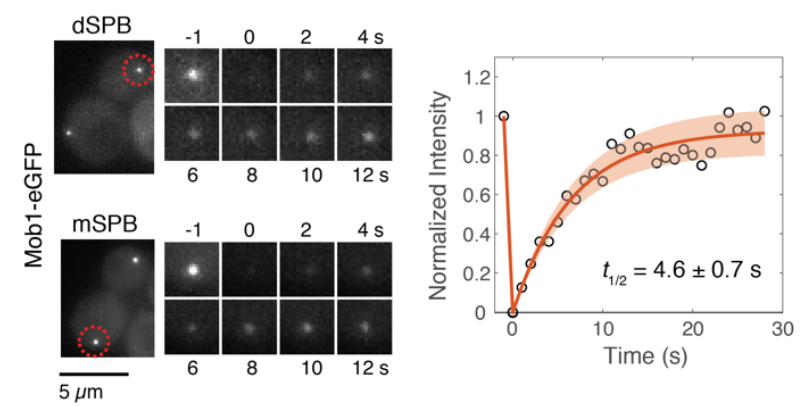

C

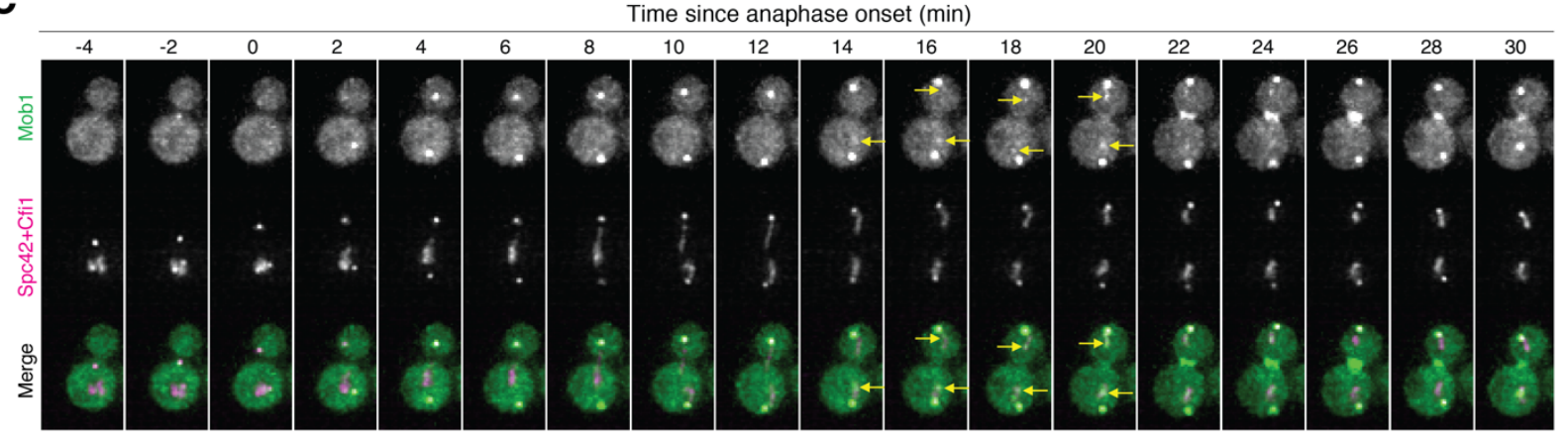

D

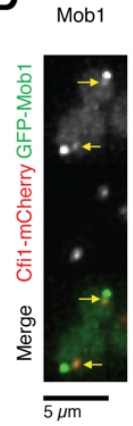

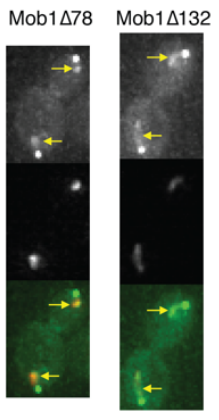

E

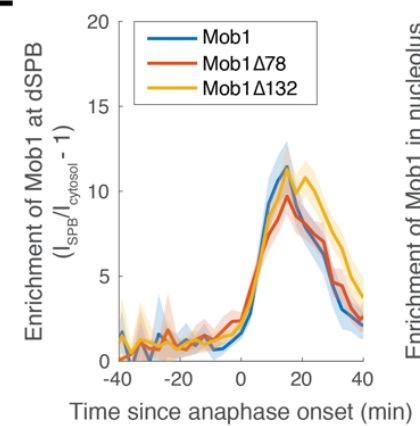

F

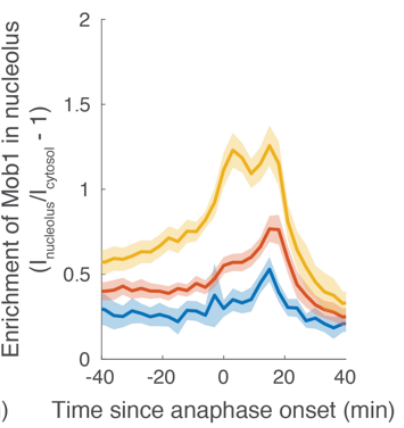

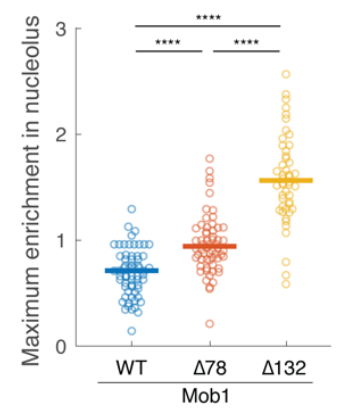

(A) Major components of the MEN and their subcellular localization.

(B) FRAP analysis of Mob1-eGFP (A39695). Red circles indicate the area of photo-bleaching. Cells were grown and imaged at room temperature in SC medium $+2 \%$ glucose. Graph to the right represents average measurements of double normalized fluorescence intensities ( $n=6$ cells) after correcting for photo-bleaching during acquisition. Red curve is the average fit and shaded area represents standard deviation (SD) of the fits. Half recovery time $t_{1 / 2} \pm \mathrm{SD}$ is indicated.

(C) Localization of Mob1 during the cell cycle. A40257 (with Mob1-eGFP, Cfi1-mCherry and Spc42-mCherry) cells were grown at room temperature in SC medium $+2 \%$ glucose and imaged every minute for 2 hours. Arrows highlight the nucleolar localization.

(D) Nucleolar localization of full-length (A39931) and N-terminally truncated (A39933 and A39935) Mob1. Cells were grown at room temperature in SC medium $+2 \%$ glucose and imaged every 3 minutes for 4 hours. Arrows highlight the nucleolar localization. 
(E) Enrichment of Mob1 (A41211, $n=62$ cells), Mob1 $\Delta 78$ (A41212, $n=60$ cells) and Mob1 $\Delta 132$ (A41213, $n=48$ cells) at the dSPB (left) and in the nucleolus (right) as a function of cell cycle progression. Cells were grown at $25^{\circ} \mathrm{C}$ in SC medium $+2 \%$ glucose and imaged every 3 minutes for 4 hours. Single cell traces were aligned based on anaphase onset, as defined as spindle length $>3 \mu \mathrm{m}$ (Figure1-figure supplement 1F, measured based on SPB marker Spc42mCherry), and averaged. Solid lines represent the average, shaded areas represent $95 \%$ confidence intervals.

(F) Maximum enrichment of full-length Mob1 (WT) and truncated Mob1 (Mob1 $\Delta 78$ and Mob1 $\Delta 132)$ in the nucleolus in anaphase of cells in (E). Solid lines represent the median. **** $P$ $<0.0001$ by two-sided Wilcoxon rank sum test. 
Figure 2. Dbf2-Mob1 localizes to the nucleolus through interacting with Cfi1/Net1.

A

\begin{tabular}{|c|c|c|c|c|c|c|}
\hline \multirow{2}{*}{$\begin{array}{c}\text { \# of peptides } \\
\text { detected }\end{array}$} & \multicolumn{5}{|c|}{ Bait (TurbolD tagged) } \\
\cline { 2 - 7 } & Mob1 & Dbf2 & Tem1 & Cdc15 & Untagged \\
\hline \multirow{4}{*}{ Hits } & Cfi1 & 84 & 45 & 0 & 0 & 0 \\
\cline { 2 - 7 } & Dbf2/Dbf20 & 16 & 9 & 2 & 5 & 1 \\
\cline { 2 - 7 } & Mob1 & 12 & 4 & 0 & 0 & 0 \\
\cline { 2 - 7 } & Nud1 & 5 & 2 & 2 & 2 & 0 \\
\hline
\end{tabular}

B

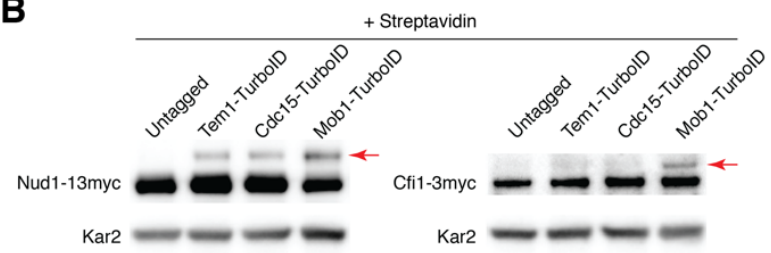

C

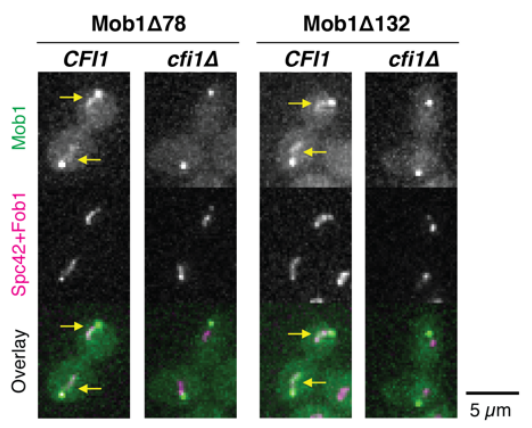

E

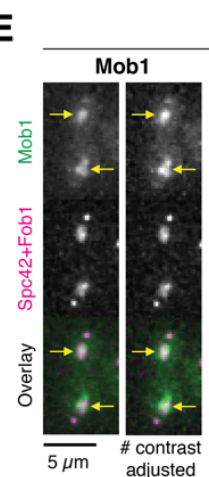

D
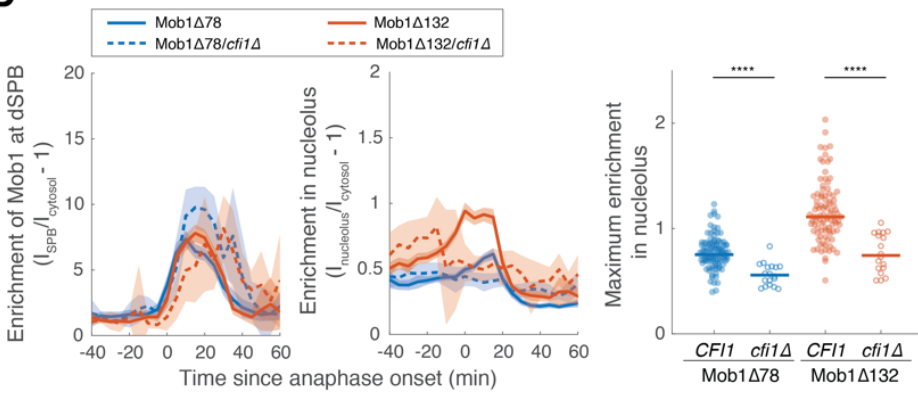

$\mathbf{F}$

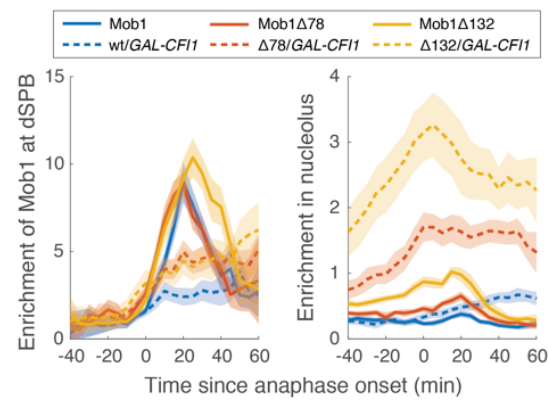

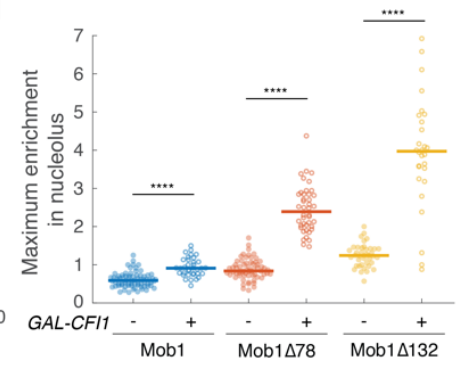

(A) Results of proximity-based biotinylation with TurboID for MEN proteins (A41367, A41370, A41368, A41369 and A2588). Cells were grown at room temperature in YEP $+2 \%$ glucose +50 $\mu \mathrm{M}$ biotin.

(B) Streptavidin gel-shift assays to probe the interactions of TurboID-labeled MEN proteins with the MEN scaffold Nud1 (left, A11869, A41381, A41382 and A41380) or Cfi1/Net1 (right, A1638, A41406, A41407 and A41372). Cells were grown at room temperature in YEP $+2 \%$ glucose and lysates were treated with streptavidin and immunoblotted as indicated. Red arrows highlight biotinylated proteins.

(C and D) Representative images (C) and quantification (D) of Mob1 $\Delta 78$ localization in wildtype CFI1/NET1 (A41344, $n=106$ cells) or $c f i 1 / n e t 1 \Delta$ (A41347, $n=18$ cells) cells and Mob1 132 localization in CFI1/NET1 (A41345, $n=95$ cells) or cfil/net1 $\Delta$ (A41348, $n=18$ cells) cells. Cells were grown at $25^{\circ} \mathrm{C}$ in SC medium $+2 \%$ glucose and imaged every 5 minutes for 4 hours. Arrows highlight nucleolar localization.

(E and F) Representative images (E) and quantification (F) of Mob1 localization in wild-type (A41343, $n=110$ cells) or GAL-CFI1/NET1 expressing cells (A41340, $n=71$ cells), Mob1 $\Delta 78$ localization in wild-type (A41344, $n=103$ cells) or GAL-CFI1/NET1 expressing cells (A41341, 
$n=68$ cells), and Mob1 $\Delta 132$ localization in wild-type (A41345, $n=71$ cells) or cells expressing GAL-CFI1/NET1 (A41342, $n=53$ cells). \# denotes that the image was linearly contrast adjusted to avoid over-saturation for Mob1 $\Delta 78$ and Mob1 $\Delta 132$. Cells were first grown at room temperature in SC medium $+2 \%$ raffinose. Cells were then mounted onto agarose pads made with SC medium $+1 \%$ raffinose $+1 \%$ galactose and imaged every 5 minutes for 5 hours at $25^{\circ} \mathrm{C}$. Arrows highlight nucleolar localization. Solid lines represent the average of single cell traces aligned to anaphase onset while shaded areas represent $95 \%$ confidence intervals. For maximum enrichment, each dot represents a single cell. The solid lines represent the median. **** $P<0.0001$ by two-sided Wilcoxon rank sum test. 
Figure 3. CDC15 regulates nuclear access of Dbf2-Mob1.

A
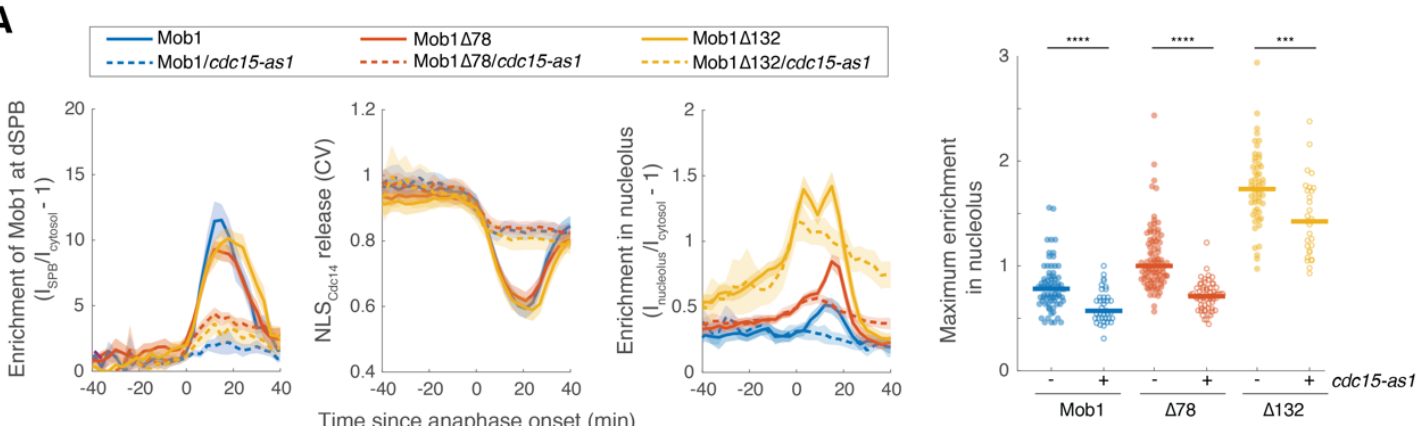

B

C

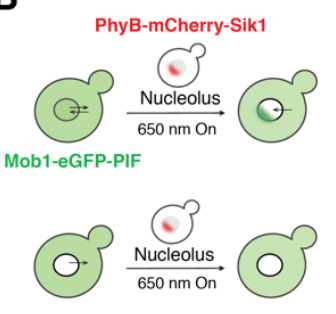

C Pre-anaphase
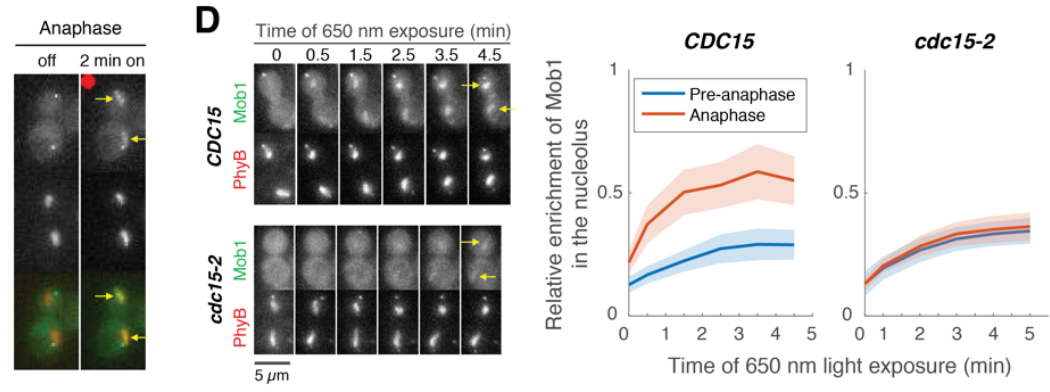

E
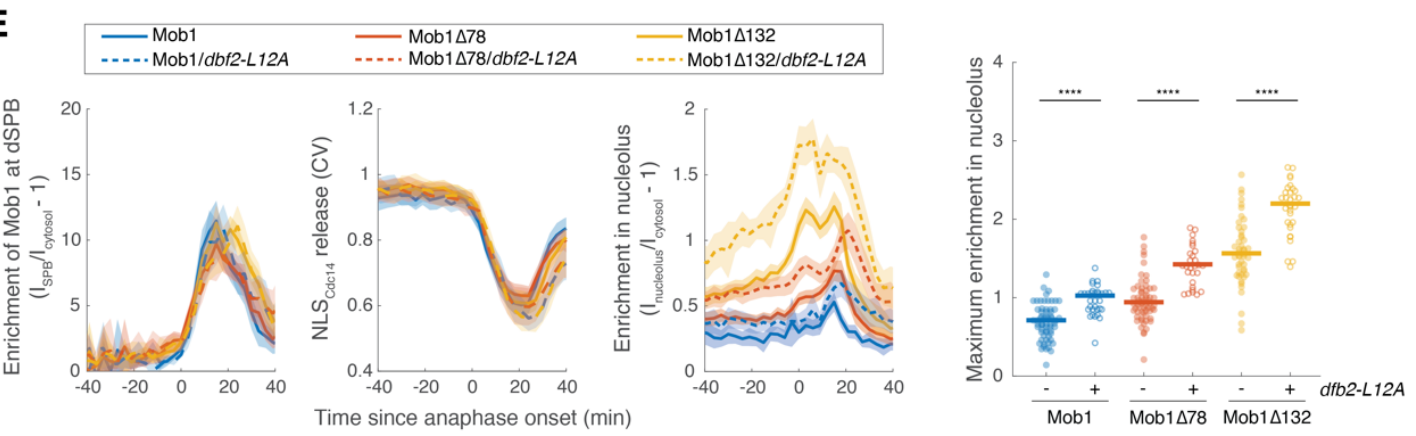

(A) Enrichment of Mob1 at the dSPB, in the nucleolus, and Dbf2-Mob1's kinase activity were determined in cells going through anaphase in CDC15 (A41211, A41212, and A41213; $n=74$, 94, and 55 cells respectively) or $c d c 15$-as 1 (A41214, A41215, and A41216; $n=37,63$, and 30 cells respectively) cells. Cells were grown at $25^{\circ} \mathrm{C}$ in SC medium $+2 \%$ glucose and $10 \mu \mathrm{M} 1$ NA-PP1 and imaged every 3 minutes for 4 hours.

(B) Probing Dbf2-Mob1's nuclear access by recruiting Mob1 to the nucleolus with the PhyB-PIF optogenetics system. By anchoring PhyB to the nucleolus, diffuse nuclear Dbf2-Mob1, if present, can be visualized by recruiting Mob1-eGFP-PIF to the nucleolus.

(C) Recruiting Mob1 to the nucleolus at different cell cycle stages. A40260 cells were grown at $25^{\circ} \mathrm{C}$ in SC medium $+2 \%$ glucose, imaged after a 2-hour incubation with $12.5 \mu \mathrm{M}$ PCB in the dark. Red dot denotes the frame where $650 \mathrm{~nm}$ light was applied to activate PhyB. Yellow arrows highlight the light-induced recruitment.

(D) Recruitment of Mob1 to the nucleolus in CDC15 (A41360) or cdc15-2 (A41361) cells. Quantifications of Mob1's enrichment in the nucleolus as a function of PhyB activation time in CDC15 (A41360, $n=27$ and 16 cells for pre-anaphase and anaphase respectively) or $c d c 15-2$ 
(A41361, $n=14$ and 36 cells for pre-anaphase and anaphase respectively) cells. Cells were grown at room temperature in SC medium $+2 \%$ glucose, incubated with $12.5 \mu \mathrm{M}$ PCB for 2 hours in the dark, and shifted to $34{ }^{\circ} \mathrm{C}$ for 50 minutes before imaging. (E) Nucleolar enrichment of wild-type and truncated Mob1 in wild-type and $d b f 2-L 12 A$ cells (A41394, A41395 and A41396; $n=32,28$ and 31 cells respectively). Wild-type traces for comparison were the same as in Fig. 1E. Cells were grown similarly as in Fig. 1E.

For graphs in (A) and (E), solid lines represent the average of single cell traces aligned to anaphase onset. Shaded areas represent $95 \%$ confidence intervals. For maximum enrichment, each dot represents a single cell. Solid lines represent the median. $* * * * P<0.0001 ; * * * P<0.001$ by two-sided Wilcoxon rank sum test. 


\section{Figure 4. Nucleolar localization of Dbf2-Mob1 is regulated by $C D C 5$ independently of}

\section{CDC15.}
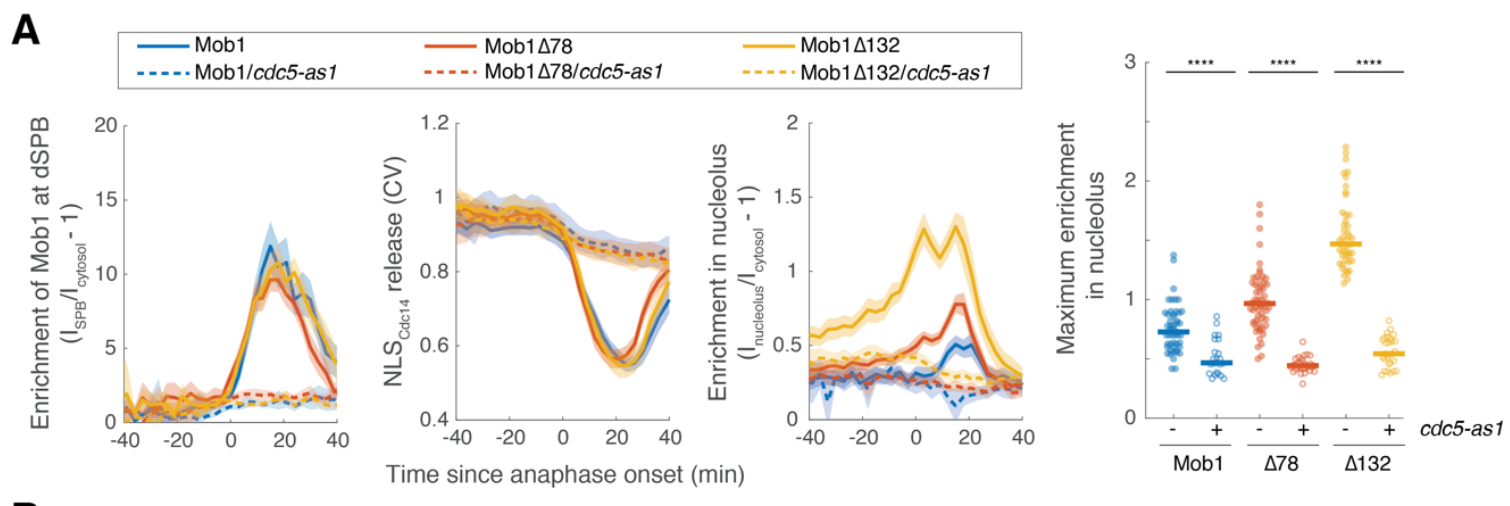

B
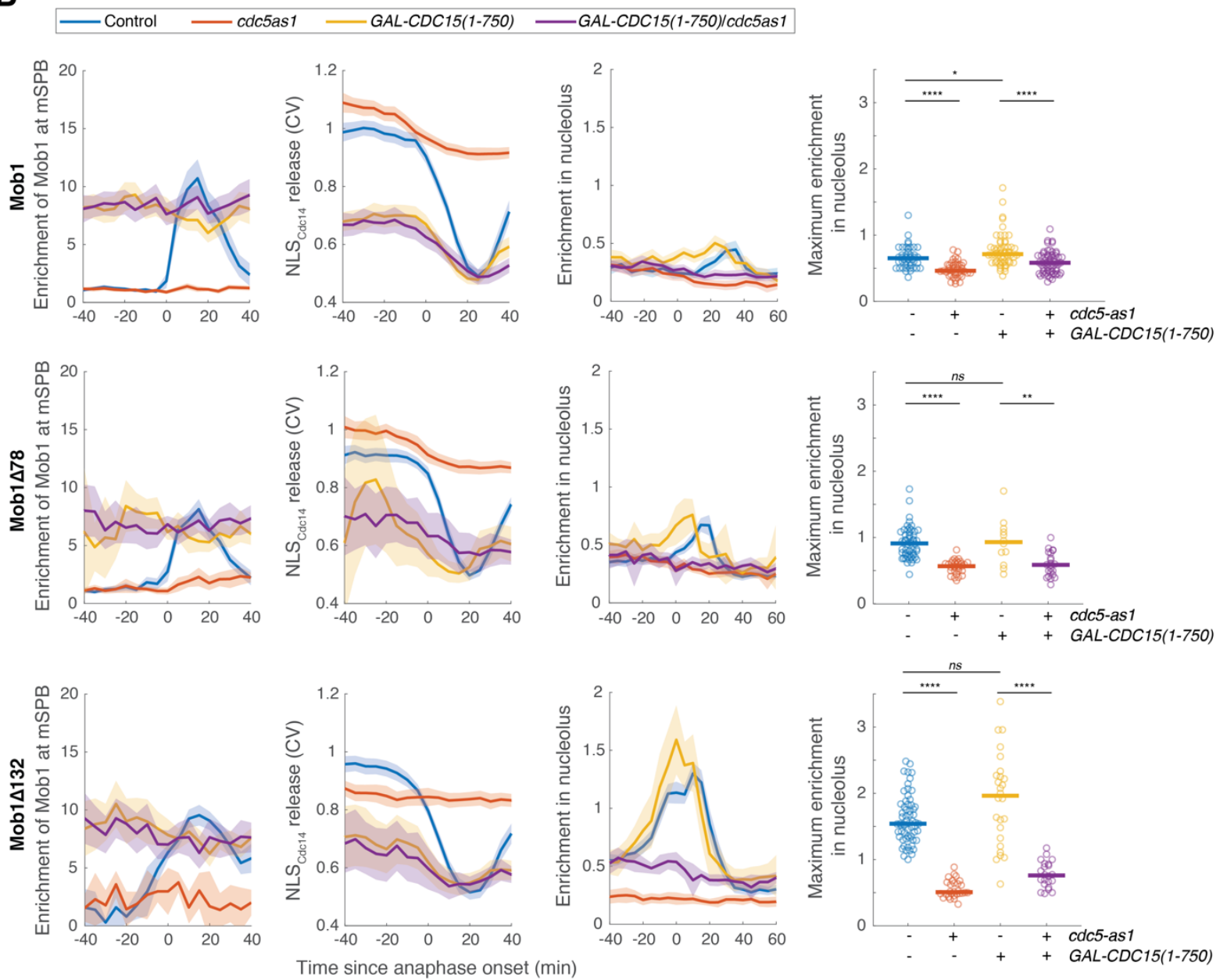

(A) Enrichment of Mob1 at the dSPB, in the nucleolus, and Dbf2-Mob1's kinase activity in cells wild-type for $C D C 5$ (A41211, A41212, and A41213; $n=49,60$ and 47 cells respectively) or harboring a $c d c 5$-as 1 allele (A41334, A41335, and A41336; $n=23,30$ and 28 cells respectively). Cells were grown at $25^{\circ} \mathrm{C}$ in $\mathrm{SC}$ medium $+2 \%$ glucose and $5 \mu \mathrm{M} \mathrm{CMK}$ and imaged every 3 minutes for 4 hours. 
(B) Cells harboring GAL-CDC15(1-750) and $c d c 5$-as 1 either containing eGFP-MOB1 (A41211, A41334, A41376 and A41337; $n=44,41,58$ and 61 cells respectively), or eGFP-MOB1 $\triangle 78$ (A41212, A41335, A41377, and A41338; $n=54,30,12$ and 22 cells respectively), or $e G F P$ $M O B 1 \Delta 132$ (A41213, A41336, A41378 and A41339; $n=62,28,26$ and 22 cells respectively) were analyzed to determine Mob1 localization. Localization to the mSPB instead of dSPB was quantified here because cells expressing GAL-CDC15(1-750) often exit from mitosis in the mother (without movement of a SPB into the bud). For cells exited with two SPBs in the mother cell, maximum intensities of the two SPBs were used. Cells were grown at $25^{\circ} \mathrm{C}$ in SC medium + $1 \%$ raffinose, $1 \%$ galactose and $5 \mu \mathrm{M} \mathrm{CMK}$ and imaged every 5 minutes for 5 hours. Solid lines represent the average of single cell traces aligned to anaphase onset. Shaded areas represent $95 \%$ confidence intervals. For maximum enrichment, each dot represents a single cell. Solid lines represent the median. $* * * * P<0.0001 ; * * P<0.01 ; * P<0.05$ by two-sided Wilcoxon rank sum test. 


\section{Figure 5. Cdc5 promotes Dbf2-Mob1's nucleolar localization by phosphorylating}

\section{Cfi1/Net1.}

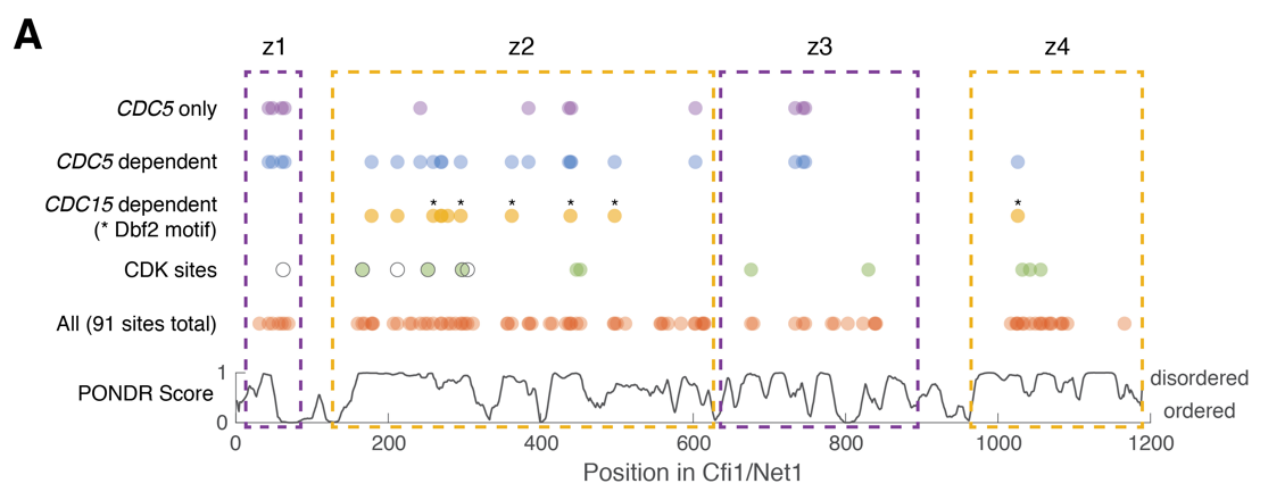

B

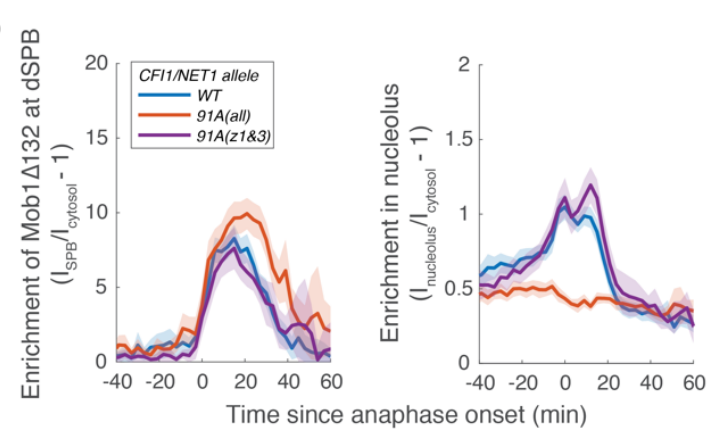

D

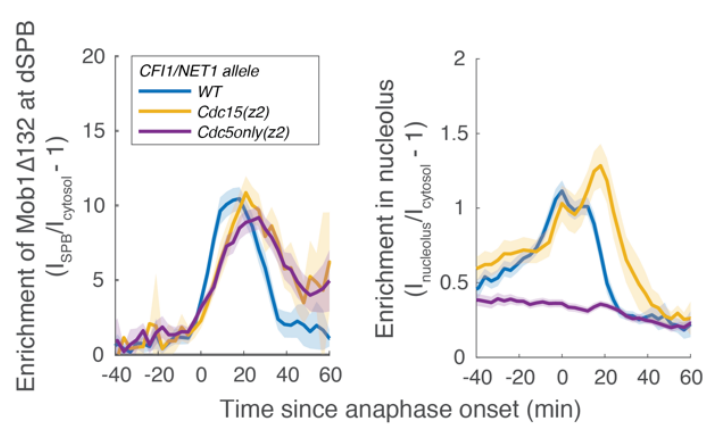

C

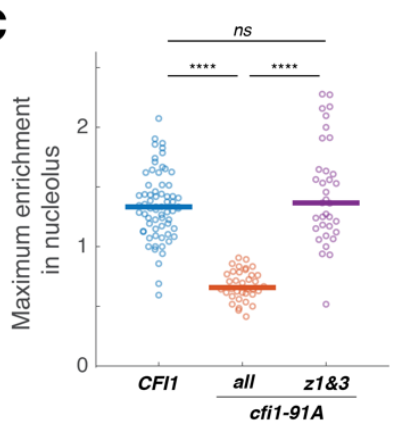

$\mathbf{E}$

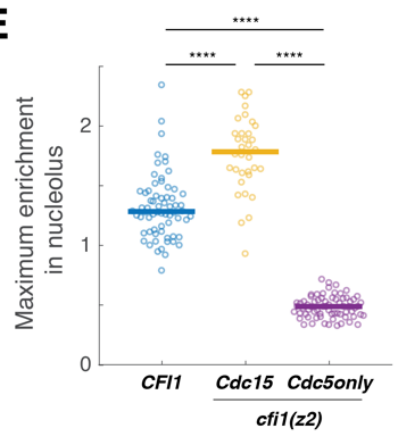

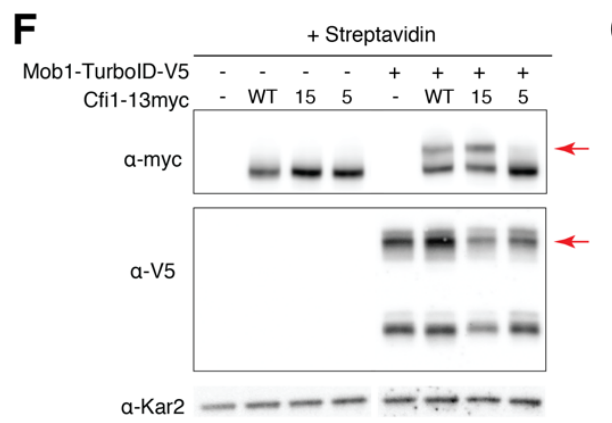

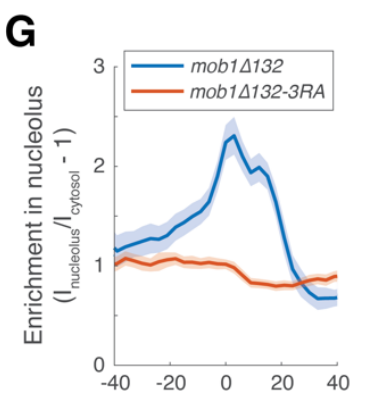

Time since anaphase onset $(\mathrm{min})$

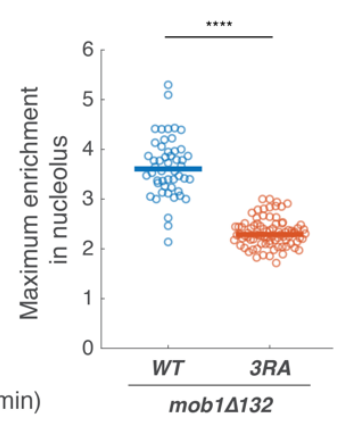

(A) Distribution of all, CDK sites, CDC15- and CDC5-dependent phosphorylation sites (Table S4) and disordered regions in Cfi1/Net1. For CDK sites, open circles represent sites identified and mutated in Azzam et al. 2004 (cfil/net1-6Cdk) and filled circles represent sites identified in Holt et al. 2009. Dashed boxes denote the four zones. 
(B-E) Localization of Mob1 132 in CFI1/NET1 (A41411, $n=67$ cells for B-C and 66 cells for D-E), cfil-91A mutants (A41412 and A41413, $n=36$ and 35 cells), cfil-Cdc15(z2) (A41593, $n=$ 34 cells) or $c f i 1-C d c 5$ only(z2) (A41594, $n=69$ cells). Cells were grown at $25^{\circ} \mathrm{C}$ in SC medium + $2 \%$ glucose and imaged every 3 minutes for 4 hours.

(F) Streptavidin gel-shift assays to probe the interactions between TurboID-tagged Mob1 and different CFI1/NET1 alleles (from left to right: A2587, A41596, A41597, A41598, A41379, A41611, A41612, A41613). -, not tagged; WT, wild-type Cfi1-13myc; 15, Cfi1-Cdc15(z2)13myc; 5, Cfi1-Cdc5only(z2)-13myc. Cells were grown at room temperature in YEP $+2 \%$ glucose and lysates were treated with streptavidin and immunoblotted as indicated. Red arrows highlight biotinylated proteins.

(G) Enrichment of Mob1 $\Delta 132$ (A41664, $n=50$ cells) or Mob1 $\Delta 132-3 \mathrm{RA}$ (A41665, $n=85$ cells) in the nucleolus. Cells were grown at $25^{\circ} \mathrm{C}$ in SC medium $+2 \%$ glucose and imaged every 3 minutes for 4 hours.

For graphs in (B-E and G), solid lines represent the average of single cell traces aligned to anaphase onset. Shaded areas represent 95\% confidence intervals. For maximum enrichment, each dot represents a single cell. Solid lines represent the median. $* * * * P<0.0001$ by two-sided Wilcoxon rank sum test. 


\section{Figure 6. MEN and Cdc5 promote release of Cdc14 from the nucleolus by phosphorylating}

\section{Cfi1/Net1.}

A
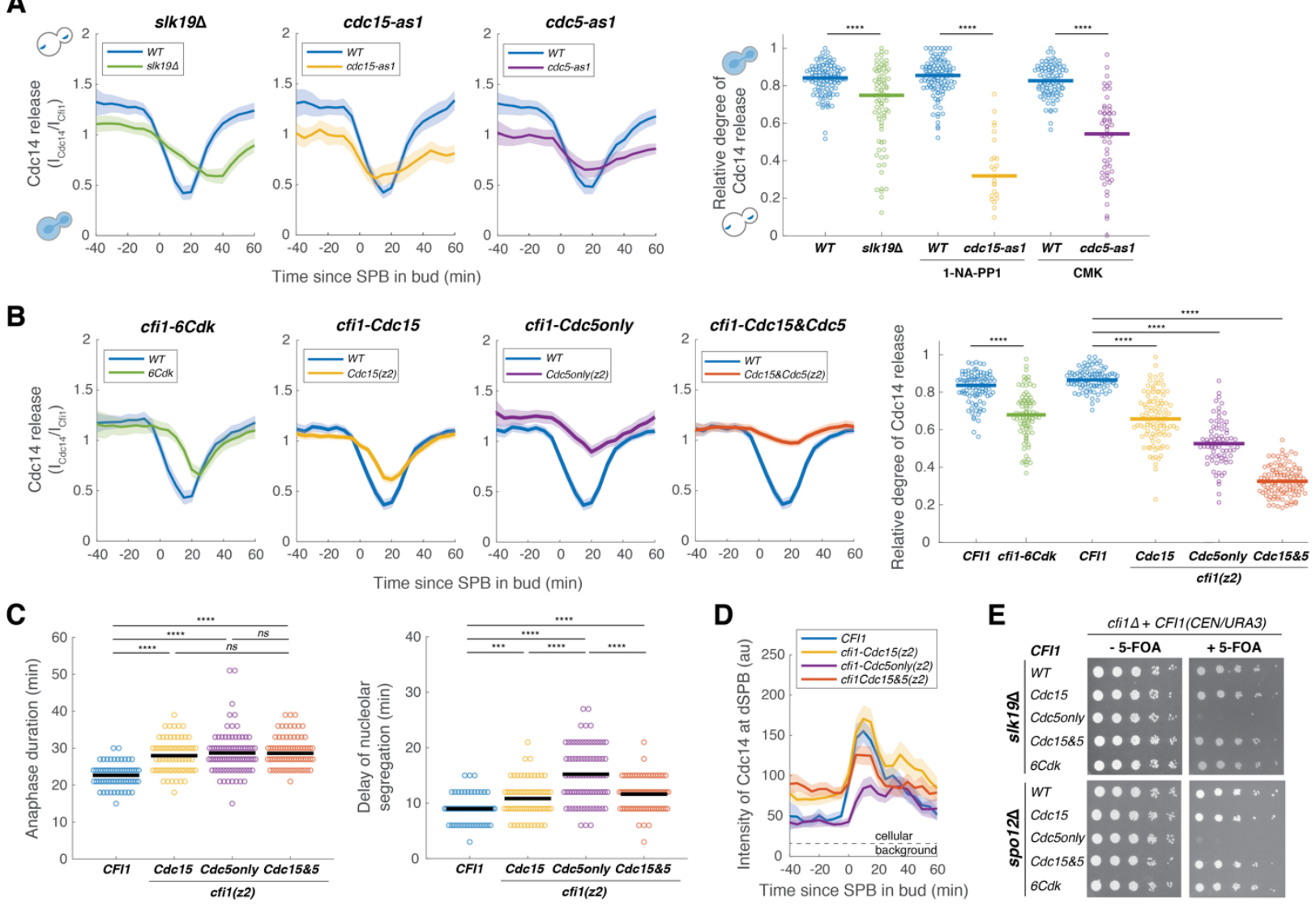

(A) Cdc14 nucleolar release kinetics in wild-type (A41387, $n=134,123$ and 96 cells for each condition), slk19A (A41410, $n=86$ cells), $c d c 15$-as 1 (A41408, $n=38$ cells) or $c d c 5$-as 1 mutant (A41409, $n=61$ cells). Cells were grown at $25^{\circ} \mathrm{C}$ in SC medium $+2 \%$ glucose with corresponding inhibitors and imaged every 5 minutes for 5 hours. Release of Cdc14 from the nucleolus was quantified as the ratio of fluorescence intensity of Cdc14-eGFP to Cfi1/Net1$\mathrm{mScarlet}$ in the nucleolus $\left(\mathrm{I}_{\mathrm{Cdc} 14} / \mathrm{I}_{\mathrm{Cfi} 1}\right)$. Relative degree of Cdc14 release from the nucleolus was calculated as the normalized minimal Cdc14 level in the nucleolus: $\left(\mathrm{I}_{\mathrm{Cdc} 14}\left(t_{\min }\right) / \mathrm{I}_{\mathrm{Cfi} 1}\left(t_{\min }\right)\right) /$ $\left(\mathrm{I}_{\mathrm{Cdc1} 14}\left(t_{-20}\right) / \mathrm{I}_{\mathrm{Cfi} 1}\left(t_{-20}\right)\right)$ where $t_{\min }$ represents the frame with minimal Cdc14 level in the nucleolus and $t_{-20}$ represent $20 \mathrm{~min}$ before movement of the SPB into bud.

(B) Cdc14 nucleolar release kinetics in cells harboring wild-type CFI1/NET1 (A41387, $n=102$ and 114 cells) or CFI1/NET1 phospho-mutants for CDK sites (A41420, $n=95$ cells), Cdc15 sites (A41587, $n=104$ cells), Cdc5 sites (A441588, $n=86$ cells), and Cdc15\&Cdc5 sites (A41589, $n=131$ cells). Cells were grown at $25^{\circ} \mathrm{C}$ in SC medium $+2 \%$ glucose and imaged every 5 minutes for 5 hours.

(C) Distribution of anaphase duration and relative delay of nucleolar segregation for different CFI1/NET1 phospho-mutants (A41436, A41590, A41591 and A41592; $n=76,85,99,92$ cells respectively) measured using the SPB marker Spc42-eGFP and the nucleolar marker Cfi1/Net1- 
mScarlet- I (see Figure 6-figure supplement 3 for details). Cells were grown at $25^{\circ} \mathrm{C}$ in SC medium $+2 \%$ glucose and imaged every 3 minutes for 4 hours.

(D) Intensities of Cdc14-eGFP at dSPBs in different CFI1/NET1 phospho-mutant cells (A41387, A41587, A441588 and A41589; $n=80,82,77$ and 89 cells respectively). Cells were grown and imaged as in (B).

(E) Genetic interactions between different CFI1/NET1 phospho-mutants and slk19D (A41645, A41646, A41647, A41648, A41649) or spo12s (A41650, A41651, A41652, A41653, A41654) analyzed by plasmid shuffling (see Methods for details). 5-fold serial dilutions were spotted onto plates with or without 5'-fluoroorotic acid (5-FOA) and incubated at $25^{\circ} \mathrm{C}$ for 2 to 3 days. The presence of 5-FOA selects cells that are viable after losing the $C F I 1(U R A 3 / C E N)$ plasmid. For all graphs, single cell traces were aligned to the frame where the dSPB entered the bud and averaged. Solid lines represent the average. Shaded areas represent $95 \%$ confidence intervals. For distributions, each dot represents a single cell. Solid lines represent the median for (A-B) and the mean for $(\mathrm{C}) .{ }^{* * * *} P<0.0001 ;{ }^{* * *} P<0.001 ; * * P<0.01 ; * P<0.05$ by two-sided Wilcoxon rank sum test. 


\section{Figure 7. Phosphorylation of Cfi1/Net1 by Cdc5 and Dbf2-Mob1 promotes mitotic exit.}

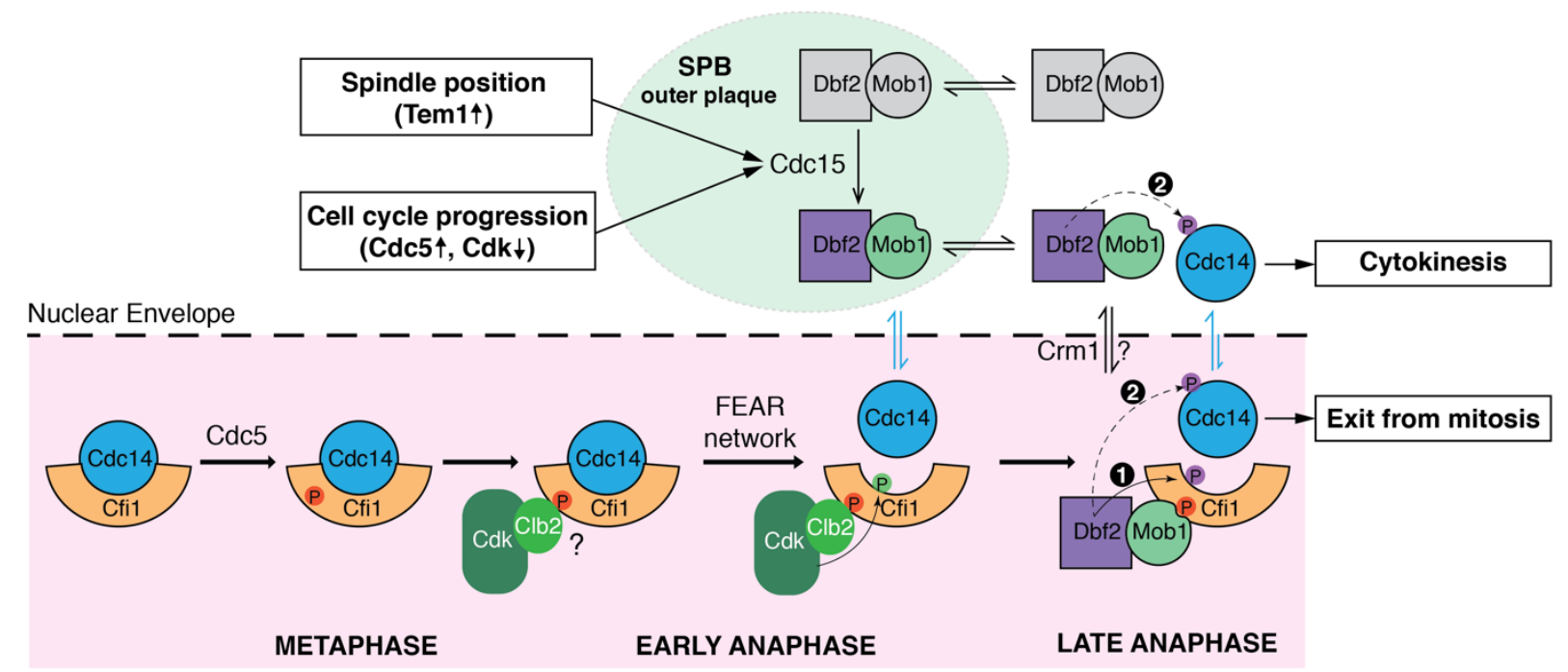

A model for Cdc14 activation. In metaphase, Cdc5 phosphorylates Cfi1/Net1 in the nucleolus to prepare for $\mathrm{Cdc} 14$ release/activation in anaphase. Upon anaphase onset, the FEAR network promotes phosphorylation of Cfi1/Net1 by Clb2-Cdk1 which results in transient release of Cdc14 from the nucleolus. In the meantime, the MEN kinase Cdc15 is activated integrating inputs from both spindle position (via Tem1) and cell cycle progression (via Cdc5 and CDK activities). Activated (SPB-localized) Cdc15 phosphorylates the SPB outer plaque protein Nud1 which creates a dynamic docking site for the MEN terminal kinase complex Dbf2-Mob1 and facilitates phosphorylation and activation of Dbf2-Mob1 by Cdc15. Activated Dbf2-Mob1 gains access to the nucleus and is targeted to the nucleolus by interacting with Cdc5-primed Cfi1/Net1.

Nucleolar Dbf2-Mob1 then phosphorylates Cfi1/Net1, keeping Cdc14 dissociated from its nucleolar inhibitor to trigger exit from mitosis. In addition, active Dbf2-Mob1 in the nucleolus and/or cytoplasm phosphorylates Cdc14 at its NLS resulting in cytoplasmic retention of Cdc14 to facilitate cytokinesis. 
Figure 1-figure supplement 1: N-terminally truncated Mob1 is hyperactive.

A

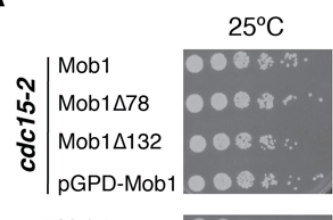

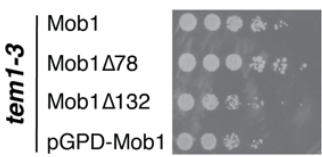

ঠ্ঠ் $\mid \begin{aligned} & \text { Mob1 } \\ & \text { Mob1 } \Delta 78 \\ & \text { Mob1 } 13132 \\ & \text { pGPD-Mob1 }\end{aligned}$

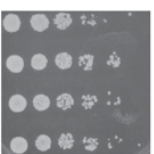

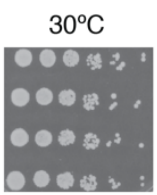
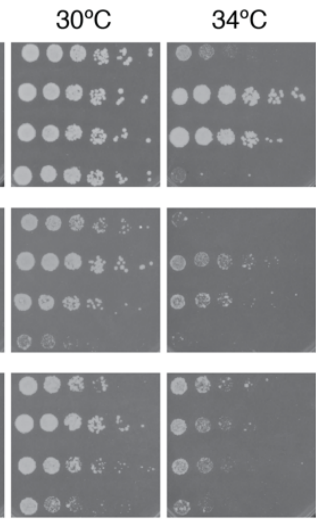

$37^{\circ} \mathrm{C}$
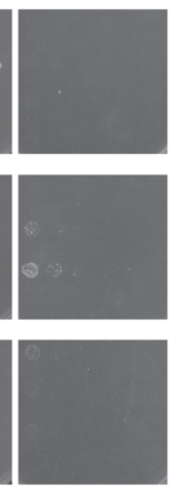

B

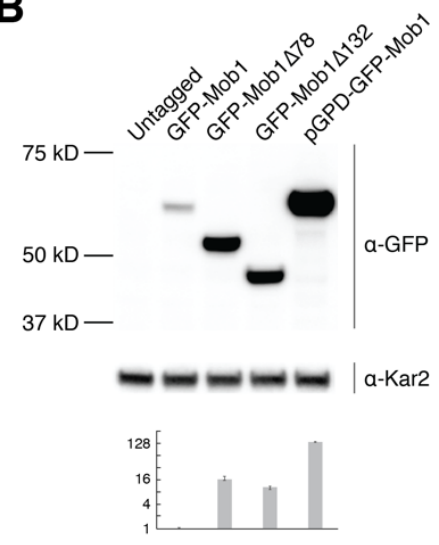

C

C
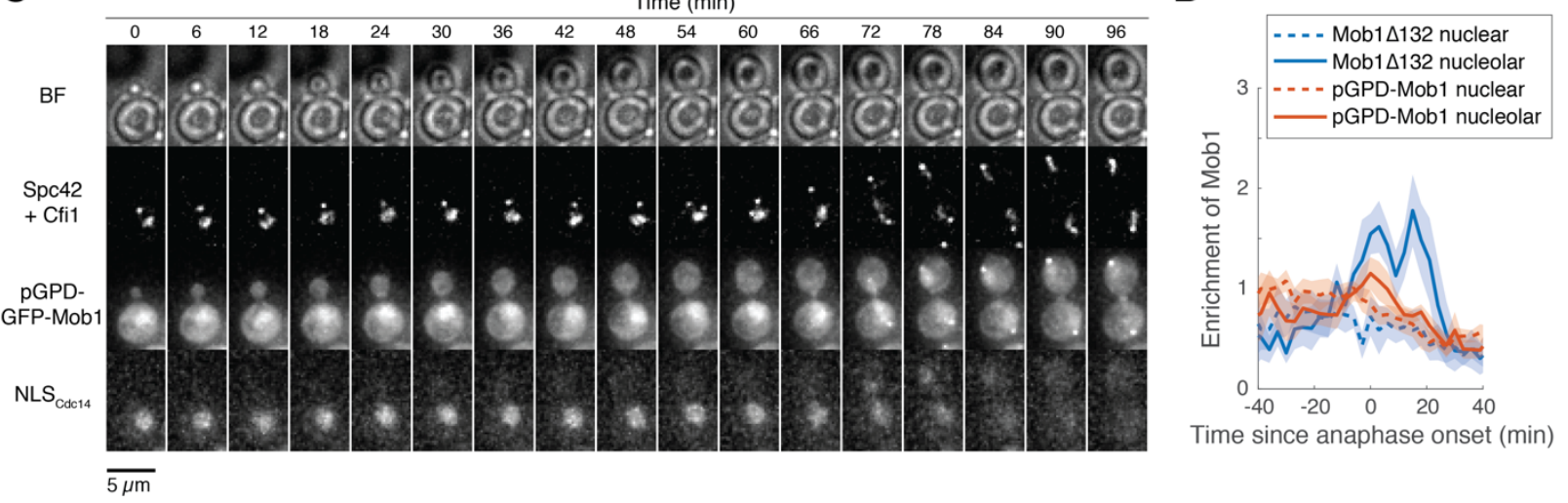

$\mathbf{E}$

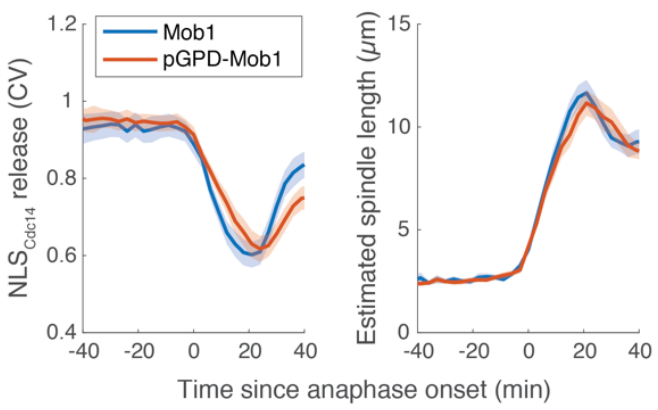

$\mathbf{F}$

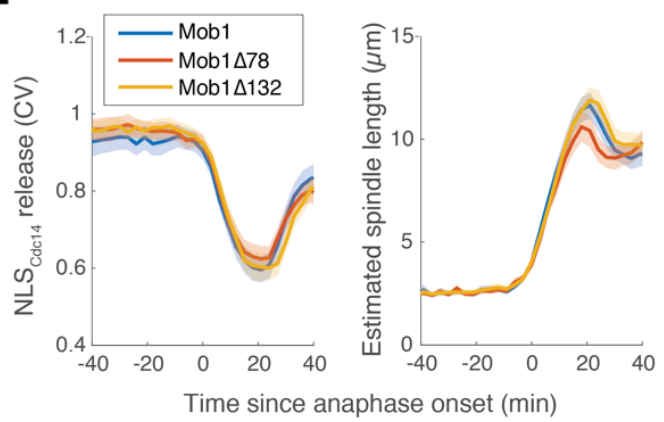

(A) 5-fold serial dilutions of $c d c 15-2$ (A41424, A41425, A41426, A41427), tem1-3 (A41429, A41430, A41431, A41428) and $c d c 5-1$ (A41432, A41433, A41434, A41435) harboring the indicated $M O B 1$ constructs in YEP $+2 \%$ glucose at the indicated temperatures.

(B) Immunoblot (top) and quantification (bottom) of untagged (A2587), full-length (A41351) and truncated GFP-Mob1 (A41352, A41353) as well as full-length GFP-Mob1 expressed from the $p G P D / T D H 3$ promoter (A41350).

(C) Localization of GFP-Mob1 expressed under the control of $p G P D$ promoter (A41595) during the cell cycle. Cells were grown and imaged as in Figure 1E. Increased nuclear but not nucleolar localization of Mob1 was observed. 
(D) Enrichment of Mob1 $\Delta 132$ (A41213, $n=14$ cells) and pGPD-Mob1 (A41595, $n=17$ cells) in the nucleolus (solid lines) compared to the nucleus (dashed lines) as a function of cell cycle progression. Cells were grown and imaged as in Figure 1E.

(E) Kinetics of MEN activation as measured by the release of NLS $_{\mathrm{Cdc} 14}$ reporter from the nucleus (see Figure 1-figure supplement 2) and anaphase progression as indicated by spindle length for cells harboring Mob1 (A41213, $n=62$ cells) or pGPD-Mob1 (A41595, $n=43$ cells). pGPD-

Mob1 slightly delays MEN activation and exit from mitosis.

(F) Kinetics of MEN activation and anaphase progression for experiments shown in Figure 1E.

Mob1 $\Delta 78$ slightly accelerated mitotic exit.

For graphs in (D-F), single cell traces were aligned based on anaphase onset and averaged. Solid lines represent the average, shaded areas represent $95 \%$ confidence intervals. 


\section{Figure 1-figure supplement 2: Mob1's nucleolar localization correlates with MEN activation and $\mathrm{Cdc14}$ release from the nucleolus.}

A

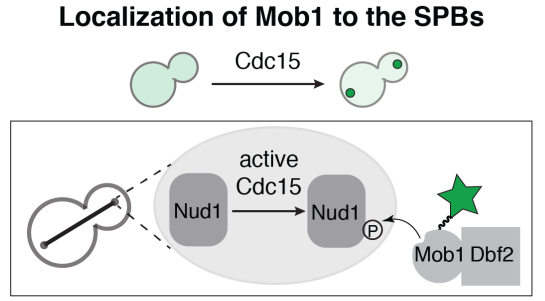

Translocation of $\mathrm{NLS}_{\mathrm{Cdc} 14}$ reporter

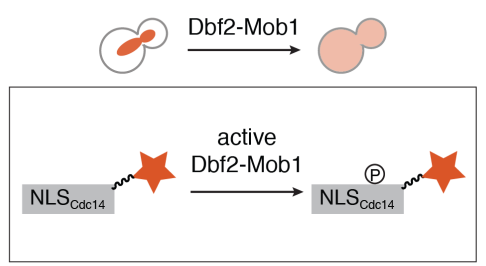

B

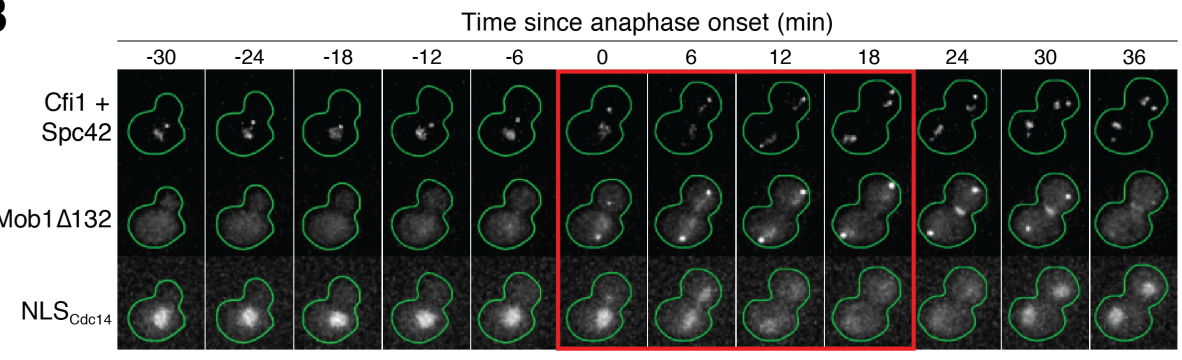

C

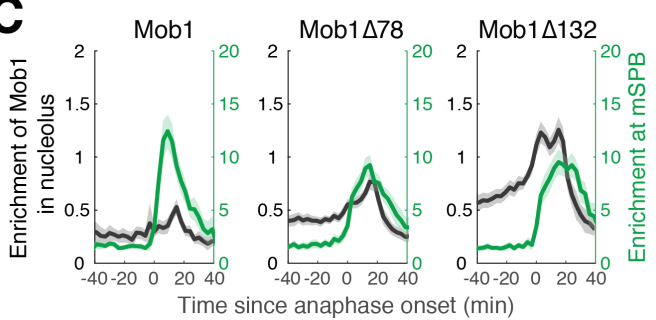

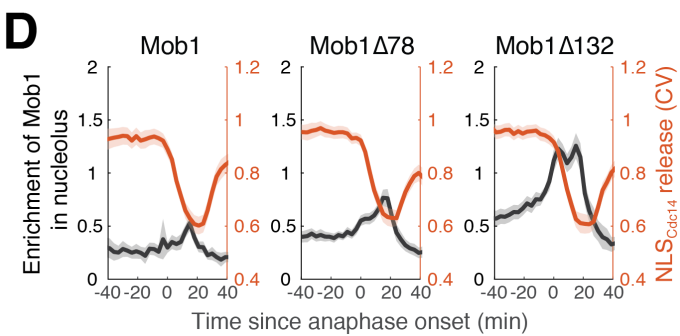

Time since anaphase onset ( $\mathrm{min}$ )

$\mathbf{E}$

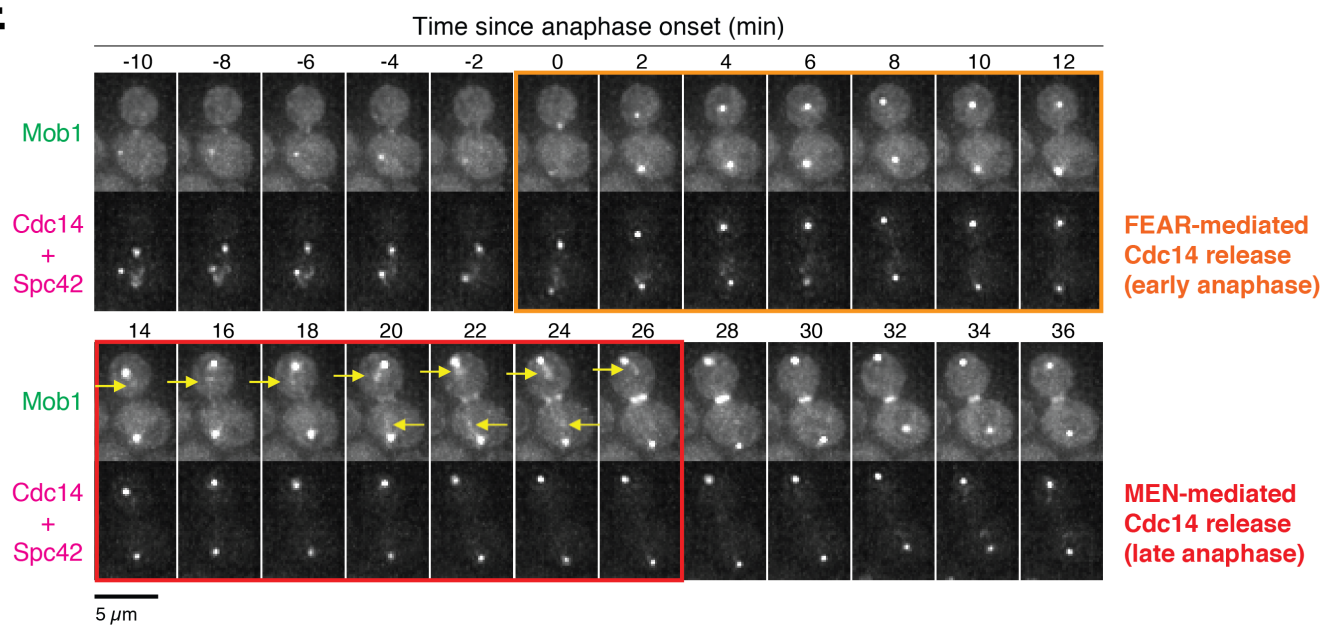

(A) Illustration of Mob1's SPB localization and translocation of NLS Cdc14 $_{\text {reporter in response to }}$ MEN activation.

(B) Localization of Mob1 $\triangle 132$ and the MEN activity reporter $\mathrm{NLS}_{\mathrm{Cdc} 14}$ during the cell cycle. A41213 (GFP-MOB1A132, CFI1/NET1-mCherry, SPC42-mCherry and NLS Cdc14-ymiRFP670) cells were grown as in Figure 1E. Red square indicates anaphase. 
(C) Relative timing of nucleolar localization of Mob1 (black) and SPB localization of Mob1 (green) in cells harboring the indicated $M O B 1$ alleles.

(D) Relative timing of nucleolar localization of Mob1 (black) and release of the NLS Cdc14 $_{4}$ reporter from the nucleus (red) in cells harboring the indicated $M O B 1$ alleles.

(E) Localization of Mob1 and Cdc14 during the cell cycle. A40314 (MOB1-eGFP, SPC42$m C h e r r y$ and $C D C 14-m C h e r r y)$ cells were grown at room temperature in SC medium $+2 \%$ glucose and imaged every 2 minutes for 4 hours. The colored squares indicate the frames where Cdc14 is released from the nucleolus mediated by either the FEAR network or the MEN. Yellow arrows highlight localization of Mob1 in the nucleolus. 


\section{Figure 2-figure supplement 1: TurboID identified interaction between Dbf2-Mob1 and} Cfi1/Net1.

A

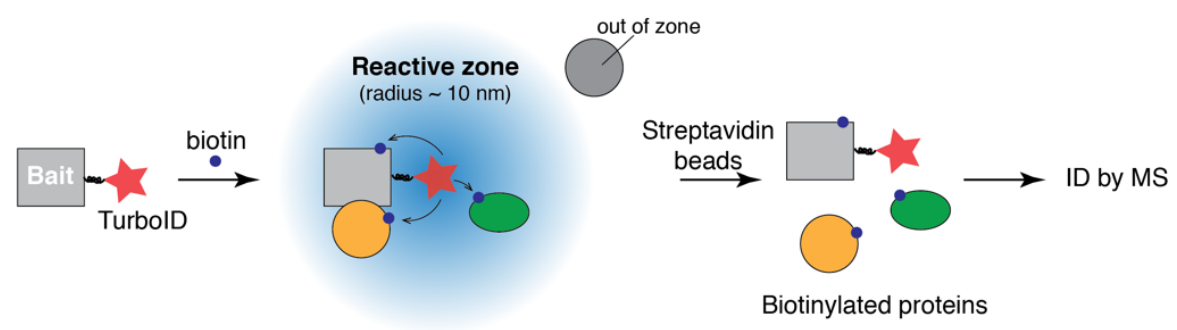

B
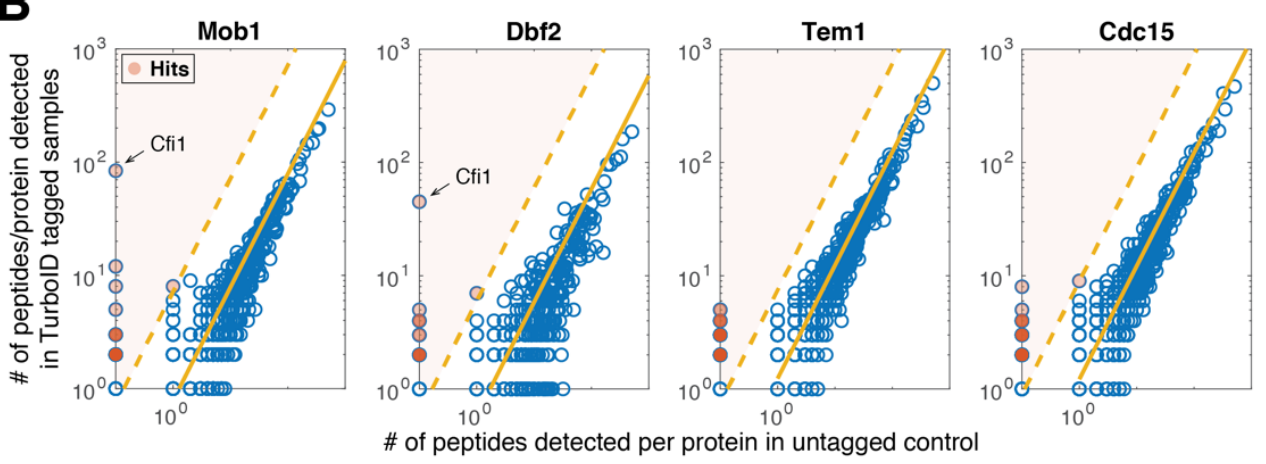

C
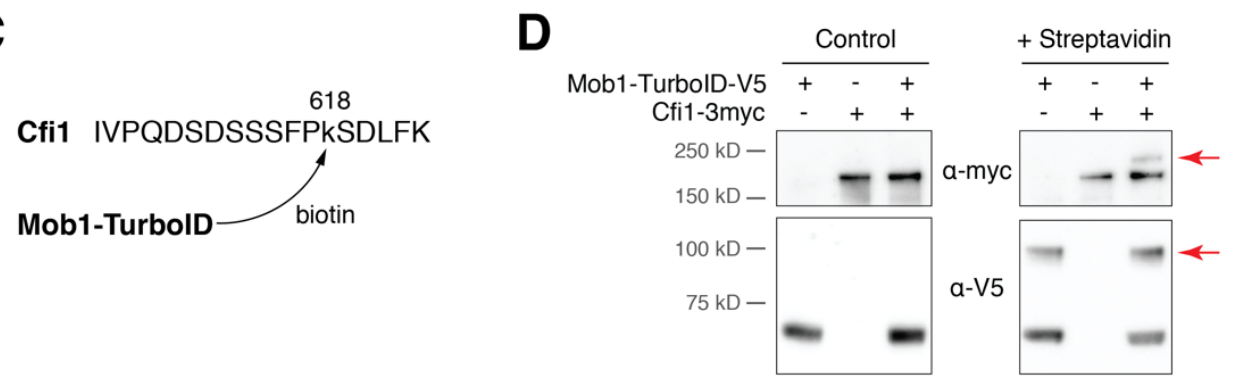

(A) Overview of TurboID proximity-based biotinylation to identify interaction partners of a target protein.

(B) Number of total peptides detected for MS-identified proteins in cells with TurboID tagged baits relative to untagged control cells (source data for Figure 2A). Shaded red dots represent proteins (hits) identified as interaction partners of the bait protein. Solid yellow lines denote the mean ratio of total peptide detected for all proteins. Dashed lines denote the threshold used for identifying hits (10 standard derivations above the mean).

(C) Biotinaylated peptide of Cfi1/Net1 detected in cells harboring Mob1-TurboID.

(D) Streptavidin gel-shift assay to probe the interaction between Mob1 and Cfi1/Net1. Lysates of A41379, A1638, and A41372 cells with or without streptavidin treatment were immunoblotted as indicated. Red arrows highlight biotinylated proteins. 
Figure 3-figure supplement 1: Examining nuclear access of Dbf2-Mob1 by optogenetics.

A

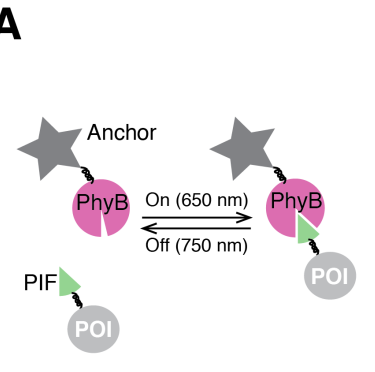

B

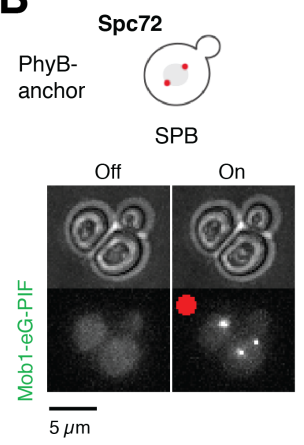

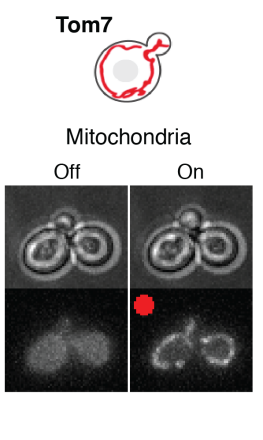

C
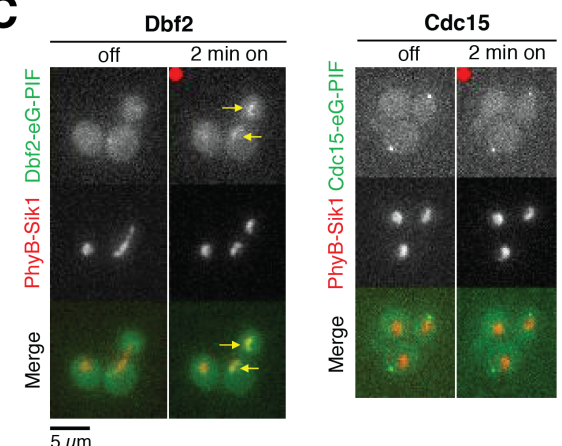

D
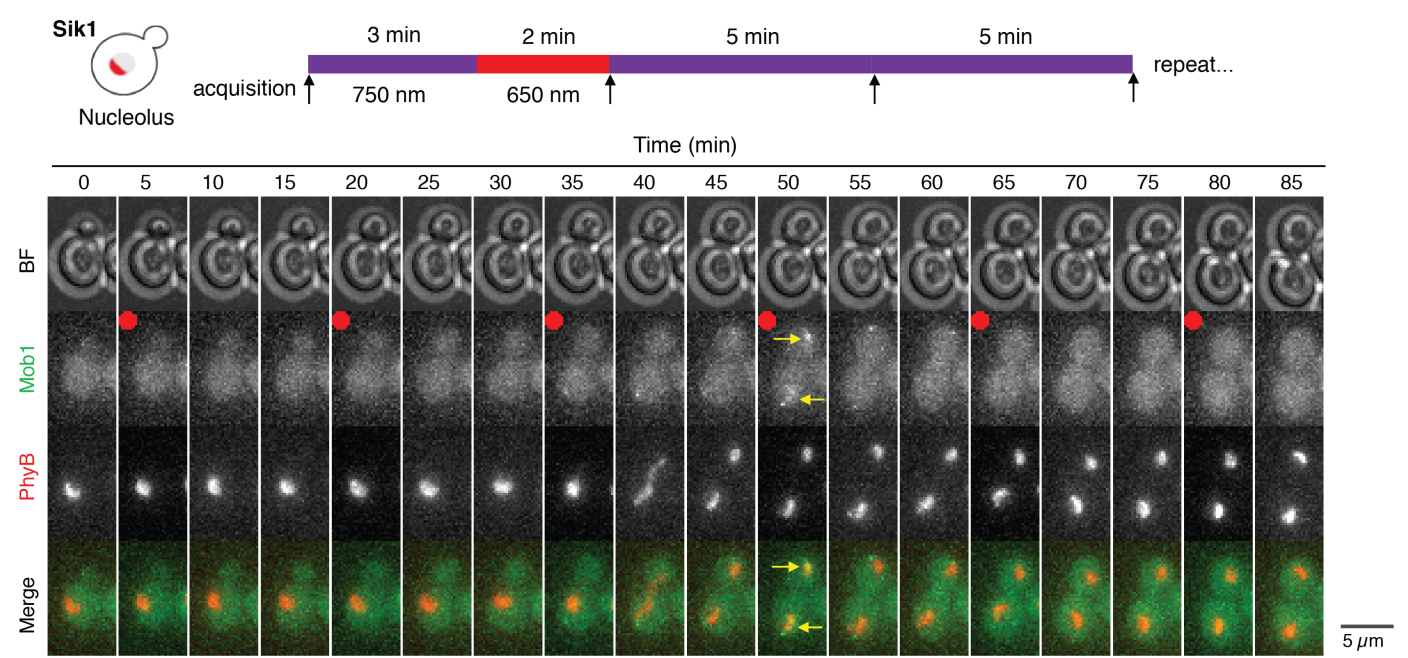

\section{$\mathbf{E}$}
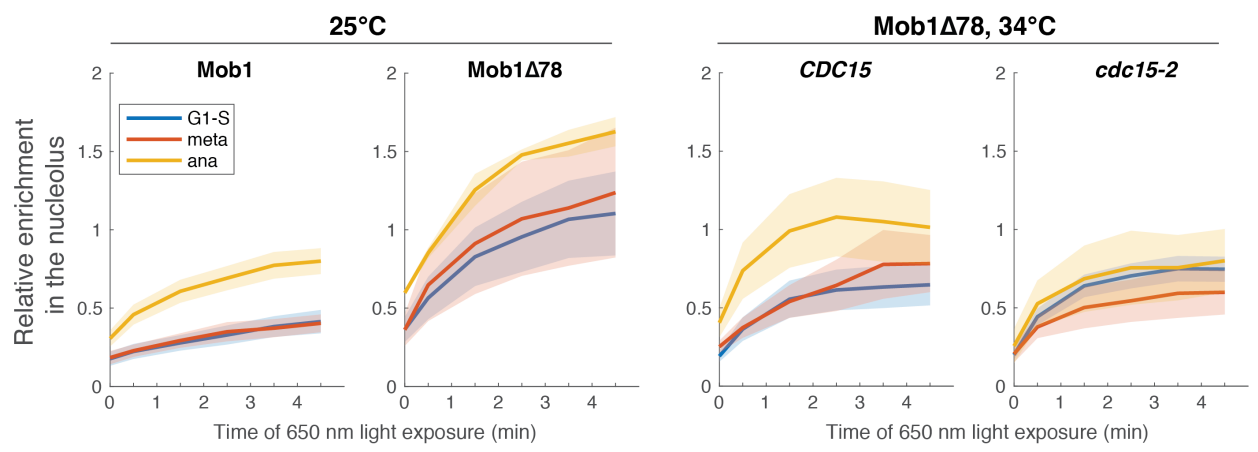

(A) The PhyB-PIF based light-inducible organelle targeting system. When exposed to $650 \mathrm{~nm}$ light, anchored PhyB interacts with PIF and thus targets protein of interest (POI) to designated subcellular regions. This interaction is reversed with exposure to $750 \mathrm{~nm}$ light.

(B) Recruiting Mob1 to SPBs (A40346) or the mitochondrial surface (A40354) with the PhyBPIF optogenetics system. Cells were grown at room temperature in $\mathrm{SC}$ medium $+2 \%$ glucose, incubated with $12.5 \mu \mathrm{M}$ PCB for 2 hours in the dark prior to imaging. Red dots indicate application of red light $(650 \mathrm{~nm})$ for 5 minutes to activate PhyB. 
(C) Recruiting Dbf2 (A40262) or Cdc15 (A40258) to the nucleolus with PhyB-Sik1. Cells were grown similarly to (B). Yellow arrows highlight the light-induced recruitment.

(D) Probing Mob1's nuclear access during the cell cycle with PhyB-Sik1. A40260 cells were grown similarly to (B) and imaged every 5 minutes while the red light $(650 \mathrm{~nm})$ was applied for 2 minutes every 15 minutes. Red dots denote frames where $650 \mathrm{~nm}$ light was applied to activate PhyB prior to imaging as indicated in the cartoon above. Yellow arrows highlight the lightinduced recruitment.

(E) Quantifications of enrichment of Mob1 in the nucleolus as a function of PhyB activation time for wild-type Mob1 (A41360; $n=22,14$, and 21 cells for G1-S, metaphase and anaphase respectively), Mob1 $\Delta 78$ (A41366; $n=11,6$, and 2 cells for G1-S, metaphase and anaphase respectively) at $25^{\circ} \mathrm{C}$ and for Mob1 $\triangle 78$ in $C D C 15$ (A41366; $n=25,4$, and 9 cells for G1-S, metaphase and anaphase respectively) or $c d c 15-2$ cells (A41365; $n=39$, 9, and 10 cells for G1$\mathrm{S}$, metaphase and anaphase respectively) at $34^{\circ} \mathrm{C}$. Cells were grown similarly to (B). 
Figure 3-figure supplement 2: Identification of a functional NES in Dbf2.

A

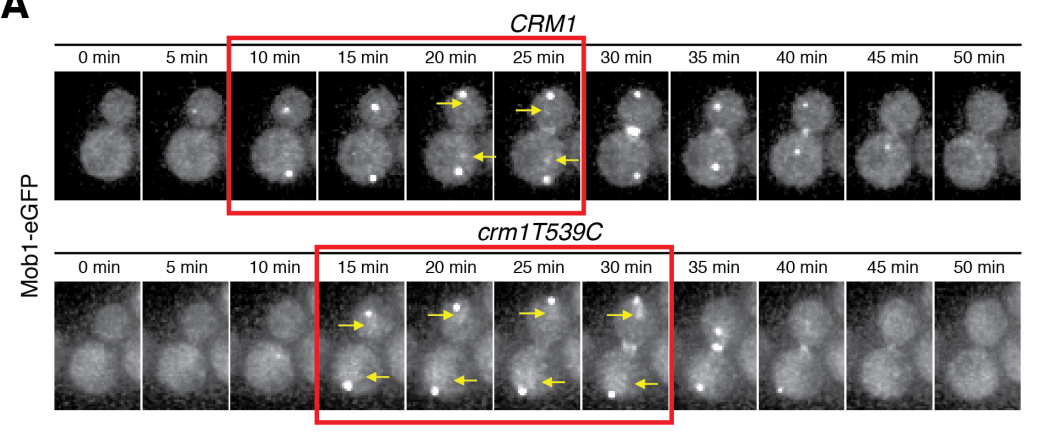

B

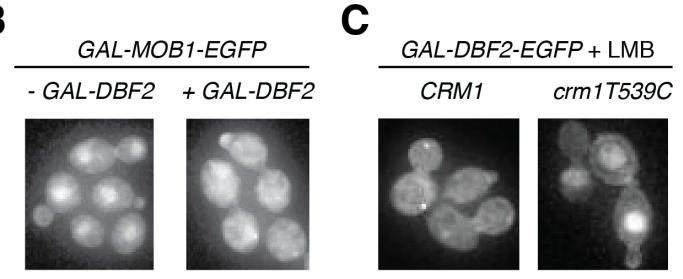

E

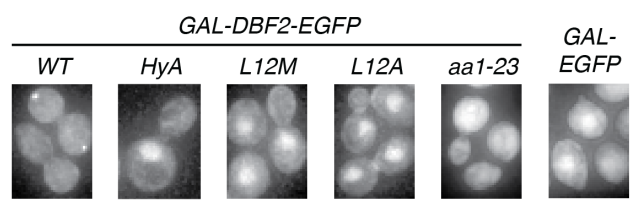

$\mathbf{F}$

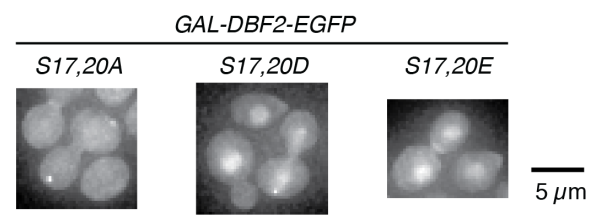

G

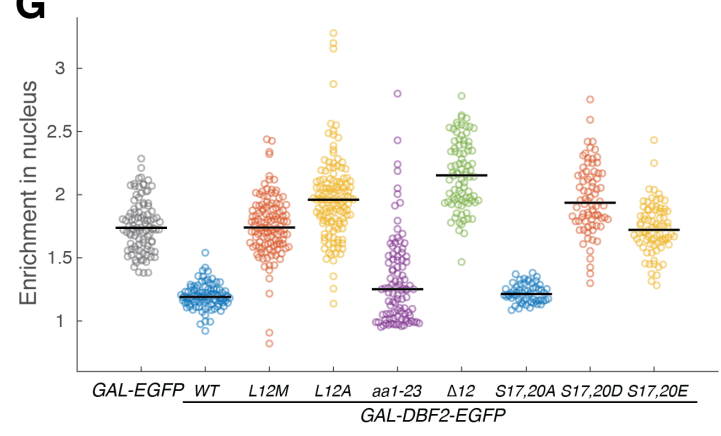

D

Ascomycota

. Saccharomycetales

.. Saccharomycetaceae

... Saccharomyces

....S. cerevisiae

..... s. paradoxus

....S. arborico

....S. bayanus

....S. pastoria

...V. polyspora

.... N. dairenensis

... Z. bailii

... T. delbrueckii

... K. africana

.... S. cerevisiae Dbf20

.... S. pastoria Dbf20

... T. blattae

.... S. paradoxus Dbf20

.... S. arborico Dbf20

... E. cymbalariae

... E. gossypii

...K. lactis

... L. thermotolerans

.. O. parapolymorpha

... P. tannophilus

.. C. Iusitaniae

..C. albicans

.S. pombe Sid2

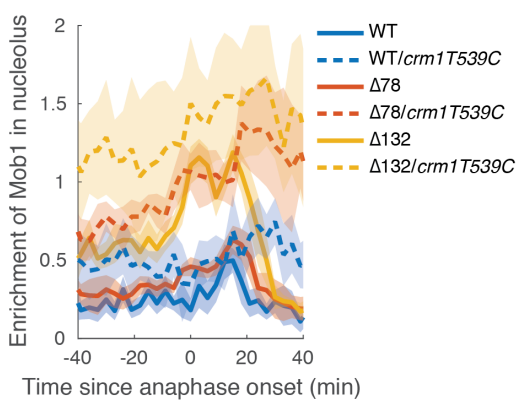

Time since anaphase onset (min)

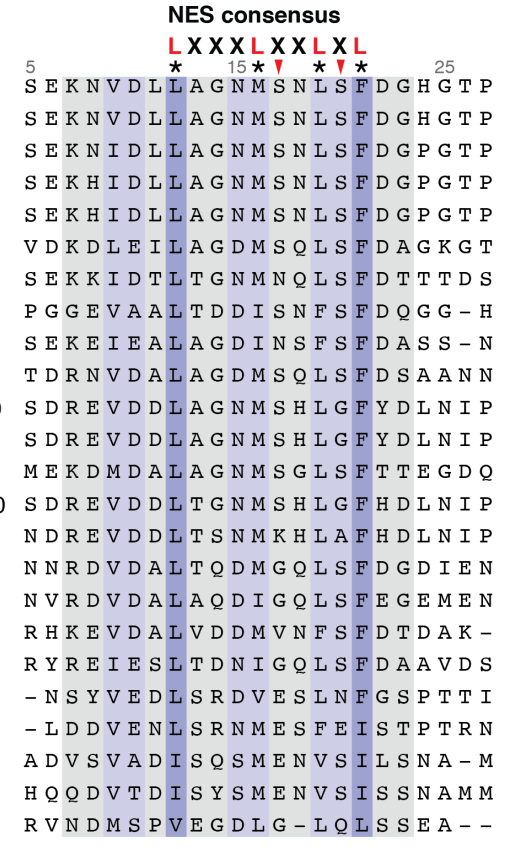

NES consensus $\llcorner X X X\llcorner X X \subset X L$

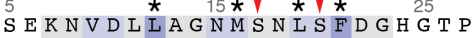
SEKH I DLLAGNM SNLS F D G P T P EKH I DL L A G N S N L S F D P G T P PGGEVAALTDDISNFSFDQGG-H S EKEIEALAGDINSFSFDASS - N DRVDALACDMSQLSFDSARN NNRDVDALT QDMGQLSFDGDIEN RDVDALAODIGOLSFEGEMEN RYREIESLTDNIGOLSFDAAVDS - NSYVEDLSRDVESLNFG SPTTI DVENLSRNMESFEIS RVNDMSPVEGDLG-LQLSSEA--

(A) Mob1's cellular localization when nuclear export is inhibited. Left, cells (A39893, A41349) were grown at room temperature in SC medium $+2 \%$ glucose and leptomycin B. Red box indicates anaphase and yellow arrows highlight increased nuclear and nucleolar localization. Right, comparison of nucleolar enrichment of Mob1 in CRM1 (A41211, A41212 and A41213; $n$ $=12,18$ and 11 cells respectively) and crm 1T539C cells (A41373, A41374 and A41375; $n=13$, 9 and 16 cells respectively). Cells were grown at $25^{\circ} \mathrm{C}$ in SC medium $+2 \%$ glucose with 100 $\mathrm{ng} / \mathrm{ml} \mathrm{LMB}$ and imaged every 3 minutes for 4 hours. 
(B) Localization of overexpressed Mob1-eGFP from the GAL1-10 promoter with (A41363) or without (A41364) co-overexpressing Dbf2 from the same promoter. Cells were grown in SC medium $+2 \%$ raffinose and mounted onto agarose pads made with $\mathrm{SC}$ medium $+1 \%$ raffinose and $1 \%$ galactose.

(C) Localization of overexpressed Dbf2-eGFP with (A41383) or without (A41384) inhibiting Crm1 with LMB. Cells were grown in SC medium $+2 \%$ raffinose and mounted onto agarose pad made with SC medium $+1 \%$ raffinose, $1 \%$ galactose and $100 \mathrm{ng} / \mathrm{ml} \mathrm{LMB}$.

(D) Alignment of Dbf2 homologs in Saccharomycetes and S. pombe.

(E-G) Localization of various Dbf2-eGFP mutants expressed from the GAL1-10 promoter (A41388, A41389, A41386, A41390, A41391, A41392, A41393, A41440, A41441 and A41442; $n=97,98,123,135,120,88,58,76$ and 79 cells respectively). Cells were grown as in (B) and analyzed after 5 hours of growth in galactose containing medium. 
Figure 3-figure supplement 3: Phosphorylation of Dbf2's NES partially regulates Dbf2Mob1's nuclear access.

A

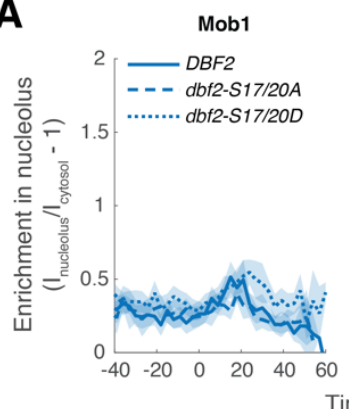

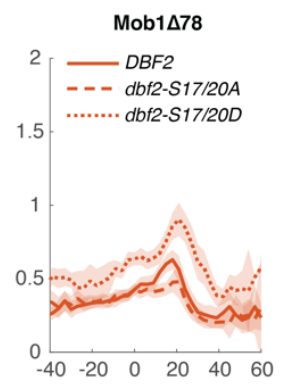

Time since anaphase onset ( $\mathrm{min})$
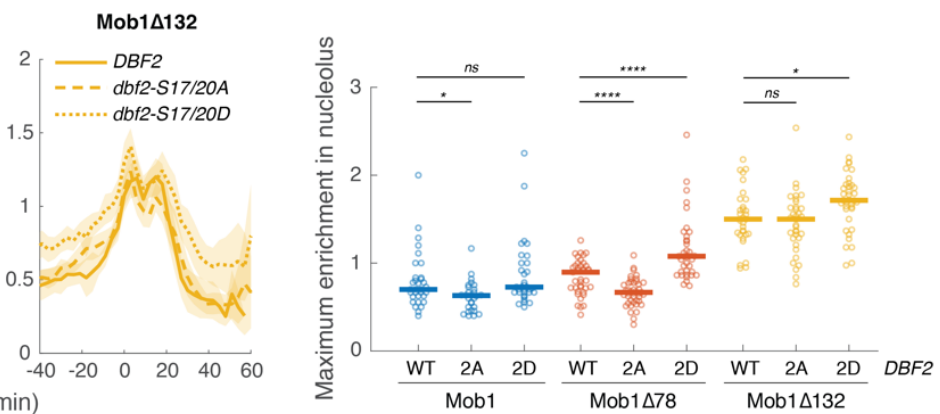

B

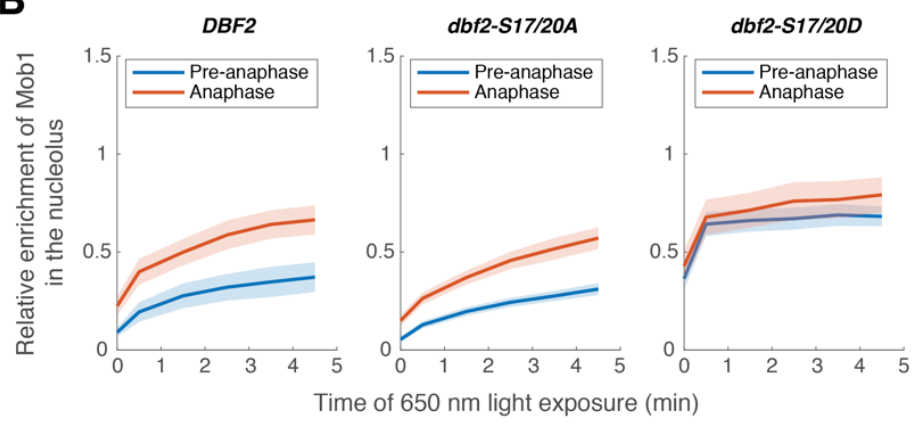

C

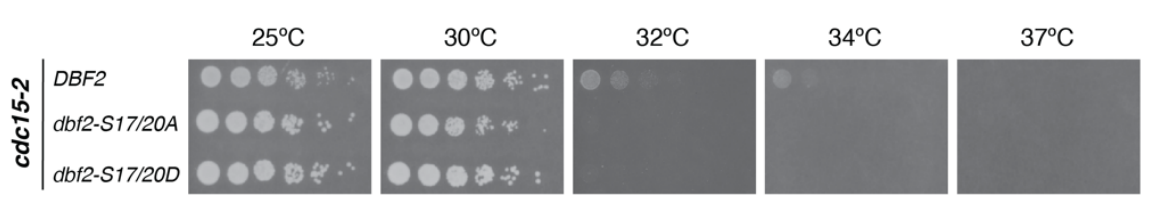

(A) Nucleolar enrichment of wild-type and truncated Mob1 in wild-type, $d b f 2-S 17 / 20 A$ or $d b f 2$ S17/20D cells (A41614, A41617, A41620, A41615, A41618, A41621, A41616, A41619, A41622; $n=32,28,33,39,43,37,31,35$ and 37 cells respectively). Cells were grown and imaged as in Figure 1E. Solid lines represent the average; shaded areas represent 95\% confidence intervals. For maximum enrichment, each dot represents a single cell. Solid lines represent the median. $* * * * P<0.0001 ; * P<0.05$ by two-sided Wilcoxon rank sum test. (B) Quantifications of enrichment of Mob1 in the nucleolus as a function of PhyB activation time for wild-type $D B F 2$ (A41608; $n=42$ and 24 cells for pre-anaphase and anaphase, respectively), $d b f 2-S 17 / 20 A$ (A41609; $n=55$ and 41 cells for pre-anaphase and anaphase, respectively) and $d b f 2-S 17 / 20 D$ (A41610; $n=58$ and 28 cells for pre-anaphase and anaphase, respectively). Cells were grown as in Figure3-figure supplement 1.

(C) 5-fold serial dilutions of $c d c 15-2$ cells harboring wild-type DBF2 (A41624), $d b f 2-S 17 / 20 A$ (A41625) or $d b f 2-S 17 / 20 D$ (A41626) in YEP $+2 \%$ glucose at the indicated temperatures. 
Figure 4-figure supplement 1: Nucleolar localization of Dbf2-Mob1 does not depend on the FEAR network.

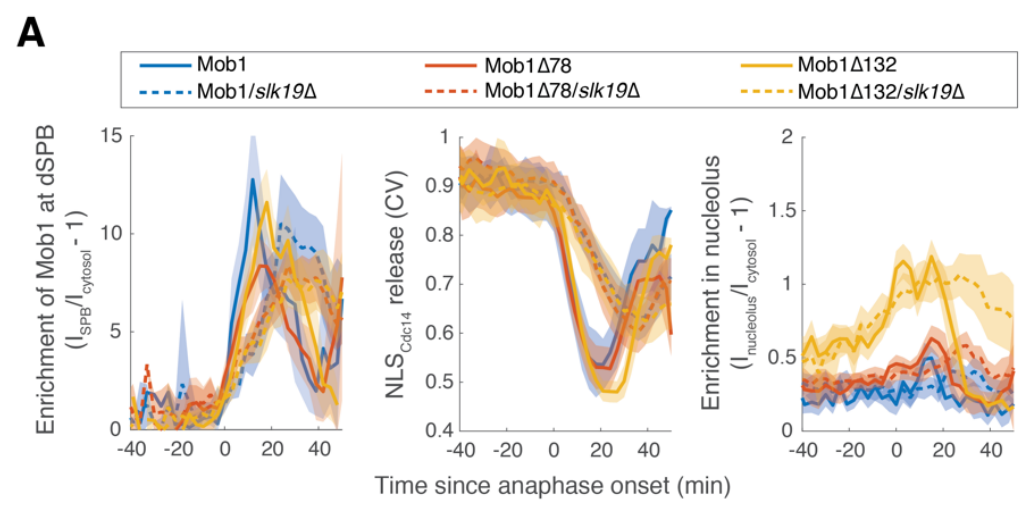

\section{B}

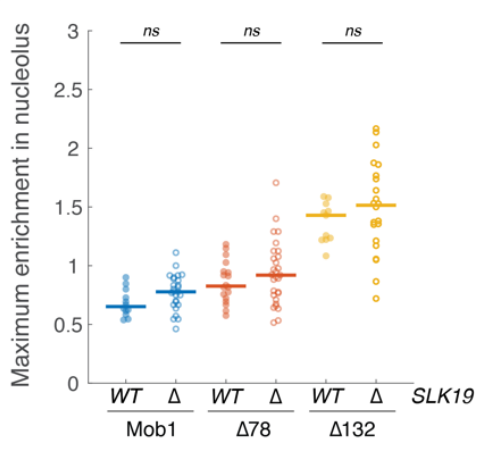

(A) Enrichment of Mob1 at the dSPB, in the nucleolus, and Dbf2-Mob1's kinase activity in wildtype (A41211, A41212 and A41213; $n=12,18,11)$ or slk19D (A41357, A41358, A41359; $n=$ $26,29,22$ cells) cells. Cells were grown at $25^{\circ} \mathrm{C}$ in $\mathrm{SC}$ medium $+2 \%$ glucose and imaged every 3 minutes for 4 hours. Solid lines represent the average of single cell traces aligned to anaphase onset. Shaded areas represent $95 \%$ confidence intervals.

(B) Maximum enrichment of Mob1 in the nucleolus. Each dot represents a single cell. The solid lines represent the median. $n s$, not significant $(P>0.05)$ by two-sided Wilcoxon rank sum test. 


\section{Figure 5-figure supplement 1: Phosphoproteomics identifies CDC15 (MEN) and CDC5 dependent phosphorylation in anaphase.}
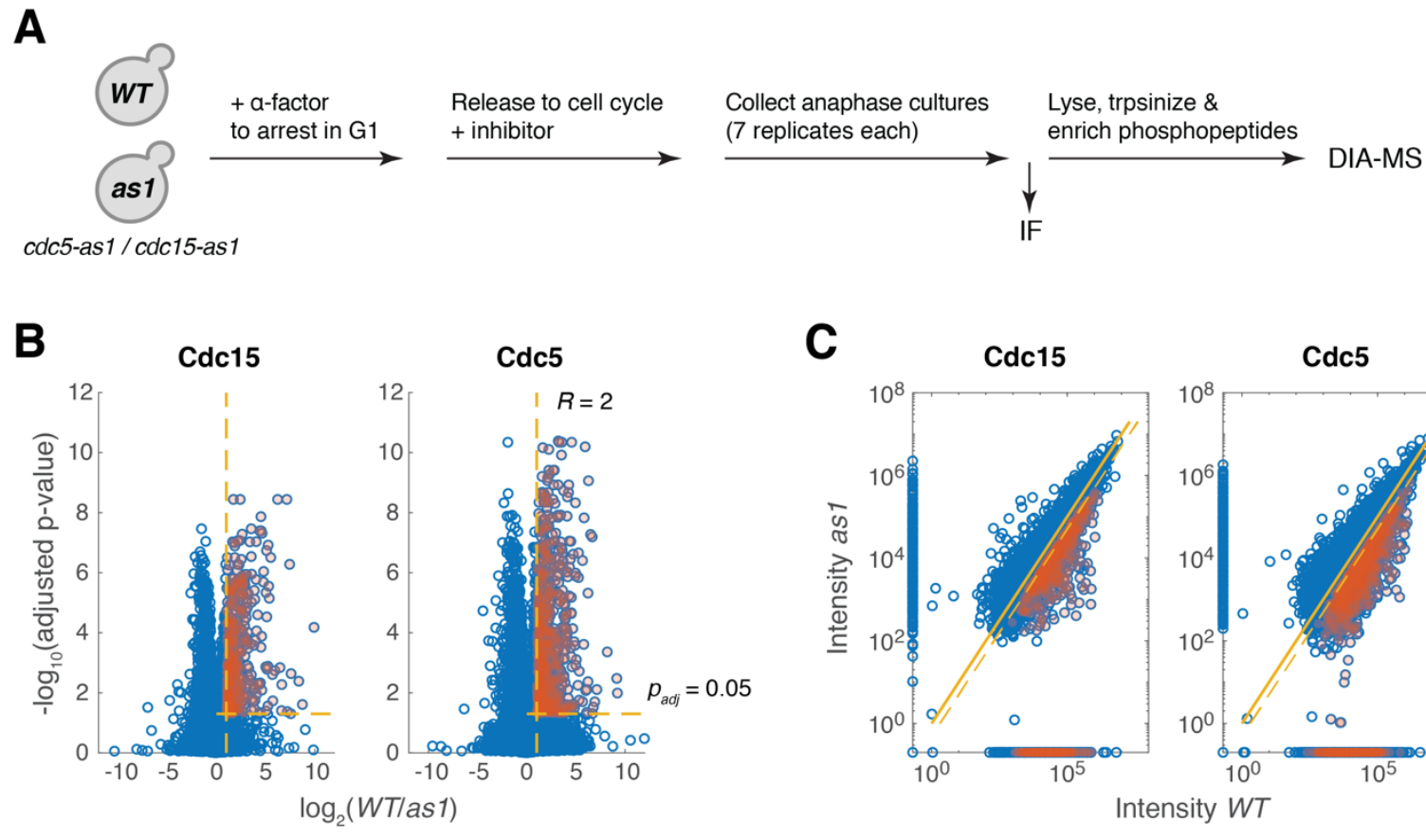

D Phosphorylation sites

17123

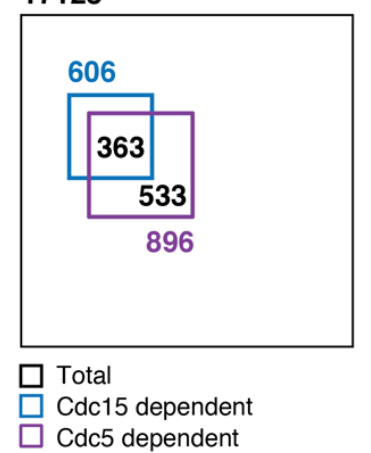

E

\section{Protein targets}

2651

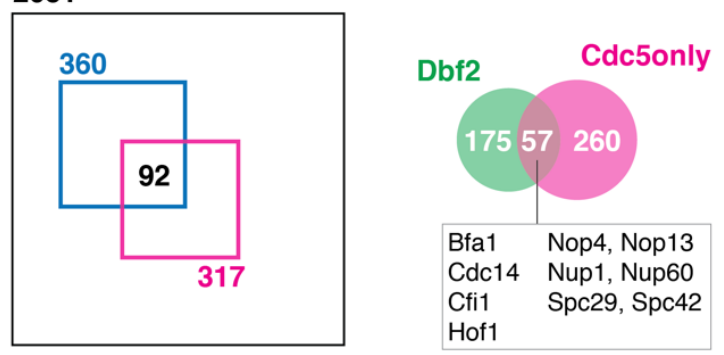

All phospho-proteins detected

Proteins with Cdc15 dependent sites

Proteins with Cdc5only sites

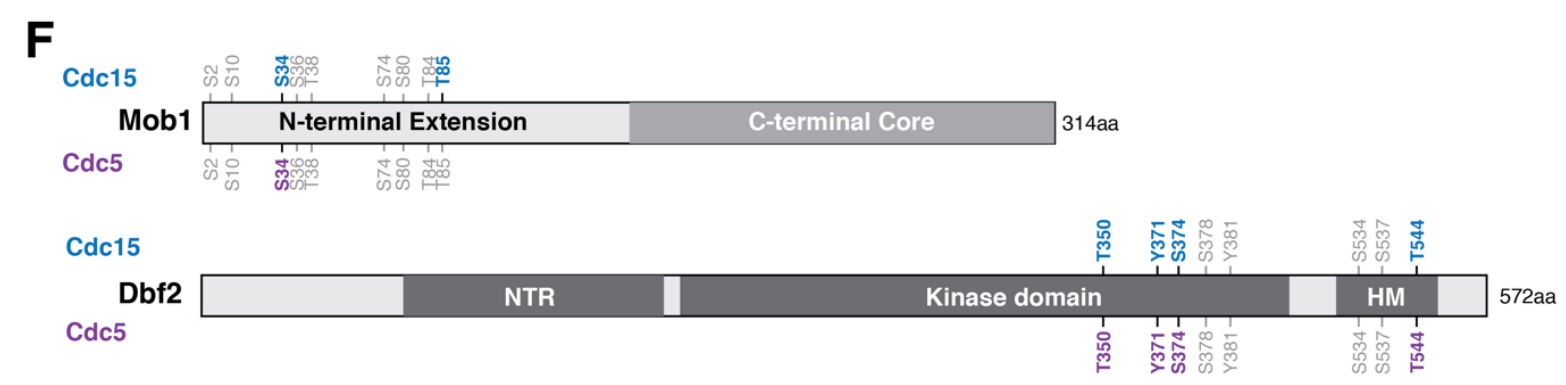

(A) Overview of the sample preparation for phosphoproteomics analysis to map CDC15 (MEN) and CDC5 dependent phosphorylation in anaphase. Paired wild-type (WT, A2587) and cdc15asl (A10991) or paired wild-type and $c d c 5$-as1 (A40903) cultures were synchronized in G1 with $\alpha$-factor $(5 \mu \mathrm{g} / \mathrm{ml})$. After 150 minutes cells were released into fresh medium with the 
corresponding inhibitors in the absence of pheromone at room temperature. After $\sim 100$ minutes cells were harvested to extract proteins and processed for data-independent acquisition mass spectrometry (DIA-MS) analysis with 7 technical replicates for each sample. Immunofluorescence (IF) using an anti-tubulin antibody was performed on the collected cells to determine the percentage of cells with anaphase spindle ( $\sim 70 \%$ for wild-type cells and $\sim 95 \%$ for cdc5-as 1 and cdc15-as1 cells).

(B) Volcano plots of $-\log _{10}$ transformed FDR adjusted $P$-value versus $\log _{2}$ (fold change or ratio) of intensities measured for peptides identified in anaphase cells with $W T$ or analog-sensitive (as1) alleles of $C D C 15$ or $C D C 5$. Yellow dashed lines indicate the cutoff $\left(R>2\right.$ and $\left.p_{\text {adj }}<0.05\right)$ used to identify peptides whose phosphorylation depends on the corresponding kinase as marked with red shaded dots.

(C) Correlations of peptide intensity in WT and as 1 samples for Cdc15 and Cde5 inhibition in anaphase. Data points on the axis represent peptides that were only detected in one sample but not the other. Red shaded dots denote hits for $C D C 15$ or $C D C 5$-dependent phosphopeptides identified based on the cutoff described in (B) and for peptides that were detected in at least 5 out of 7 replicates in $W T$ samples but were missing in as 1 samples (thus no fold change could be calculated).

(D-E) Summary of phosphorylation sites (D) and phospho-proteins (E) determined as CDC15- or CDC5-dependent. Potential Dbf2-Mob1 targets were identified as CDC15-dependent and to fit the Dbf2 phosphorylation consensus motif RXXS*, where * denotes the site of phosphorylation. Cdc5-only sites are sites that are CDC5-dependent but not CDC15-dependent.

(F) CDC15- and CDC5-dependent sites in Mob1 and Dbf2. Light gray sites represent sites that were detected but were not determined as either $C D C 15$ - or $C D C 5$-dependent. 
bioRxiv preprint doi: https://doi.org/10.1101/2020.10.01.322719; this version posted December 17, 2020. The copyright holder for this preprint

(which was not certified by peer review) is the author/funder, who has granted bioRxiv a license to display the preprint in perpetuity. It is made available under aCC-BY-NC-ND 4.0 International license.

Figure 5-figure supplement 2: Phosphorylation of Cfi1/Net1 modulates Dbf2-Mob1's nucleolar localization.

A
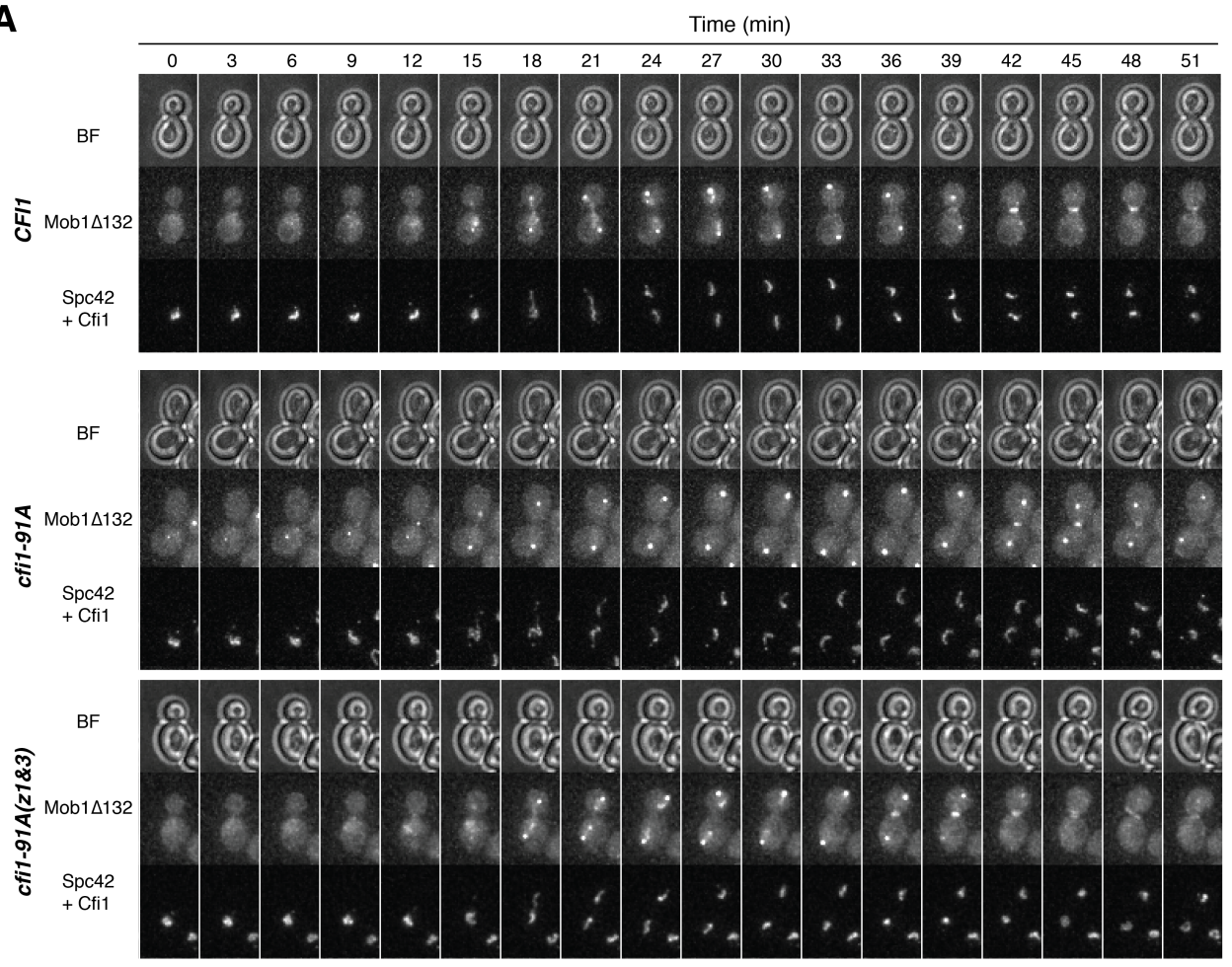

B
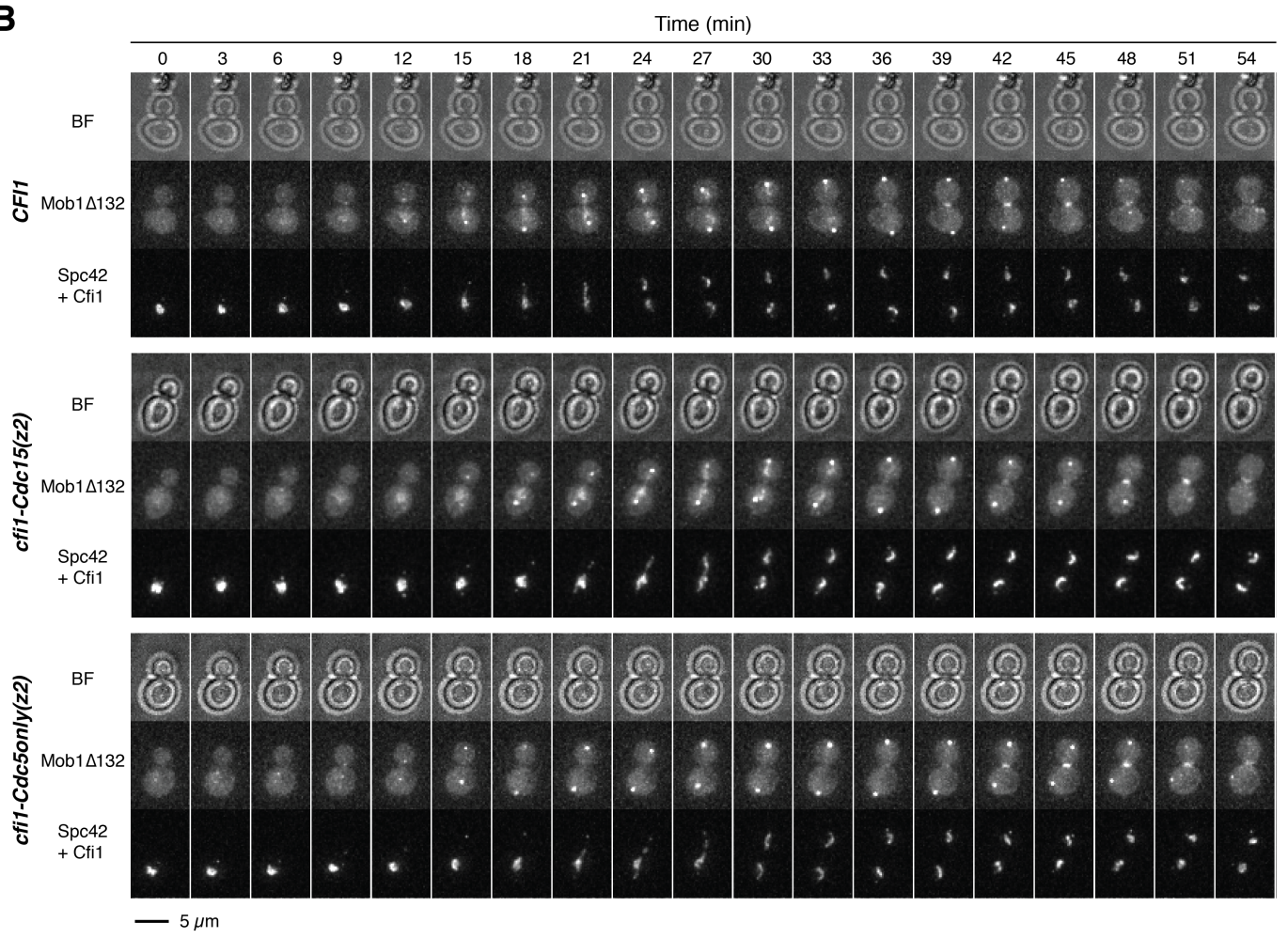

(A-B) Representative images of Mob1 132 localization in CFI1/NET1 (A41411), cfi1-91A (A41412 and A41413), cfil-Cdc15(z2) (A41593) or cfil-Cdc5only(z2) (A41594) cells. 


\section{Figure 5-figure supplement 3: Identification of CDC5-dependent phosphorylation sites in} metaphase.

A

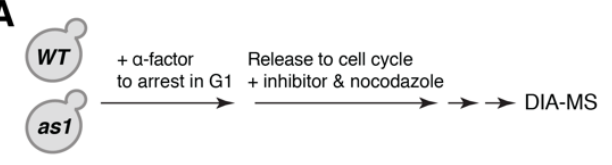

$\mathbf{B}_{12}$

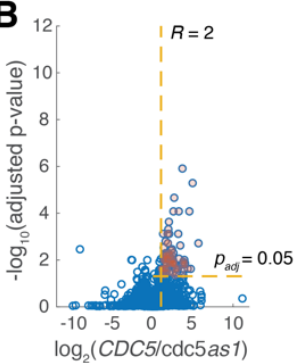

$\log _{2}(C D C 5 /$ cdc5as 1$)$

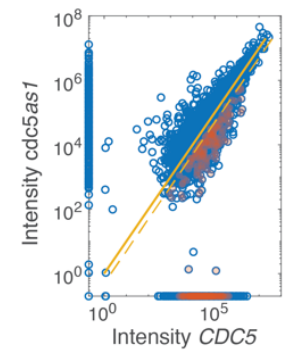

C

Phosphorylation sites

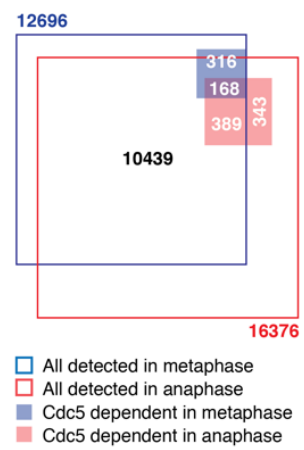

D

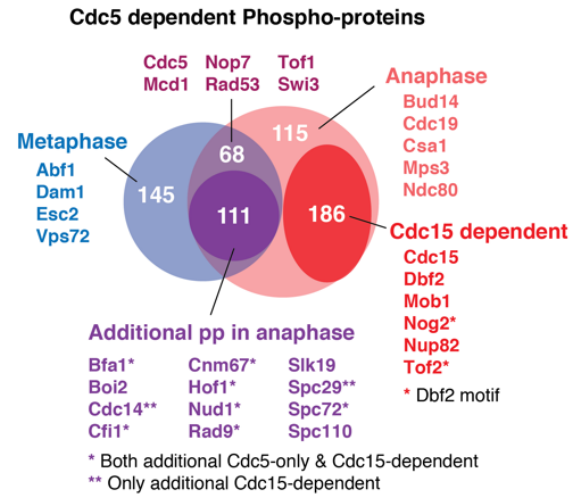

E

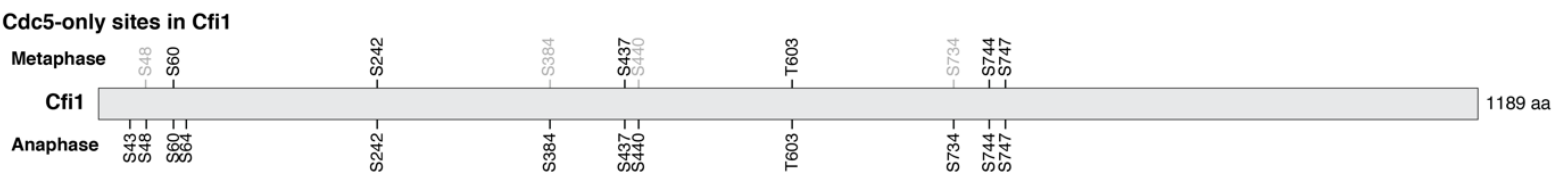

Cdc15-dependent sites in Cfi1

Metaphase

Cfi1

Anaphase

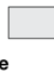

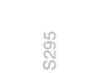

总要

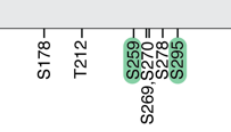

Cdc15 and Cdc5 dependent sites in Cdc14

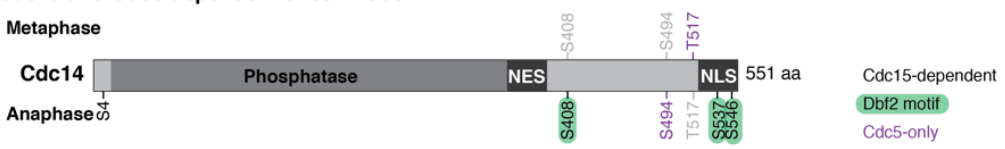

(A) Overview of the sample preparation for phosphoproteomics analysis to map CDC5dependent phosphorylation sites in metaphase. Same procedures were followed as in Figure S8A except that following release of cells from the $\mathrm{G} 1$ arrest, cells were resuspended in medium containing the inhibitor CMK $(5 \mu \mathrm{M})$ and nocodazole $(15 \mu \mathrm{g} / \mathrm{ml})$.

(B) Volcano plot and correlation of peptide intensities with and without inhibition of Cdc5 ( $c d c 5-a s 1$ or $W T)$ in metaphase. Yellow dashed lines indicate the cutoff $\left(R>2\right.$ and $P_{a d j}<0.05$, or detected in at least 4 out of 6 replicates in $W T$ sample but missing in cdc5as 1 sample) used to identify peptides whose phosphorylation depends on CDC5 as marked with red shaded dots. (C-D) Summary and comparison of phosphorylation sites (C) and phospho-proteins (D) detected in metaphase and anaphase.

(E) CDC5-only and CDC15-dependent sites in Cfi1/Net1 and Cdc14 mapped in metaphase and anaphase. Light gray sites in metaphase/anaphase represent phosphorylation sites that were detected but were not determined as CDC5-dependent. 
Figure 5-figure supplement 4: Cdc5 interacts with Cfi1/Net1 in vivo.

A

\begin{tabular}{|c|c|c|c|}
\hline \multirow{2}{*}{$\begin{array}{c}\text { \# of peptides } \\
\text { detected }\end{array}$} & \multicolumn{2}{|c|}{ Bait (TurbolD tagged) } \\
\cline { 2 - 4 } & Cdc5 & Untagged \\
\hline \multirow{4}{*}{ Hits } & Cfi1 & 164 & 6 \\
\cline { 2 - 4 } & Boi2 & 21 & 0 \\
\cline { 2 - 4 } & Mps3 & 20 & 0 \\
\cline { 2 - 4 } & Csa1 & 17 & 0 \\
\hline
\end{tabular}

B

Cfi1 IVPQDSDSSSFPKSDLFK

623

Cfi1 IVPQDSDSSSFPKSDLFKMIEGDDTDLPQWFK

$\uparrow_{\text {biotin }}$
C

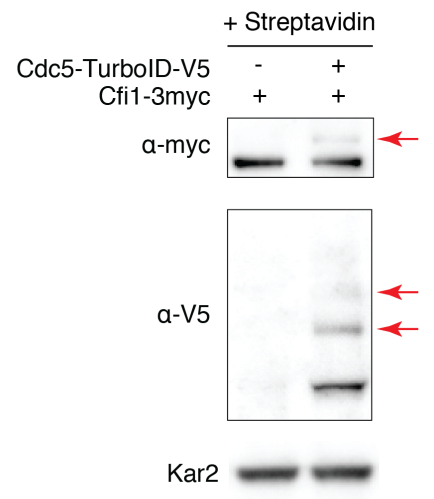

(A) Results of TurboID proximity-based biotinylation for Cdc5 (A41385 and A2588).

(B) Biotinaylated peptides of Cfi1/Net1 detected in cells with Cdc5-TurboID.

(C) Streptavidin gel-shift assay to probe the interaction between Cdc5-TurboID and Cfi1/Net1 (A1638 and A41418). Cells were grown at room temperature in YPED. Lysates were treated with streptavidin and immunoblotted as indicated. Red arrows highlight biotinylated proteins. 
Figure 5-figure supplement 5: Dbf2-Mob1 localizes to the nucleolus via Mob1's phosphoserine-threonine binding domain.

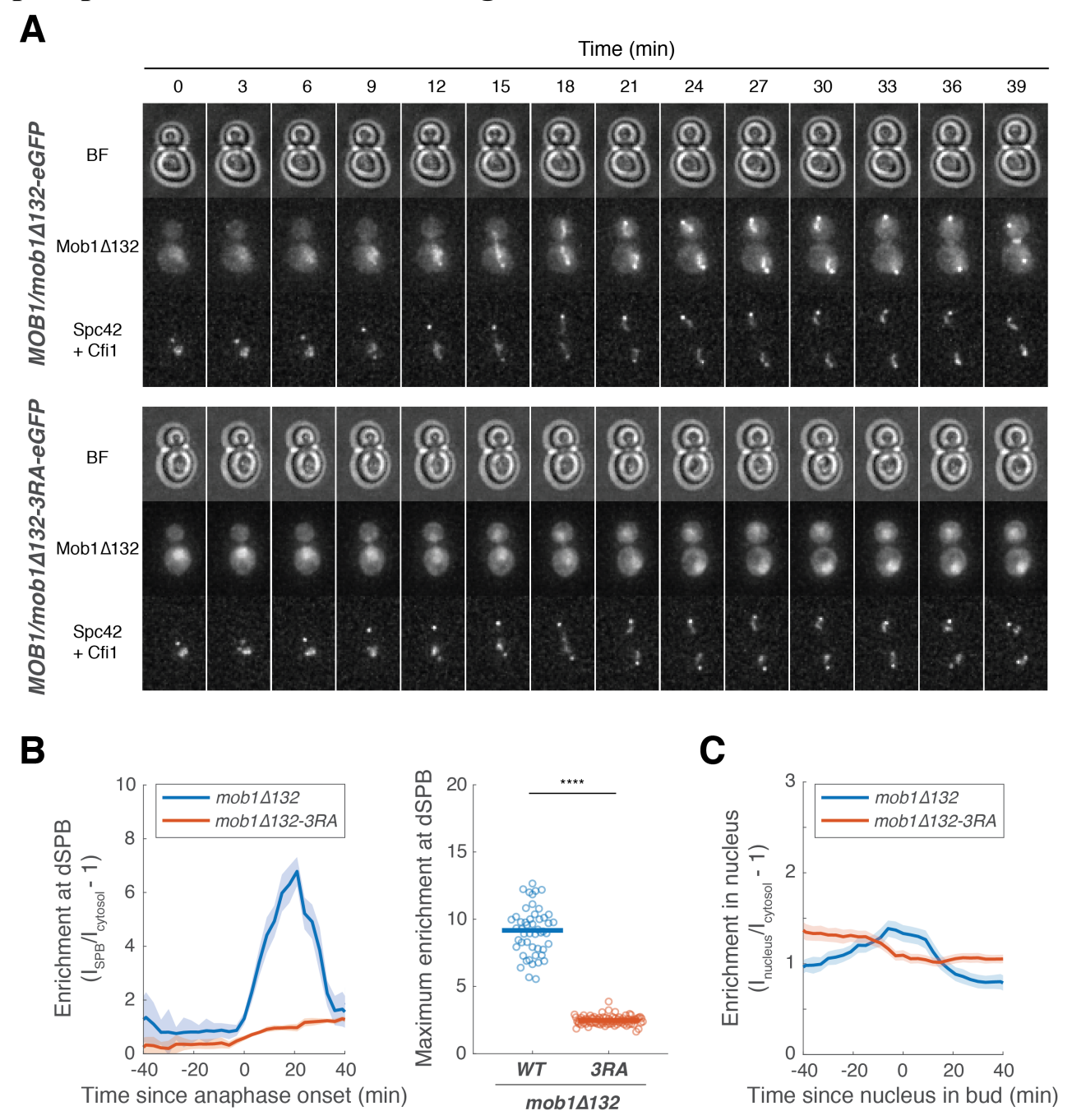

(A) Representative images of Mob1 132 (A41664) and Mob1 132 -3RA (A41665) localization.

(B) Enrichment of Mob1 $\Delta 132$ (A41664, $n=50$ cells) or Mob1 $\Delta 132-3 R A$ (A41665, $n=85$ cells) at the dSPB. Cells were grown like in Figure 5G. Solid lines represent the average of single cell traces aligned to anaphase onset. Shaded areas represent $95 \%$ confidence intervals. For maximum enrichment, each dot represents a single cell. Solid lines represent the median. $* * * * P$ $<0.0001$ by two-sided Wilcoxon rank sum test.

(C) Enrichment of Mob1 $\Delta 132$ (A41666, $n=54$ cells) or Mob1 $\Delta 132-3 R A$ (A41667, $n=77$ cells) in the nucleus. Cells were grown at $25^{\circ} \mathrm{C}$ in $\mathrm{SC}$ medium $+2 \%$ glucose and imaged every 3 minutes for 4 hours. Solid lines represent the average of single cell traces aligned to anaphase onset. Shaded areas represent $95 \%$ confidence intervals. 
bioRxiv preprint doi: https://doi.org/10.1101/2020.10.01.322719; this version posted December 17, 2020. The copyright holder for this preprint

(which was not certified by peer review) is the author/funder, who has granted bioRxiv a license to display the preprint in perpetuity. It is made available under aCC-BY-NC-ND 4.0 International license.

Figure 6-figure supplement 1: Phosphorylation in zone 2 of Cfi1/Net1 regulates Cdc14 release from the nucleolus.

A
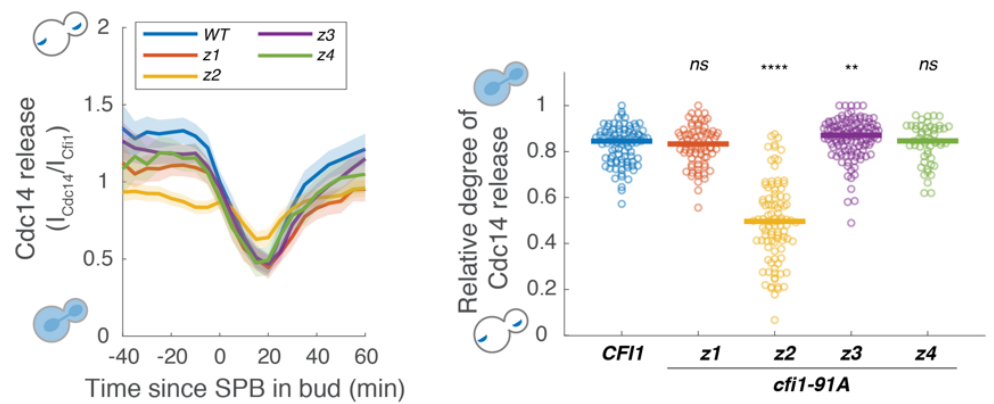

B
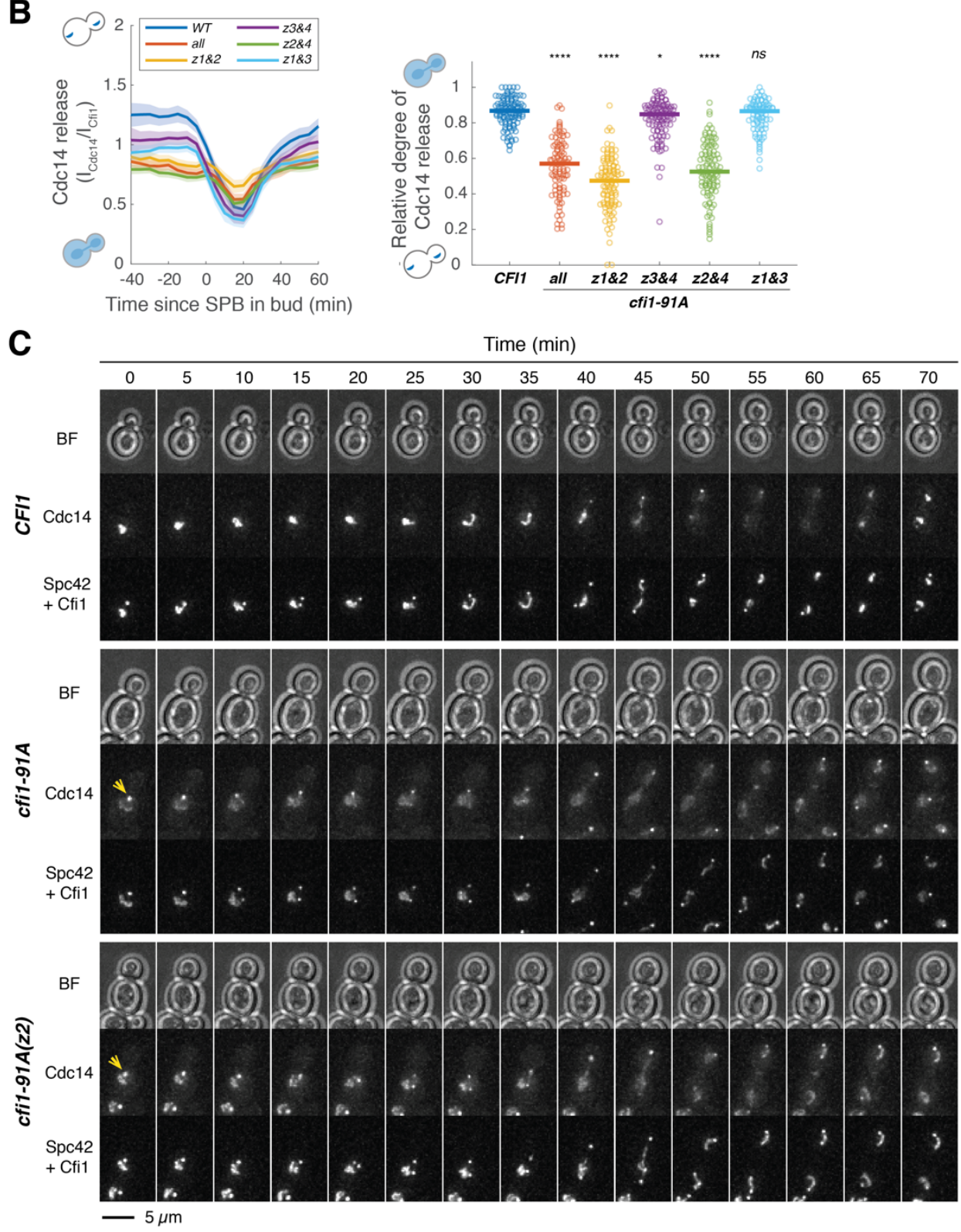
(A-B) Kinetics of Cdc14 release from the nucleolus in cells harboring wild-type CFI1/NET1 (A41387, $n=103$ cells for A, $n=130$ cells for B) or different CFI1/NET1 phospho-null mutants (A41398, A41399, A41400, A41401, A41404, A41405, A41397, A41402 and A41403; $n=95$, $103,146,59,102,113,128,114$ and 102 cells respectively). Cells were grown at $25^{\circ} \mathrm{C}$ in SC medium $+2 \%$ glucose and imaged every 5 minutes for 5 hours. Release of Cdc 14 from the nucleolus was quantified as the ratio of fluorescence intensity of Cdc14-eGFP to Cfi1/Net1$\mathrm{mScarlet}$ in the nucleolus $\left(\mathrm{I}_{\mathrm{Cdc} 14} / \mathrm{I}_{\mathrm{Cfi1}}\right)$. Relative degree of $\mathrm{Cdc} 14$ release from the nucleolus was calculated as the normalized minimal Cdc14 level in the nucleolus: $\left(\mathrm{I}_{\mathrm{Cdc} 14}\left(t_{\min }\right) / \mathrm{I}_{\mathrm{Cfi} 1}\left(t_{\min }\right)\right) /$ ( $\left.\mathrm{I}_{\mathrm{Cdc} 14}\left(t_{-20}\right) / \mathrm{I}_{\mathrm{Cfi1}}\left(t_{-20}\right)\right)$ where $t_{\min }$ represents the frame with minimal Cdc14 levels in the nucleolus and $t_{\text {-20 }}$ represent $20 \mathrm{~min}$ before movement of the SPB into bud. Each dot represents a single cell and the solid lines represent the median. ${ }^{* * * *} P<0.0001 ; * * P<0.01 ; * P<0.05$ by two-sided Wilcoxon rank sum test.

(C) Representative images showing Cdc14 nucleolar release kinetics for cells harboring wildtype CFI1/NET1 (A41387) or CFI1/NET1 phospho-mutants with all 91 sites (A41404) or only sites in zone 2 (A41399) mutated to alanine. Yellow arrows highlight localization of Cdc14 at dSPB prior to anaphase. 
bioRxiv preprint doi: https://doi.org/10.1101/2020.10.01.322719; this version posted December 17, 2020. The copyright holder for this preprint

(which was not certified by peer review) is the author/funder, who has granted bioRxiv a license to display the preprint in perpetuity. It is made available under aCC-BY-NC-ND 4.0 International license.

Figure 6-figure supplement 2: The $\mathrm{MEN}$ and $C D C 5$ promote release of $\mathrm{Cdc14}$ from the nucleolus by phosphorylating Cfi1/Net1.

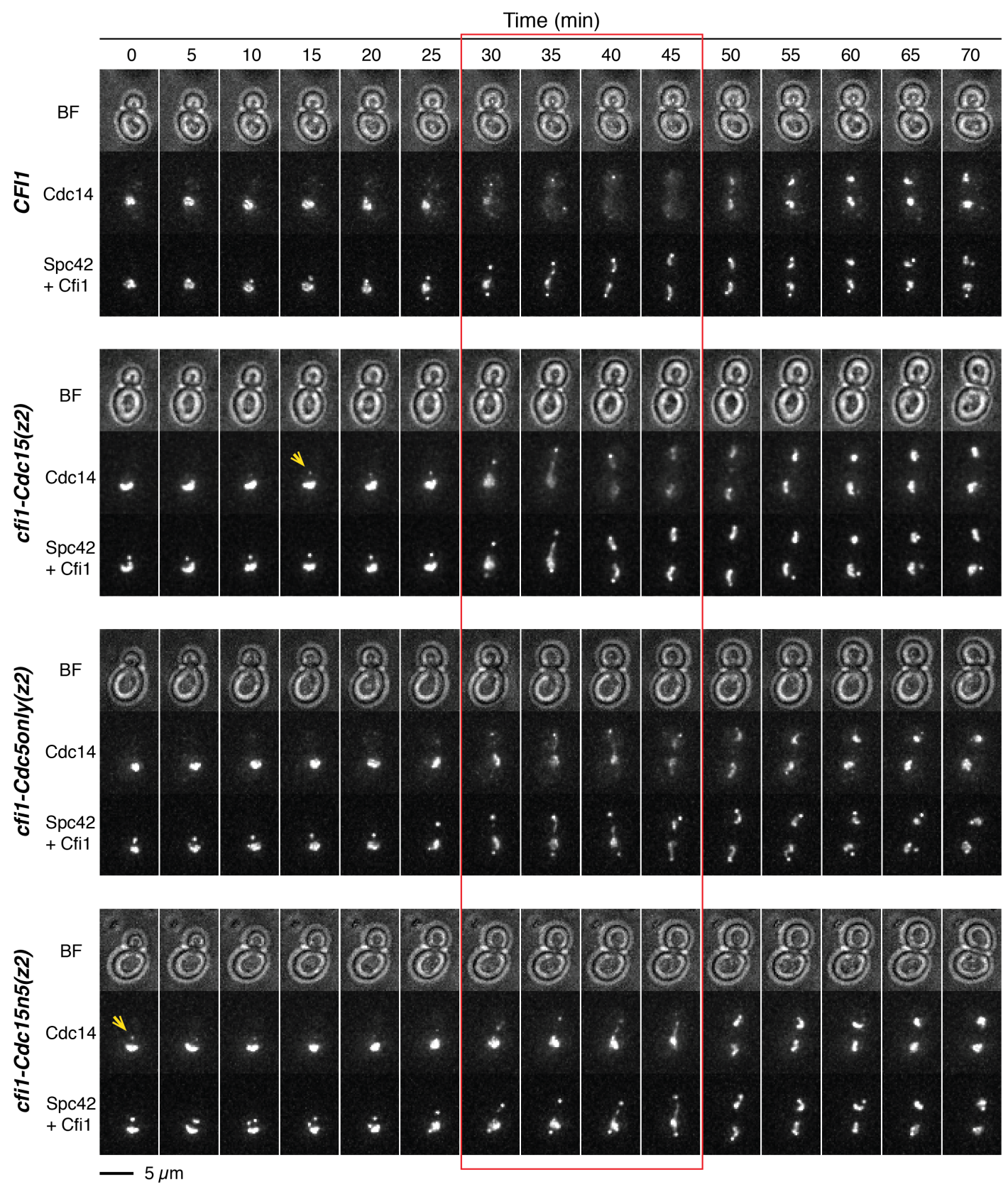

Representative images showing Cdc14 nucleolar release kinetics for cells harboring wild-type CFI1/NET1 (A41387) or CFI1/NET1 phospho-mutants for Cdc15 sites (A41587), Cdc5 sites (A441588), and Cdc15\&Cdc5 sites (A41589). Red box highlights anaphase when Cdc14 is fully released in WT cells. Yellow arrows highlight localization of Cdc14 at dSPB prior to anaphase. 
Figure 6-figure supplement 3: Cfi1/Net1 phospho-mutants delay mitotic exit and nucleolar segregation.

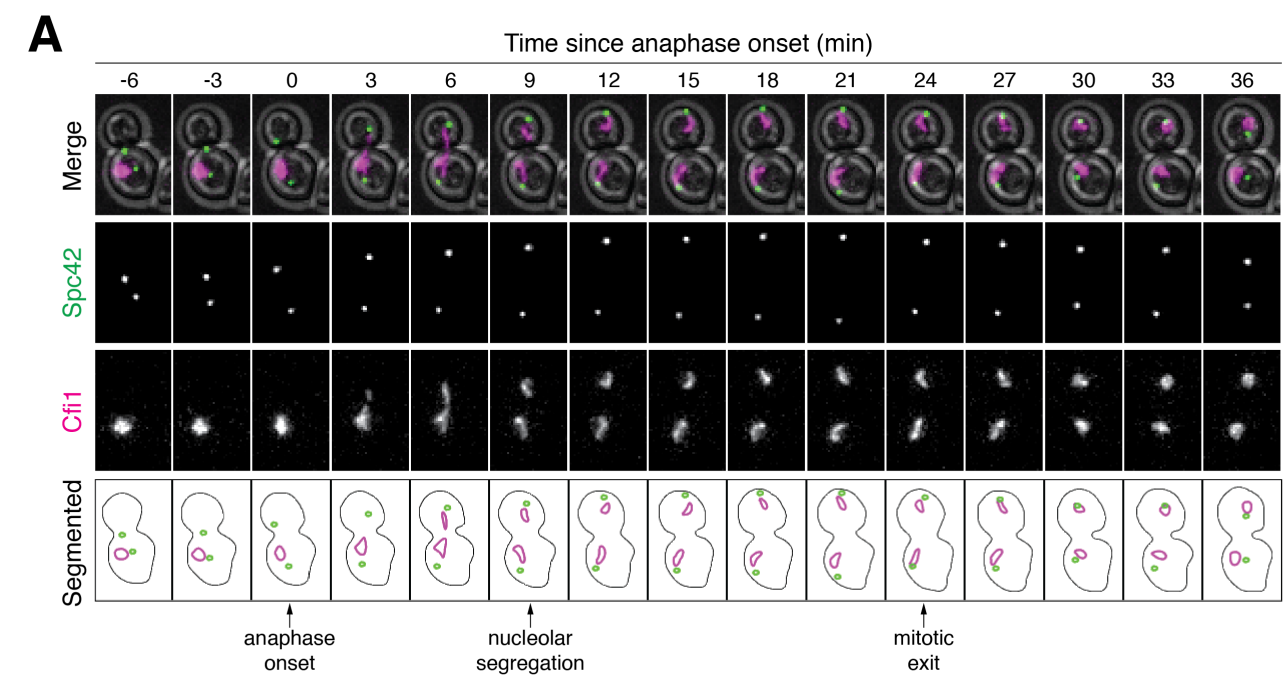

B

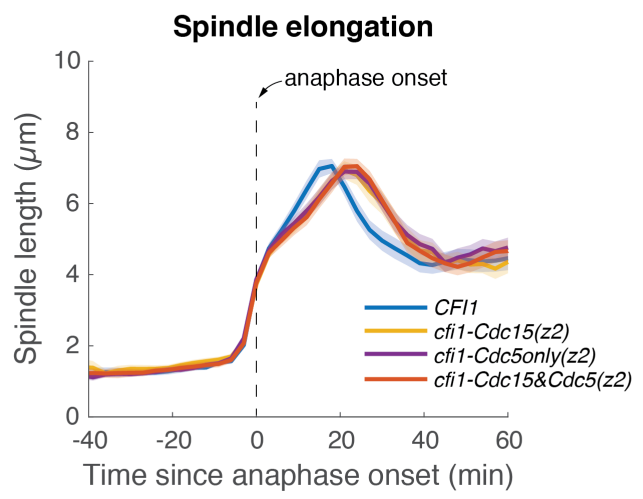

C

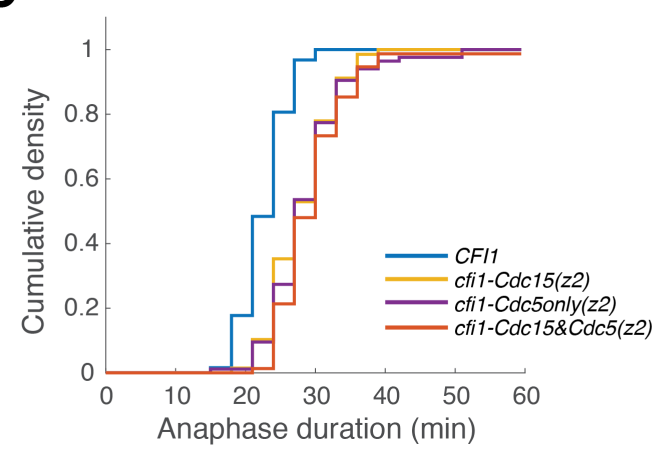

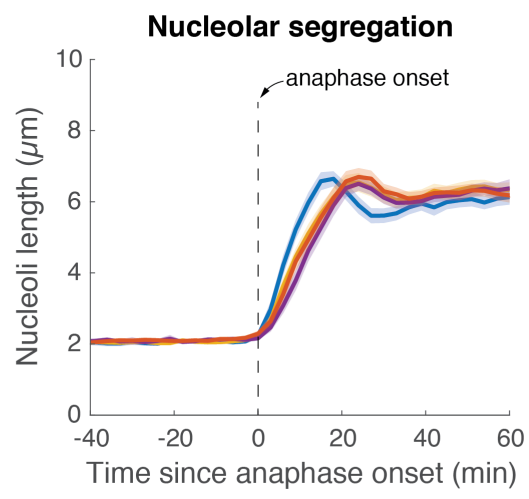

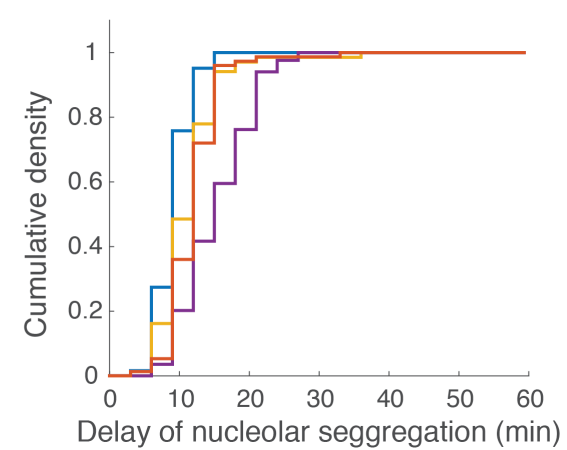

(A) Tracking anaphase progression and nucleolar segregation using Spc42-eGFP and Cfi1/Net1mScarlet-I as markers, respectively. A41436 cells were grown at $25^{\circ} \mathrm{C}$ in SC medium $+2 \%$ glucose and imaged every 3 minutes for 4 hours.

(B) Quantification of spindle elongation (spindle length was estimated by measuring the distance between the two SPBs) and nucleolar segregation (nucleoli length was estimated by measuring the length of the major axis of the nucleolar mass) for CFI1/NET1 mutants using the SPB marker Spc42-eGFP and the nucleolar marker Cfi1/Net1-mScarlet-I (A41436, A41590, A41591 and 
A41592; same dataset as in Figure 6C). Single cell traces were aligned to anaphase onset (spindle length $>3 \mu \mathrm{m}$ ) and averaged. Solid lines represent the average. Shaded areas represent 95\% confidence intervals.

(C) Cumulative density of anaphase duration (left) and delay of nucleolar segregation (right) for cells in (B). Anaphase duration was defined as the time from anaphase onset (spindle length $>3$ $\mu \mathrm{m}$ ) to mitotic exit (spindle breakdown, determined as relaxation of the distance between SPBs). Delay of nucleolar segregation was defined as the time of nucleolar segregation (clear separation of two nucleolar masses) relative to anaphase onset. 


\section{Figure 6-figure supplement 4: Phosphorylation of the Cdc14 NLS does not play a major} role in promoting mitotic exit.
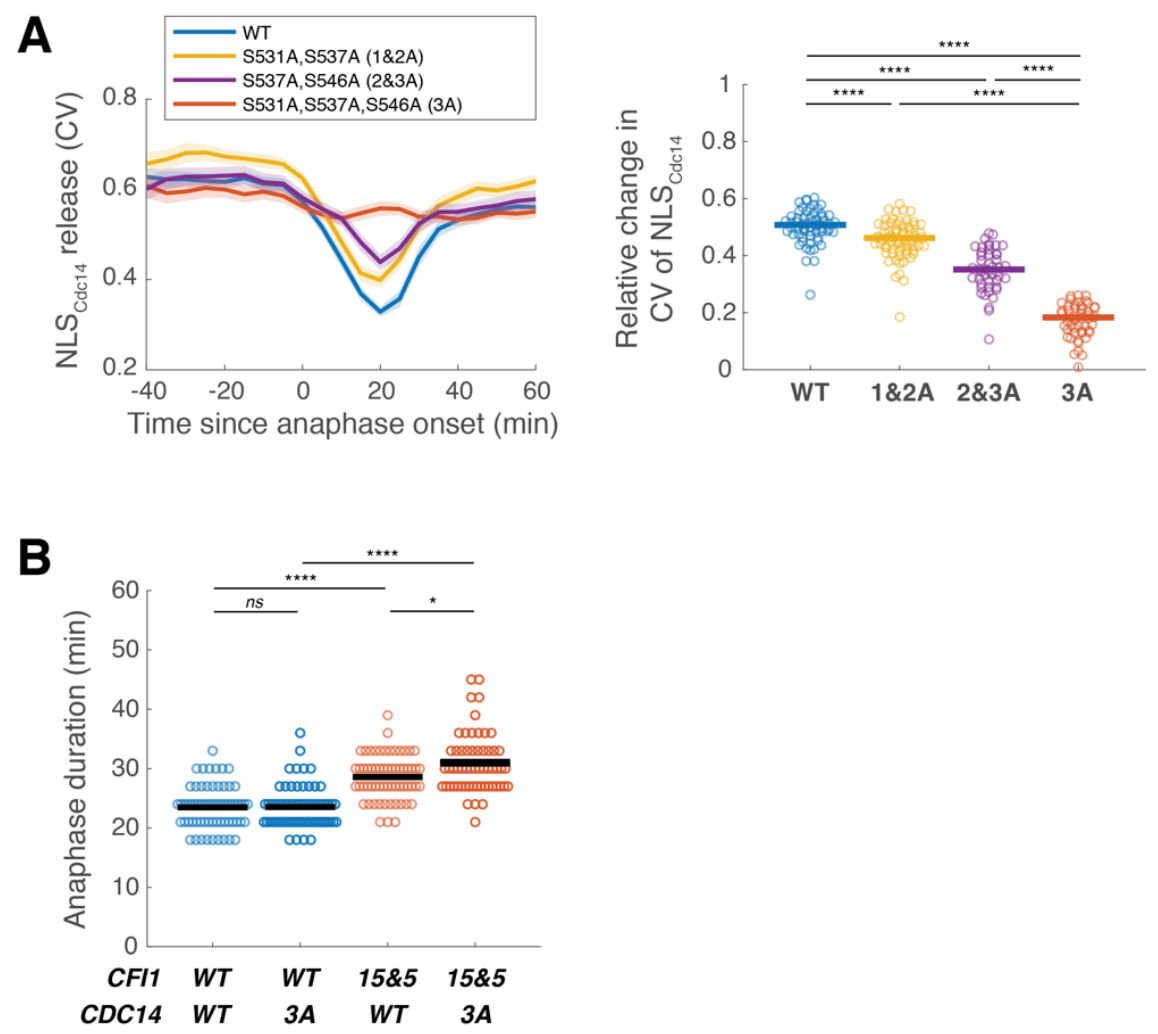

(A) Profiles (left) and relative degrees (right) of nuclear release of wild-type (A41584, $n=69$ cells) and mutant $\mathrm{NLS}_{\mathrm{Cdc} 14}$ reporters where all three potential Dbf2-Mob1 (MEN) target sites (A41585, $n=59$ cells) or only two out of three sites (A41586 and A41623, $n=77$ and 55 cells) were mutated to alanine. Cells were grown at $25^{\circ} \mathrm{C}$ in SC medium $+2 \%$ glucose and imaged every 5 minutes for 4 hours. Solid lines (right) represent the median.

(B) Distribution of anaphase duration for CDC14 phospho-mutants in combination with CFII or cfil-Cdc15\&5 measured using the SPB marker Spc42-eGFP (A41436, A41707, A41592 and $\mathrm{A} 41708 ; n=64,65,61$ and 58 cells, respectively). Cells were grown at $25^{\circ} \mathrm{C}$ in SC medium + $2 \%$ glucose and imaged every 3 minutes for 4 hours. Anaphase duration was defined as the time from anaphase onset (spindle length $>3 \mu \mathrm{m}$ ) to mitotic exit (spindle breakdown). Solid lines represent the mean. $* * * * P<0.0001 ; * P<0.05$; $n s$, not significant $(P>0.05)$ by two-sided Wilcoxon rank sum test. 


\section{Figure 6-figure supplement 5: Mutating both CDK and Cdc5 sites in Cfi1/Net1 results in severe delays in exit from mitosis and nucleolar segregation.}
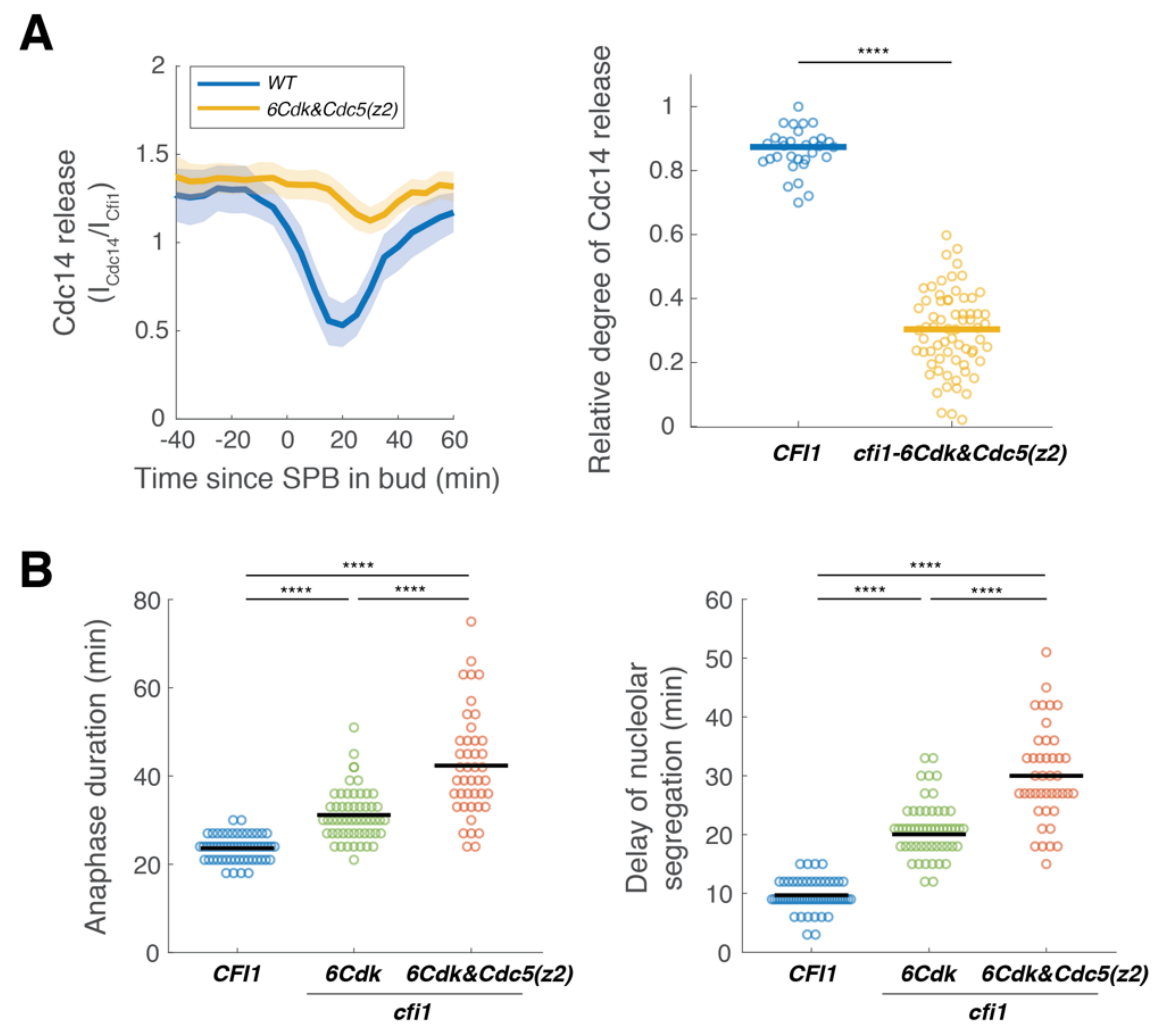

(A) Cdc14 nucleolar release kinetics in cells harboring wild-type CFI1/NET1 (A41387, $n=39$ cells) or CFI1/NET1 phospho-mutants for CDK sites combined with Cdc5 sites in zone 2 (A41691, $n=79$ cells). Cells were grown at $25^{\circ} \mathrm{C}$ in SC medium $+2 \%$ glucose and imaged every 5 minutes for 5 hours. Single cell traces were aligned to the frame where the dSPB entered the bud and averaged. Solid lines represent the average. Shaded areas represent $95 \%$ confidence intervals. Each dot represents a single cell. Solid lines represent the median. ${ }^{* * * *} P<0.0001$ by two-sided Wilcoxon rank sum test.

(B) Distribution of anaphase duration and relative delay of nucleolar segregation for different CFI1/NET1 phospho-mutants (A41436, A41692 and A41694; $n=58,55,44$ cells respectively) measured using the SPB marker Spc42-eGFP and the nucleolar marker Cfi1/Net1-mScarlet-I. Cells were grown at $25^{\circ} \mathrm{C}$ in SC medium $+2 \%$ glucose and imaged every 3 minutes for 4 hours. Each dot represents a single cell. Solid lines represent the median. $* * * * P<0.0001$ by two-sided Wilcoxon rank sum test. 


\section{Supplementary tables and datasets}

Table S1. Yeast strains used in this study.

Table S2. Plasmids used in this study.

Table S3. Summary of TurboID labeling experiments.

Table S4. Phosphorylation of Cfi1/Net1.

Dataset S1. Summary of phospho-proteomics results for inhibiting Cdc15 and Cdc5 in anaphase cells and Cdc5 in metaphase cells.

Dataset S2. Complete list of phosphopeptides for each phosphorylation site detected in the DIAMS experiments. 